University of Louisville

ThinkIR: The University of Louisville's Institutional Repository

Electronic Theses and Dissertations

8-2014

\title{
BDNF maintains adult taste innervation and is required for taste nerve regeneration after injury.
}

\author{
Lingbin Meng \\ University of Louisville
}

Follow this and additional works at: https://ir.library.louisville.edu/etd

Part of the Neurosciences Commons

\section{Recommended Citation}

Meng, Lingbin, "BDNF maintains adult taste innervation and is required for taste nerve regeneration after injury." (2014). Electronic Theses and Dissertations. Paper 963.

https://doi.org/10.18297/etd/963

This Doctoral Dissertation is brought to you for free and open access by ThinkIR: The University of Louisville's Institutional Repository. It has been accepted for inclusion in Electronic Theses and Dissertations by an authorized administrator of ThinkIR: The University of Louisville's Institutional Repository. This title appears here courtesy of the author, who has retained all other copyrights. For more information, please contact thinkir@louisville.edu. 
BDNF MAINTAINS ADULT TASTE INNERVATION AND IS

\title{
REQUIRED FOR TASTE NERVE REGENERATION AFTER INJURY
}

\author{
By \\ Lingbin Meng \\ M.D., Anhui Medical University, 2008 \\ M.S, University of Louisville, 2011
}

\begin{abstract}
A Dissertation
Submitted to the Faculty of the

School of Medicine of the University of Louisville

In Partial Fulfillment of the Requirements

For the degree of
\end{abstract}

\author{
Doctor of Philosophy \\ Department of Anatomical Sciences and Neurobiology \\ University of Louisville \\ Louisville, Kentucky
}

August 2014 

BDNF MAINTAINS ADULT TASTE INNERVATION AND IS

\title{
REQUIRED FOR TASTE NERVE REGENERATION AFTER INJURY.
}

\author{
By
}

\author{
Lingbin Meng \\ M.D., Anhui Medical University, 2008 \\ M.S, University of Louisville, 2011 \\ A Dissertation Approved on
}

June $27^{\text {th }}, 2014$

by the following Dissertation Committee:

$\overline{\text { Robin Krimm, Ph.D.; Dissertation Director }}$

Jeffrey Petruska, Ph.D.

Jun Cai, Ph.D.

Martha Bickford, Ph.D.

Robert Lundy, Ph.D 


\section{DEDICATION}

This dissertation is dedicated to my parents

Meng Yu, Duan Qichun

and my husband

Rui Ji

for their open-mindedness, unconditional love and ultimate support for education. 


\section{ACKNOWLEDGEMENTS}

I would never have been able to finish my dissertation without the guidance of my committee members, help from friends, and support from my family and husband.

I would like to express my deepest gratitude to my advisor, Dr. Robin Krimm, for her excellent guidance, caring, patience, and for providing me with an excellent atmosphere for doing research. I am indebted to my other committee members Dr's. Martha Bickford, Robert Lundy, Jeffrey Petruska and Jun Cai. Their encouragement, inspiration and support are invaluable to me.

Many thanks to Dr. Ron Gregg, Dr. David Hill, Dr. Tao Huang and Dr. Chengsan Sun for their help on my research projects. Additional thanks to my friends in the lab: Liqun Ma, Biggs Bradley, Fei Da, Tang Tao, Jennifer Rios-Pilier, and many others outside the lab and department, for their support and friendship.

Finally, my heart-felt gratitude to my husband: Rui Ji. He was always there cheering me up and stood by me through the good times and bad. 


\title{
ABSTRACT \\ BDNF MAINTAINS ADULT TASTE INNERVATION AND IS REQUIRED FOR
}

TASTE NERVE REGENERATION AFTER INJURY.

\author{
Lingbin Meng
}

June 27, 2014

Brain derived neurotropic factor (BDNF) is required for the gustatory neuron survival, target innervation, and taste bud maintenance during development. However, whether BDNF has any function in the adult gustatory system in normal conditions or after nerve injury is unclear. To address these issues, I inducibly removed BDNF in all cells expressing BDNF in adult mice. In the experimental animals, $B d n f$ expression decreased to $5 \%$ of control mice in the lingual epithelium and geniculate ganglion $(\mathrm{p}<0.01)$ at both two weeks and ten weeks after tamoxifen administration. I found no effect on taste bud morphology at four weeks following $B d n f$ gene deletion. However, ten weeks following $B d n f$ gene deletion, P2X3-positive and TUJ1-positive gustatory innervation to individual taste buds was reduced by nearly half (each with $\mathrm{p}<0.01$ ) and both taste bud volume and taste cell number decreased $30 \%$ (each with $\mathrm{p}<0.01$ ). These experiments demonstrate that BDNF is required for maintenance of normal levels of taste innervation and normal taste bud morphology in adulthood. In addition, taste cells expressing PLC $\beta 2$ (phospholipase C $\beta 2$ ), a marker for taste cells that respond to sweet, bitter and umami, did not decrease after $B d n f$ gene deletion in the adult. Thus, the missing taste cells are of another type. This indicates that taste cell loss is not uniform across the various taste cell types, 
even if nearly all taste cell types receive the P2X3 and TUJ1 innervation.

Since BDNF is required for initial innervation of the taste system and supports taste bud innervation and size in adulthood, it could also be required for nerve reinnervation after injury. To determine if $B d n f$ is still expressed following nerve section, the chorda tympani nerve (taste nerve) was sectioned and $B d n f$ level was detected with Real Time RT-PCR. Bdnf continued to be expressed at normal levels from two days to two months post-surgery in both geniculate ganglion and tongue epithelium. Therefore, BDNF could be involved with chorda tympani regeneration. To determine if this was the case, the $B d n f$ gene was deleted in adult inducible transgenic mice (under the control of a Ubiquitin promoter) two weeks before chorda tympani nerve section. Taste bud number was reduced by half in all genotypes at two weeks post-surgery $(\mathrm{p}<0.01)$. For the remaining taste buds, gustatory innervation was nearly gone with only a little innervation from the trigeminal nerve remaining in the taste bud $(p<0.01)$. Taste bud volume $(p<0.01)$ and taste cell number $(p<0.01)$ were reduced by half for both control and experimental genotypes. Eight weeks postsurgery, taste bud number recovered in mice without $B d n f$ gene deletion, but did not recover in mice following $B d n f$ gene deletion $(\mathrm{p}<0.01)$. Gustatory nerve innervation returned in $70 \%$ of the taste buds in control mice $(\mathrm{p}<0.01)$. For those reinnervated taste buds, both taste bud volume and taste cell number increased to normal levels. However, in mice lacking the $B d n f$ gene, gustatory fibers only reinnervated $7.8 \%$ of the taste buds $(\mathrm{p}<0.01)$; for most uninnervated taste buds, both taste bud volume and taste cell number remained small. These experiments demonstrate that BDNF is crucial for promoting regeneration of gustatory nerve fibers in adulthood.

Following gustatory nerve section, considerable adult plasticity has been 
observed on the contralateral side including enlarged taste buds with more cells (Guagliardo and Hill, 2007). To determine if this anatomical change was associated with alter $B d n f$ expression. I examined $B d n f$ level in the geniculate ganglion and tongue epithelium on the contralateral side following chorda tympani nerve section. Results showed $B d n f$ expression increased two fold at two weeks post-surgery in geniculate ganglion on the contralateral side $(\mathrm{p}<0.05)$, indicating BDNF may involve with the observed plastic changes. To determine if the increase in taste bud size was associated with increased innervation and/or regulated by BDNF, the Bdnf gene was then deleted in inducible knockout mice before nerve surgery, and taste bud size and amount of innervation were measured on the contralateral side. The results showed taste bud volume, taste cell number and a marker for nerve fibers all increased on the contralateral side in mice without $B d n f$ gene deletion at eight weeks post-surgery. This indicates that larger taste buds could be supported by increased TUJ1 positive fibers from trigeminal nerve. In addition, in mice lacking $B d n f$, taste bud volume, taste cell number and innervation did not increase on the contralateral side after surgery, which indicates that $B d n f$ may contribute to larger taste buds on the contralateral side following nerve section by supporting increased innervation to the larger taste buds. 


\section{TABLE OF CONTENTS}

PAGE

ACKNOWLEDGEMENTS .....................................................

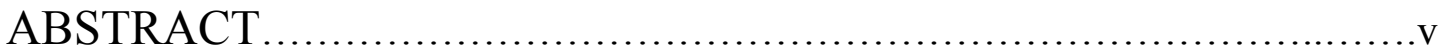

LIST OF TABLES ..........................................................

LIST OF FIGURES.........................................................

\section{CHAPTERS}

\section{I: GENERAL INTRODUCTION}

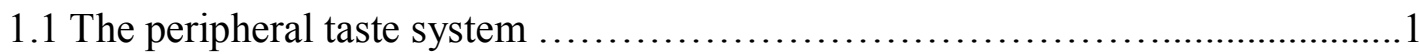

1.2 Taste system (neuron) development and the role of neurotrophins.................4

1.3 Role of innervation and neurotrophins in taste bud development................ 7

1.4 Expression of neurotrophins and their potential roles in the adult taste system... 8

1.5 Effects of gustatory nerve section on the adult taste system ...................

1.6 Regeneration following gustatory nerve sectioning ..........................12

1.7 Potential role of neurotrophins in nerve regeneration ..........................14

1.8 Plasticity of uncut nerves following chorda tympani nerve section .............16

1.9 Neurotrophin regulation of plasticity in other systems.......................18

\section{II: BDNF MAINTAINS ADULT TASTE INNERVATION.}

2.1 Introduction........................................................ 19

2.2 Materials and Methods................................................ 21 
2.2.3 Lingual epithelium and geniculate ganglion isolation for Real Time RT-

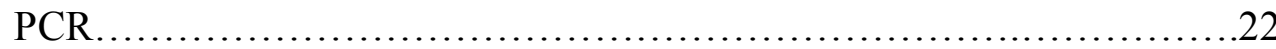

2.2.4 RNA Extraction and Real Time RT- PCR .............................23

2.2.5 Tissue preparation for Immunohistochemistry $\ldots \ldots \ldots \ldots \ldots \ldots \ldots \ldots \ldots . \ldots \ldots$

2.2.6 Immunohistochemistry ................................................

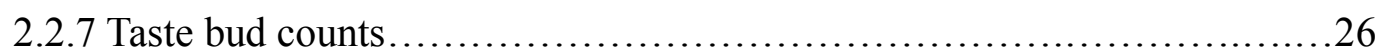

2.2.8 Stereology......................................................26

2.2.9 Microscopic analysis of maging ....................................27

2.2.10 Taste bud analysis: Quantification of taste bud size, innervation and taste cells.....

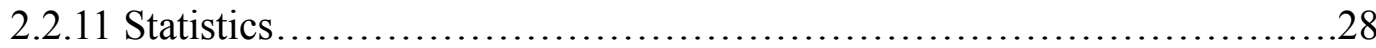

2.3 Results

2.3.1 Tamoxifen induced $B d n f$ gene recombination in adulthood reduces $B d n f$ expression to barely detectable levels .29

2.3.2 Geniculate ganglion neuron number and taste bud number were unaffected by $B d n f$ gene deletion .32

2.3.3 Neural innervation of the taste bud was reduced by half following $B d n f$ gene deletion.............................................................

2.3.4 The changes in innervation predicted changes in taste bud size.............35

2.3.5 Correlation between nerve innervations, taste bud size and cell number.....37

2.3.6 Taste bud cell loss may be specific to a subtype of cells following Bdnf gene

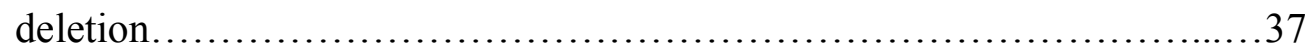

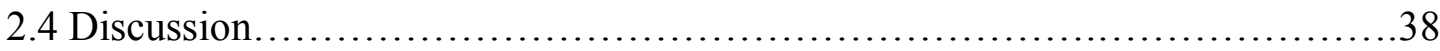




\section{III: BDNF IS REQUIRED FOR TASTE NERVE REGENERATION}

AFTER INJURY.

3.1 Introduction........................................................... 71

3.2 Materials and Methods................................................ 73

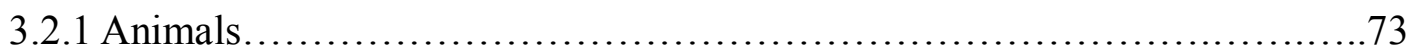

3.2.2 Tamoxifen administration.......................................... 74

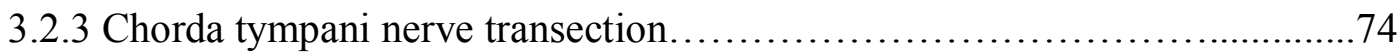

3.2.4 Lingual epithelium isolation for Real Time RT-PCR....................75

3.2.5 Taste bud and ganglion neuron isolation using LCM (laser capture micro

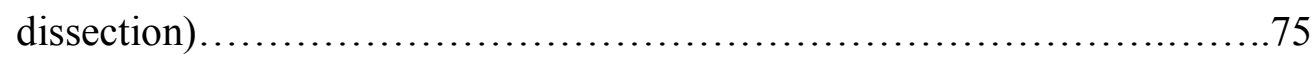

3.2.6 RNA Extraction and Real Time RT- PCR..............................76

3.2.7 Tissue preparation for Immunohistochemistry .........................77

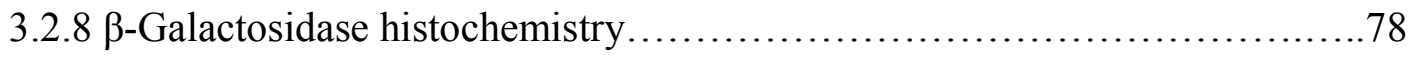

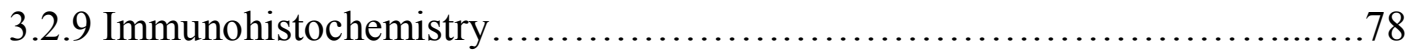

3.2.10 Taste bud counts..................................................... 79

3.2.11 Stereology.................................................. 79

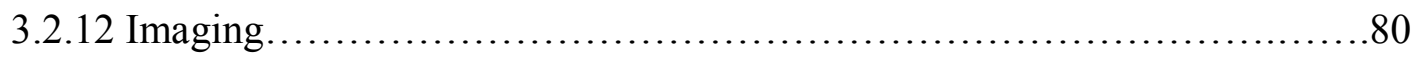

3.2.13 Taste bud analysis: Quantification of taste bud size, innervation and taste cells................................................................ 81

3.2.14 Statistics............................................................. 81

3.3 Results

3.3.1 Bdnf expression did not change following nerve section in the geniculate ganglia or lingualepithelium. ................................... 82

3.3.2 Bdnf gene deletion prevented or delayed recovery of taste bud number......84

3.3.3 Bdnf gene deletion prevented or delayed taste bud re-innervation...........86 
3.3.4 Uninnervated taste buds failed to regain size and cell number .89

3.3.5 Correlation between nerve innervations, taste bud size and cell

number.

3.3.6 Bdnf gene deletion did not increase geniculate ganglion neuron death after nerve section. .92

3.4 Discussion 93

\section{IV: BDNF MAY BE IMPORTANT FOR PLASTICITY CHANGES} IN GUSTATORY

4.1 Introduction .121

4.2 Materials and Methods................................................... 122

4.2.1 Animals............................................................ 122

4.2.2 Tamoxifen administration............................................. 124

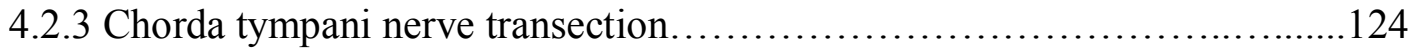

4.2.4 Lingual epithelium isolation for Real Time RT-PCR..................... 124

4.2.5 Taste bud and ganglion neuron isolation using LCM (laser capture micro

dissection)

4.2.6 RNA Extraction and Real Time RT- PCR.

4.2.7 Tissue preparation for Immunohistochemistry

4.2.8 Immunohistochemistry.

4.2.9 Taste bud counts..................................................... 128

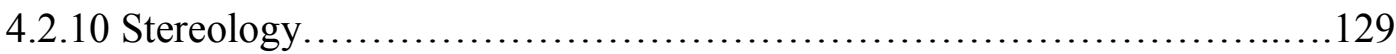

4.2.11 Imaging

4.2.12 Taste bud analysis: Quantification of taste bud size, innervation and taste- 
cells

4.2.13 Statistics.

4.3 Results.

4.3.1 $B d n f$ expression level increased in the contralateral geniculate ganglia following nerve section. .131

4.3.2 Taste bud size increases on the contralateral side following unilateral nerve section and this increase may be supported by $B d n f$. 132

4.3.3 Increased taste bud size was correlated with increased TUJ1-positive innervation.

4.3.4 Increased innervation on contralateral side was not caused by increased geniculate neuron number.

4.4 Discussion

V: SUMMARY AND DISCUSSIONS .156

REFERENCES 161

CURRICULUM VITAE 169 


\section{LIST OF TABLES}

TABLE

PAGE

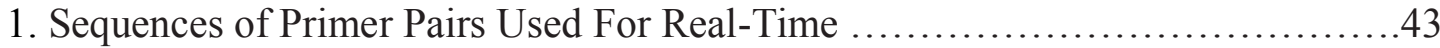

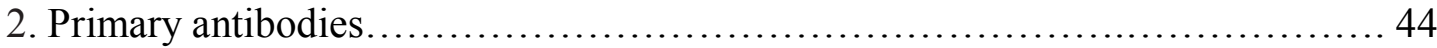




\section{LIST OF FIGURES}

FIGURE

PAGE

1. Method for measuring taste bud innervation, size, and taste cells ...............45

2. $B d n f$ expression is successfully reduced following gene recombination............47

3. Bdnf gene recombination results in increased body weight .....................49

4. Neither Nt3 nor Nt4 show altered expression after Bdnf gene deletion ............51

5. The number of geniculate ganglion neurons and taste buds were not influenced

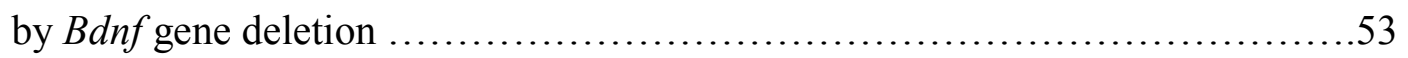

6. P2X3 and TUJ1 labeled nerve fibers appeared similar across genotypes at four

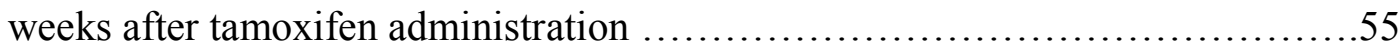

7. Taste buds appeared to contain fewer P2X3 and TUJ1 labeled nerve fibers at ten

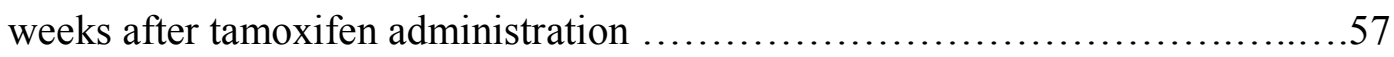

8. Quantification of $\mathrm{P} 2 \mathrm{X} 3$ and TUJ1 labeled nerve fibers confirmed a 50\% reduction in innervation to the taste bud ten weeks after $B d n f$ gene recombination .59

9. Taste buds appear smaller at ten weeks, but not four weeks following $B d n f$ induced gene recombination.

10. There were no differences in taste bud size and cell number at four weeks after tamoxifen administration, while ten weeks after tamoxifen administration, tast e bud size and cell number was reduced by $B d n f$ gene deletion 63

11. At ten weeks after tamoxifen administration, reductions in innervation predict loss of taste bud size and cell number across individual taste buds.

12. PLC $\beta 2$ cell number was not affected by $B d n f$ gene deletion. 
13. The number of PLC $\beta 2$-positive cells change following $B d n f$ gene deletion indicating that taste cell lost is not evenly distributed among taste cell subtypes

14. $B d n f$ continues to be expressed in the geniculate ganglion and lingual epithelium after chorda tympani nerve section, while expression of the taste bud marker $\mathrm{Krt} 8$ is decreased.

15. While both $B d n f$ and $K r t 8$ expression with in taste buds decreased at 14 days after nerve section, this decrease was greater for $K r t 8$ than for

$B d n f$

16. $B d n f$ expression occurs in both taste and non-taste cells in the tongue and $B d n f$ expression in non-taste cells is unaffected by nerve section 101

17. $B d n f$ removal had no influence on taste bud loss two weeks after chorda tympani nerve section, but it slowed or prevented recovery of taste bud number eight weeks after nerve section.

18. Remaining taste buds have lost most of their innervation two weeks after nerve chorda tympani section

19. Reinnervation (P2X3 and TUJ1 labeled nerve fibers) of the taste bud was prevented or slowed by $B d n f$ gene deletion at eight weeks after nerve section

20. Deletion of the $B d n f$ gene had no effect on loss of $\mathrm{P} 2 \mathrm{X} 3$-positive fibers from taste buds following chorda tympani nerve section, but prevented or slowed reinnervation of the taste bud 109

21. Bdnf removal did not influence the loss of TUJ1 (neuron specific beta III Tubulin) positive fibers in the taste bud two weeks after chorda tympani nerve section, but did prevent re-innervation of taste buds by TUJ1 fibers 
22. Taste bud size decreased two weeks after chorda tympani nerve section, recovery of taste bud size occurred eight weeks after nerve section and appeared to be prevented or delayed by $B d n f$ gene deletion.

23. Taste bud size (A) and cell number (B) were reduced by half following taste nerve degeneration, but only recovered in mice that retained $B d n f$ expression.

24. The correlation between $\mathrm{P} 2 \mathrm{X} 3$ positive innervation and taste bud size was reestablished after nerve section.

25. $B d n f$ gene deletion did not increase geniculate neuron death after nerve section

26. $B d n f$ expression increased in the geniculate ganglion on the contralateral side after unilateral chorda tympani nerve section at 14 days after surgery, while $B d n f$ and $K r t 8$ remained unchanged in lingual epithelium on the contralateral side....140

27. Taste bud specific $B d n f$ expression was unchanged at 14 days after nerve section on the contralateral side $(n=3)$

28. Taste bud size was unchanged at two weeks, but increased at eight weeks after nerve section on the contralateral side in mice without $B d n f$ gene deletion.... 144

29. Taste bud volume and cell number increased on the contralateral side at eight weeks after nerve section in mice without $B d n f$ gene deletion, but not in mice with reduced $B d n f$ expression.

30. Innervation ( $\mathrm{P} 2 \mathrm{X} 3$ positive-fibers and TUJ1 labeled nerve fibers) appears unchanged at 2 weeks after nerve section on the contralateral side for all genotypes. 148

31. Innervation (P2X3 and TUJ1 labeled nerve fibers) of taste bud appears reduced on the contralateral side of the tongue in mice with an adult $B d n f$ deletion at 8 weeks after nerve section 150 
32. The volume of TUJ1-positive fibers in the taste bud increased on the contralateral side at eight weeks after nerve section in mice without $B d n f$ gene deletion, while P2X3 positive fibers in the taste bud on contralateral side did not increase at two weeks and eight weeks after nerve section for any genotype

33. Geniculate ganglion number and taste bud number was not influenced by contralateral nerve section. 154

34. A model illustrating how we think BDNF functions in the adult taste system...159 


\section{CHAPTER I \\ GENERAL INTRODUCTION}

\subsection{The peripheral taste system}

Taste is one of the five basic senses in vertebrates. There are five essential taste qualities: sweet, bitter, sour, salty and umami (amino acid), which are detected by taste buds. In mammals, taste buds are located on the tongue, soft palate, pharynx, and epiglottis. On the tongue, taste buds are housed in specialized epithelial organs called papillae. Three types of papillae contain taste buds: fungiform papillae (scattered throughout the front two-thirds of the tongue), foliate papillae (short vertical folds found on the lateral margins of the tongue) and circumvallate papillae (situated at the very back of the tongue) (Hill, 2004; Krimm, 2007).

All taste buds regardless of their location, are composed of anywhere from 50 to 100 taste cells, depending on the species (Finger, 2005). Taste cells can be grouped into different cell types based on their function, ultrastructure or light microscope markers (Farbman, 1965; Murray et al., 1969; Kinnamon et al., 1985). The presence or absence of specific proteins can also be used to differentiate subsets of taste cells. For example, there is one type of taste cell termed as Phospholipase C $\beta 2$ taste cells since they contain Phospholipase C $\beta 2$ (PLC $\beta 2$ ), a principal G protein-coupled receptors (GPCRs) effector, involved in intracellular signaling for transducing sweet, 
bitter or umami (Hoon et al., 1999; Miyoshi et al., 2001; Finger, 2005). Another type of taste cell possesses specialized chemical synapses and co-expresses some synaptic proteins like SNAP-25 (Yang et al., 2000).

Taste buds that reside in different types of papillae are innervated by distinct nerves from the cranial ganglia. Taste buds in the palate, tongue, and larynx are innervated by specific branches of the cranial nerves VII (chorda tympani and greater superficial petrosal nerves), IX (glossopharyngeal nerve), and X (vagus nerve) (Hill, 2004; Krimm, 2007). The sensory innervation to the front of the tongue is derived from two cranial nerves: the lingual branch of the trigeminal nerve providing somatosensory innervation from the tongue and the chorda tympani (CT) branch of the facial nerve providing gustatory innervation from the taste buds. The neurons whose axons make up the chorda tympani nerve have their cell bodies in the geniculate ganglion (Hill, 2004; Krimm, 2007).

The geniculate ganglion is made up of sensory neurons which innervate taste buds in the front two-thirds of the tongue (fungiform papillae), the soft palate and the nasoincisor ducts of the hard palate (Hill, 2004; Krimm, 2007). The mouse geniculate ganglion contains around 800 neurons at E13.5 (Patel and Krimm, 2010, 2012) which is roughly half of the 1600-1900 neurons in adult rat ganglia (Carr et al., 2005). Geniculate neurons deliver information from peripheral chemosensory cells in the taste bud to the central nervous system (Mistretta and Hill, 1994). There are three sensory nerve bundles originating from the ganglion to innervate different fields (Mistretta and Hill, 1994; Krimm, 2007): the chorda tympani (CT) innervating taste buds in the fungiform papillae and anterior foliate papillae; the greater superficial petrosal nerve (GSP) innervating taste buds in the incisive papilla and soft palate; and the posterior auricular nerve innervating the skin of the external ear. The number of 
neurons in the geniculate ganglion innervating the tongue is roughly the same as the number of neurons innervating the palate (Patel et al., 2010).

Additional taste axons are supplied by neurons of the petrosal ganglion; these neurons innervate taste buds in the circumvallate papillae and most of the taste buds in the foliate papillae via the glossopharyngeal nerve. Geniculate and petrosal ganglia neurons relay taste signals to the nucleus of the solitary tract (NST). Taste information is transmitted through the parabrachial nucleus (in rodents) into the thalamus, then the thalamus delivers the information to the primary gustatory cortex in the insula (Carleton et al., 2010).

Several neurotransmitters have been proposed for communication between taste cells and nerve fibers, including acetylcholine, Adenosine triphosphate ( ATP), glutamate, serotonin (5-HT), $\gamma$-aminobutyric acid (GABA) (Nagahama and Kurihara, 1985; Nagai et al., 1998; Huang et al., 2007; Murata et al., 2010; Starostik et al., 2010). However, ATP is the key neurotransmitter in this system. Most (98.4\%) geniculate neurons express the ATP receptor, P2X3; while $52.6 \%$ of geniculate neurons can be labeled with anti-P2X2 antibodies. (Ishida et al., 2009). Most P2X2and P2X3-immunoreactive nerve fibers in the taste buds in the anterior two-thirds of tongue are derived from the chorda tympani nerve (Ishida et al., 2009). In response to gustatory stimulation, taste bud cells release ATP to activate $\mathrm{P} 2 \mathrm{X} 2$ and $\mathrm{P} 2 \mathrm{X} 3$ receptors on gustatory nerve fibers (Finger et al., 2005). Combined mutations in these two ATP receptors eliminated taste responses in gustatory nerves, while the responses to cool saliva and touch remains (Finger et al., 2005). Thus, ATP is an important chemical signal connecting taste buds to taste nerve fibers (Finger et al., 2005; Huang et al., 2007; Ishida et al., 2009; Murata et al., 2010). 
Taste bud cells are very plastic and have a limited life-span (Beidler and Smallman, 1965). Therefore they are constantly renewed (Beidler and Smallman, 1965). As a result of taste cell turnover, taste cells need to constantly be reinnervated by gustatory nerve fibers. Some of these taste cells synapse with gustatory nerves (Yee et al., 2003), the constant turnover of taste cells necessitates continuing support for synaptogenesis throughout an animal's life time. While it is unclear what controls this constant reinnervation of new taste cells by gustatory afferents, it is easy to envision that neurotrophins (which have this role during development) could continue to orchestrate taste cell-nerve fiber connections in adulthood.

1.2. Taste system (neuron) development and the role of neurotrophins.

During geniculate ganglion genesis, the number of geniculate neurons is determined by a balance between neuron proliferation, differentiation, and apoptosis. In the geniculate ganglion, neuron production peaks around E10 followed by loss of neuron cell number and ganglion volume from E12.5 to E14.5 in mice (Patel and Krimm, 2010). Therefore, the geniculate ganglion overproduces neurons first and then reduces these numbers through programed cell death (Carr et al., 2005).

As taste neurons of the geniculate ganglion differentiate they send out axons that follow spatially restricted pathways from geniculate neurons to the tongue surface (Mbiene and Mistretta, 1997), indicating that molecular cues guide them to these locations. At E14.5, chorda tympani nerves reach the tongue epithelium, penetrate the epithelium and form a distinctive nerve ending called neural bud (Lopez and Krimm, 2006c). Both attractive and repulsive cues have been found for axon guidance, including: semaphorins, ephrins, and netrins (Yu and Bargmann, 2001).In the taste 
system, Sema3A is one of these guidance molecules regulating axon guidance of geniculate neurons (Vilbig et al., 2004). Sema3A is expressed in the tongue and is required for both trigeminal and geniculate axon guidance (Vilbig et al., 2004). It prevents premature and aberrant growth of axons into the mid-region of the tongue (Vilbig et al., 2004).

While numerous factors regulate the development of taste neurons, the focus of this project is on neurotrophic factors. Neurotrophins are major regulators of multiple developmental processes including neuron differentiation, survival, dendritic pruning and patterning of innervation (Huang and Reichardt, 2001). There are four neurotrophins crucial for survival and differentiation of neurons in both the peripheral and central nervous system (Huang and Reichardt, 2001). They are nerve growth factor (NGF), brain-derived neurotrophic factor (BDNF), neurotrophin-3 (NT-3), and neurotrophin-4 (NT-4). There are two classes of receptors for these four neurotrophins: the p75 neurotrophin receptor and Trk receptor tyrosine kinases (Huang and Reichardt, 2001). P75 binds all four neurotrophins; NGF binds TrkA; BDNF and NT-4 bind TrkB; and NT-3 mainly binds TrkC (Huang and Reichardt, 2001). In the taste system, most studies have been focused on the role of BDNF and NT -4 . These neurotrophins regulate taste neuron survival, taste nerve outgrowth and target innervation during development (Zhang et al., 1997; Krimm et al., 2001; Lopez and Krimm, 2006b; Ma et al., 2009; Patel et al., 2010; Patel and Krimm, 2010).

During development of many sensory systems, neurotrophins support neuron survival (Crowley et al., 1994; Smeyne et al., 1994). In the gustatory system, BDNF and NT-4 are important regulators of geniculate neuron number (Patel and Krimm, 2010, 2012). In mice overexpressing BDNF or NT-4 driven by a keratin promoter K14, geniculate neuron numbers are increased during development (Lopez and 
Krimm, 2006b). Bdnf $f^{/-}$and $N t f 4^{-/-}$mice lose about half of their geniculate neurons during development (Patel et al., 2010; Patel and Krimm, 2010), while Bdnf $f^{/-} / \mathrm{Ntf}^{-/-}$ mice lose around $90 \%$ of their geniculate neurons from E13.5- E18.5 (Patel et al., 2010). As we know, Bax is a member of the Bcl-2 family of proteins that play key roles in programmed cell death, which may contribute to neuron loss (White et al., 1998). In BDNF-null mice, Bax removal rescues neuron losses, demonstrating BDNF may promote survival of ganglion neuron by suppressing the Bax-dependent cell death pathway (Patel et al., 2010). Together, these findings indicate that geniculate ganglion neurons are very dependent on neurotrophins during development.

In addition to promoting neuronal survival, neurotrophins regulate axon elongation, target innervation, and synapse formation in many sensory systems (Campenot, 1977; Fundin et al., 1997; Huang and Reichardt, 2001). In the gustatory system, BDNF regulates taste nerve outgrowth and guidance to the final target (i.e. taste buds) during taste system development (Lopez and Krimm, 2006c; Ma et al., 2009). Bdnf mRNA is found in fungiform papilla epithelium when geniculate axon growth cones are arriving there (Nosrat and Olson, 1995; Nosrat et al., 1996). In addition, BDNF has been shown to promote outgrowth and attract geniculate ganglion neurites in vitro (Hoshino et al., 2010). When BDNF is overexpressed in non-taste epithelium in-vivo, non-taste filiform papillae were innervated by gustatory fibers, indicating that BDNF attracted the chorda tympani nerves to incorrect locations in the tongue (Lopez and Krimm, 2006b). Following BDNF removal, gustatory axons fail to correctly locate and innervate fungiform papillae, indicating that BDNF is necessary for normal targeting (Ma et al., 2009). In conclusion, BDNF is important for taste nerve outgrowth and guidance to the taste bud during development. 
1.3. Role of innervation and neurotrophins in taste bud development.

The initial formation of fungiform papillae occurs without innervation; however, the maintenance of fungiform papillae and taste buds is dependent on gustatory innervation (Farbman and Mbiene, 1991; Sollars and Bernstein, 2000; Sollars, 2005). Specifically, fungiform papillae are present at the tongue as early as E13.5 in mice (Kim et al., 2003). By E14.5, the chorda tympani has reached the developing fungiform papillae and penetrated the epithelium (Lopez and Krimm, 2006a). Gustatory nerve innervation is necessary for maintaining the taste bud in later development. For example, when the chorda tympani nerve is sectioned during postnatal development, the effects on the structural integrity of fungiform papillae and taste buds were more severe at younger than at older ages (Sollars, 2005). Nerve section at the earliest ages results in a complete and permanent loss of both taste buds and fungiform papillae (Sollars, 2005). Therefore, postnatal taste bud development is very dependent on innervation.

Taste bud number and size are reduced in mice that lack neurotrophins during development (Nosrat et al., 1997; Patel et al., 2010).Specifically, mice lacking BDNF lose more than half of their fungiform taste buds (Nosrat et al., 1997; Mistretta et al., 1999), and have a 59\% reduction in the volume of taste buds (Patel et al., 2010). Since most geniculate neurons are lost and fail to innervate taste buds during development of mice lacking BDNF and taste buds require innervation to develop, taste buds could be lost because innervation is lost. In addition, taste buds are more sensitive to BDNF than NT-4 deletion during development (Patel et al., 2010). Absence of BDNF in mice leads to a more malformed taste bud and greater reduction in number of taste buds on the tongue; compared to NT4 knockout mice (Patel et al., 2010). This is because in addition to regulating neuron survival, BDNF is required for innervation to 
reach and successfully innervate taste buds. Thus, disruption in targeting means that fewer taste buds are innervated in BDNF compared with NT4 knockouts. Therefore, unlike gustatory neurons, which are equally dependent on BDNF and NT-4, more taste buds in the tongue are lost in $B d n f^{--}$mice.

1.4. Expression of neurotrophins and their potential roles in the adult taste system.

BDNF continues to be expressed in the adult geniculate ganglion, fungiform, foliate, and circumvallate taste buds. (Ganchrow et al., 2003; Yee et al., 2003; Huang and Stahler, 2009; Nosrat et al., 2012). BDNF and the synaptic protein (SNAP-25) are co-expressed in the same adult taste cells (Yee et al., 2003). BDNF's major receptor, TrkB, is also expressed in the geniculate ganglion and taste cells of adult mice (Matsumoto et al., 2001; Huang and Stahler, 2009; Nosrat et al., 2012). Since BDNF and its receptor both continue to be expressed in adult geniculate ganglion and taste cells, it is possible BDNF may continue to regulate the adult taste system. In the adult taste system taste cells are constantly renewed and form new connections with nerve fibers (Beidler and Smallman, 1965). Therefore, developmental factors like BDNF could continue to regulate innervation of new taste cells or synapse formation between taste cells and nerve fibers as they did in development.

Although the gustatory system is one of the most plastic sensory systems, it is not the only system where neurotrophins continue to be expressed in adulthood. Neurotrophin factors are also expressed in the adult somatosensory (Bergman et al., 2000), visual systems (Hirsch et al., 2000), auditory systems (Popper et al., 1999), and motor systems (Sartini et al., 2013). Considering they are expressed in many locations in adult mice, these neurotrophins might potentially play a crucial role in maintaining 
and regulating peripheral nerve innervation. Some evidence for this comes from correlations between loss of neurotrophins and loss of peripheral innervation in aging and neurodegenerative diseases (Bergman et al., 2000; Ola et al., 2013). In aging, decreases in NT3 and NT4 in the root sheath of ringwulst (mesenchymal sheath of the follicle) were accompanied with a loss of sensory axons into peripheral receptive fields on skin (Bergman et al., 2000). In some neurodegenerative diseases, neurotrophin factors are also reduced. In diabetes, the taste bud number was reduced (Le Floch et al., 1989) accompanied with a decrease neurotrophin support (Jakobsen et al., 1981). In addition, dermal innervation is lost in diabetic mice (Greene et al., 1999) accompanied by reduced NGF support to peripheral nerve (Jakobsen et al., 1981). More importantly, when neurotrophin (NGF) was supplied, it induced increases in dermal innervation in adult diabetic mice (Christianson et al., 2007). In general, these experiments are correlative (both neurotrophins and innervation are reduced) therefore, it is still unclear whether it is the loss of neurotrophins that results in the loss of sensory innervation. However, together these studies would predict that loss of neurotrophin would cause loss of innervation in the adult.

1.5. Effects of gustatory nerve section on the adult taste system.

Following gustatory nerve section, nerve fibers inside of the taste bud disappear and taste evoked responses from nerve are absent (Cain et al., 1996; Guagliardo and Hill, 2007; Ishida et al., 2009). By 7 days after chorda tympani nerve section, $\mathrm{P} 2 \mathrm{X} 3$ positive fibers and taste buds both disappear from fungiform papillae in rat (Ishida et al., 2009). Similarly, in mice, nerve fibers were absent from fungiform papillae within 14 days after chorda tympani and lingual nerve section (Guagliardo 
and Hill, 2007). Electrophysiological responses were absent 2 weeks after chorda tympani nerve crush in hamster (Cain et al., 1996). Therefore, the gustatory nerve fibers in the taste bud and taste function completely disappear during the first twoweeks following chorda tympani nerve section.

In addition to losing nerve fibers within the fungiform papillae, gustatory nerve section causes a loss of taste bud number, taste bud size ,and taste cell number (Guth, 1957; Farbman, 1969; Ganchrow and Ganchrow, 1989; Segerstad et al., 1989; Guagliardo and Hill, 2007). For example, 8 days following unilateral section of the combined chorda tympani and lingual nerves in rats, $25 \%$ of the taste buds are lost and $65 \%$ have altered morphology, none are normal (Oakley et al., 1993). How many taste buds remain following gustatory nerve section depending on which nerve was sectioned. Circumvallate taste buds are completely lost when the glossopharyngeal is sectioned (Oakley, 1970), while some fungiform taste buds remain following chorda tympani nerve section (Oakley et al., 1993). Remaining, uninnervated taste buds are smaller than normal and lack a pore (Oakley et al., 1993), and so I will refer to them as taste bud remnants. The number of taste buds lost and remnants remaining following gustatory nerve section differs across animal species; impressively species examined not only include rat, hamster and mouse (Segerstad et al., 1989; Oakley et al., 1993; Guagliardo and Hill, 2007), but also include dog, cats, chickens and fish (Olmsted, 1922; Langworthy, 1924; May, 1925; Torrey, 1936; Ganchrow et al., 1986). For our purposes the most important species is the mouse. However, only one study has examined taste bud denervation following nerve section in mouse (Guagliardo and Hill, 2007). They found the number of taste buds was reduced by $70 \%$ and the volume of remaining taste bud remnants was reduced by $60 \%$ at 14 days after chorda tympani-lingual nerve section in mice (Guagliardo and Hill, 2007). 
Although it is clear that nerve fibers maintain taste buds, the mechanisms are still unclear. One possibility is that taste neurons produce some sort of trophic factor, which is released at nerve terminals and supports taste cell survival. Evidence for this idea comes from studies where colchicine is used to block axon transport, leading to similar damage as caused by nerve section. Specifically, taste bud number was reduced by $94 \%$ and taste responses were reduced by $60 \%$ at 15 days after colchicine application to the gerbil's chorda tympani nerve (Sloan et al., 1983), compared to a 71\% taste bud loss and no chorda tympani response after nerve section in gerbil (Cheal et al., 1977; Oakley et al., 1993). Therefore, it is very likely that disruption of axon transport is the major reason for taste bud degeneration after nerve section. Additional evidence that taste buds are maintained by a secreted factor comes from the finding that the length of time a taste bud survives after nerve section is directly related to the length of the remaining nerve (State and Dessouky, 1977; Sloan et al., 1983; Oakley et al., 1984). Specifically, by sectioning each side of the bilateral rabbit glossopharyngeal nerves in different locations, taste buds on the cut side of the short distal stump degenerate more quickly compared to taste buds on the cut side of the long distal stump (State and Dessouky, 1977). These findings indicate that the long distal stump could contain and transport more secreted factor to support taste buds.

Typically, nerve re-innervation eventually follows nerve section, which prevents any evaluation of the long-term effects of nerve section on the taste bud. Long-term effects on the taste bud and the fungiform papillae have been studied by preventing nerve regrowth back into the taste bud. To prevent nerve regeneration after nerve section, Oakley et al. sutured the proximal transected chorda-lingual nerve to the nearby mylohyoid nerve to disrupt chorda-lingual nerve's direction during 
regeneration and keep it from returning to the tongue (Oakley et al., 1990). He found that $61 \%$ of the fungiform papillae lacking taste buds had developed spines six months following nerve section (Oakley et al., 1990). Since these spines closely resembled the spine of an ordinary filiform papilla (the non-taste bud containing papillae of the tongue), they were called ectopic filiform spines (Oakley et al., 1990). If fungiform papillae are re-innervated, the nerve prevents the formation of ectopic filiform spine and taste buds reform instead. Regrowth of either chorda tympani nerve or trigeminal nerve can prevent ectopic filiform spines from forming (Oakley et al., 1990). It has even been suggested that trophic factors from nerve fibers may both promote the formation of taste buds and prevent the formation of filiform spines (Oakley et al., 1990).

\subsection{Regeneration following gustatory nerve sectioning}

Following gustatory nerve section, nerve fibers eventually grow back and their functional responses to taste stimuli return (Cheal and Oakley, 1977; Robinson, 1989; Hill and Phillips, 1994; Cain et al., 1996). The degree and timing of physiological recovery varies among different species. Specifically, in gerbil, taste responses returned as early as days 11 after chorda tympani nerve section (Cheal et al., 1977; Cheal and Oakley, 1977). In mice, sweet responses recovered at 4 weeks after the chorda tympani (CT) nerve crush (Yasumatsu et al., 2007). However, in rat, at least 50 days after chorda tympani nerve section was needed to restore taste responses (Hill and Phillips, 1994), and full neural regeneration may not be complete until much later. In addition, even if responses from whole regenerated nerve appear normal, it is still unlikely that single-fiber recordings fully recover. For example, the response 
from regenerated whole nerves were close to normal at 12 weeks after chorda tympani nerve section in cat, however, single-fiber recordings revealed much less vigorous responses with slower conduction velocities, and the range of stimuli response narrowed (Robinson, 1989). This finding indicates that recovery of integrity of nerve function is not complete. Taken together, the degree and timing of functional regeneration ranged among different species. Although initial reinnervation and return of function can be rapid in most species, full recovery is slow and may never be complete.

Most taste buds regain their anatomical integrity during regeneration. The gustatory nerve returns by following the original pathways in the tongue. When taste axons arrive at the lingual epithelium taste bud regeneration is initiated, and both taste bud and cell number increase (Cheal et al., 1977; Cheal and Oakley, 1977; Robinson, 1989; Guagliardo and Hill, 2007). The degree of anatomical regeneration also varies among species, (Cheal and Oakley, 1977; Robinson, 1989; Montavon et al., 1996; Guagliardo and Hill, 2007). Specifically, in gerbil, less than 2 weeks after chorda tympani nerve section, some taste fibers regenerated into the tongue and taste bud number and size increased progressively (Cheal and Oakley, 1977). However, in rats, even though most of the fungiform taste buds regain anatomical integrity, there appears to be slightly less innervation in the taste bud, even as long as 6 months postchorda tympani nerve section (Montavon et al., 1996). One reason why recovery may never be complete is because the numbers of geniculate ganglion cells contributing to the chorda tympani nerve is reduced nearly $20 \%$ following nerve section (Shuler et al., 2004). 
Although some neurons are lost permanently following nerve section (Shuler et al., 2004), regeneration in the gustatory system is in general fairly robust (Guth, 1957; Oakley et al., 1993). Although it is difficult to compare across sensory systems, it is not always the case that regeneration in other sensory systems is robust. Regeneration is slow following sciatic nerve injury (Wolthers et al., 2005). By comparing sciatic nerve transection with nerve crush, the regeneration following sciatic nerve crush is relative faster and more complete than that following sciatic nerve transection, which is delayed and only partial recovered (Wolthers et al., 2005). For example, at 150 days after sciatic nerve crush, $40 \%$ of the large myelinated fibers undergo regeneration, while only $9 \%$ of the large myelinated fibers regenerate in mice with sciatic nerve transection (Wolthers et al., 2005). Most regeneration studies in dorsal root ganglion use nerve crush, since the recovery is slow and subtle following transection. In contrast, gustatory nerve regeneration is robust by 2 months after nerve transection (Hill and Phillips, 1994) and therefore most studies transect the nerve rather than crush it (Guth, 1957; Oakley et al., 1993; Hill and Phillips, 1994; Montavon et al., 1996; Shuler et al., 2004; Guagliardo and Hill, 2007). Perhaps reinnervation in taste system is so robust because the system is extremely plastic in adulthood. Taste cells turn over and are constantly reinnervated by nerve fibers (Beidler and Smallman, 1965). Thus, reinnervation does not just occur following nerve injury, but instead is part of normal biology of the taste system. The continued presence of BDNF in adult taste system may contribute to this process.

1.7. Potential role of neurotrophins in nerve regeneration. 
Neurotrophin expression increased in the cell bodies of the neurons that were sectioned in many sensory systems (Popper et al., 1999; Zhou et al., 1999; Hirsch et al., 2000; Ha et al., 2001). For example, in the visual system, the number of BDNFpositive retinal ganglion cells increased 2 fold at 2 days after optic fiber section in adult mice (Hirsch et al., 2000); in the somatosensory system, BDNF expression in the dorsal root ganglion significantly increased 1 day after nerve lesion and lasted for 2 weeks (Zhou et al., 1999). These data indicate that neurotrophin expression is influenced by sensory nerve injuries.

There is some evidence that neurotrophins promote nerve regeneration after nerve section. Application of neurotrophin can promote regeneration of sensory axons (Ramer et al., 2000). Following nerve section, treatment with NGF, NT3 and GDNF promotes peripheral nerve regeneration resulting in an abundance of fiber sprouting in skin (Bradbury et al., 1999; Ramer et al., 2000). A conclusion from these related studies is that neurotrophic factors contribute to a favorable environment that encourages regeneration in periphery sensory systems (Zhang et al., 2000; Donnerer, 2003; English et al., 2005; Hou et al., 2012).

Although neurotrophins augment regeneration, it is not clear whether neurotrophins are necessary for nerve regeneration. Blocking NGF by injecting antiNGF serum to adult mice, resulted in normal regeneration following dorsal root nerve section (Diamond et al., 1992b), providing evidence that neurotrophins are not required for regeneration. However, it is unclear how effective the anti-NGF antibody was at eliminating NGF-TrkA signaling through the entire period of regeneration. It is also possible that there is variation in the role of neurotrophins in regeneration across systems or neurotrophic factors. Specifically, while NGF was not found to be necessary for sensory nerve regeneration, deletion of the $B d n f$ gene prevented motor 
nerve regeneration (Wilhelm et al., 2012). In this study, the tibia nerve of thy-1-YFP$H$ mice ( mice without $B d n f$ gene deletion) was cut bilaterally, and then grafted with the same nerve from mice lacking BDNF in Schwann cells or wild-type mice (Wilhelm et al., 2012). Two weeks later, axonal regeneration into nerve grafts without BDNF was markedly less than wild type grafts (Wilhelm et al., 2012). Interestingly, treadmill training could significantly improve regeneration of both grafts. However, if motor neurons were also deprived of BDNF, even treadmill training failed to rescue regeneration into grafts without BDNF (Wilhelm et al., 2012). This study demonstrated that both Schwann cell- and neuron-derived BDNF play and important role in motor nerve regeneration.

Unfortunately, very little is known about the influence of neurotrophins on nerve regeneration in the gustatory system. Cutting the glossopharyngeal nerves (innervating taste buds at the back of the tongue) results in a loss of BDNF in both nerve fibers and taste buds (Yee et al., 2005). During regeneration (3 weeks after nerve transection), nerve fibers exhibited weak BDNF immunostaining in the taste buds, demonstrating that BDNF expression comes back during regeneration. The authors concluded that BDNF may be involved in taste nerve regeneration (Yee et al., 2005).

1.8. Plasticity of uncut nerves following chorda tympani nerve section.

In a number of different systems the remaining intact nerves show changes (plasticity) following section of a nearby nerve. For example, neighboring intact axons (collateral sprouting) grow into a denervated area, where dorsal root nerve innervation is lost after nerve section (Nixon et al., 1984). This collateral sprouting 
may improve functional recovery after spinal cord injury by enhancing the extent of innervation (Hagg, 2006).

In the gustatory system, plasticity has been observed in the contra-lateral taste nerve following unilateral chorda tympani section. Specifically, whole nerve chorda tympani recordings showed a $40 \%$ increase in responses to $\mathrm{NaCl}$ in the contralateral chorda tympani nerve 50 days after nerve section combined with sodium restriction (Hill and Phillips, 1994). This change in response properties of the uncut side is dynamic because responses to $\mathrm{NaCl}$ in the contralateral chorda tympani nerve were extremely low immediately following sectioning in sodium-restricted rats (Hill and Phillips, 1994). Surprisingly, this harsh reduction of sodium responses could be restored by systematic injection of LPS, indicating the reduction of sodium responses is caused by immune deficiency in sodium restricted rats (Phillips and Hill, 1996). A further study was performed to show that activated macrophage numbers on the anterior fungiform papilla did not increase in sodium restricted rats while the number had a dramatic increase in cut controls (McCluskey, 2004). These findings suggest a beneficial role for the immune system in maintaining normal taste function after injury. In addition to physiological plasticity, taste buds on the uncut side increase in size due to an increase in the number of taste cells per bud following chorda tympani nerve section (Guagliardo and Hill, 2007). This anatomical plasticity has not been studied nearly to the extent that physiological plasticity so it's mechanisms and relationship with functional plasticity are unclear. Taken together, there are both physiological and anatomical changes on the uncut side, one possible regulator of gustatory plasticity is the immune system, but other factors are also likely involved. 
1.9. Neurotrophin regulation of plasticity in other systems

Evidence from other sensory systems suggests that neurotrophins may be involved with in plasticity. For example, NGF deprivation (with anti-NGF serum) prevents collateral sprouting following dorsal root nerve section (Diamond et al., 1987). This effect was reversible in that once administration of the anti-NGF serum was stopped, the collateral sprouting resumed (Diamond et al., 1992a). Therefore, collateral sprouting of intact sensory nerves following partial denervation of skin is dependent on NGF. In addition to a role for NGF in collateral sprouting there could be a role for BDNF. Specifically, following dorsal cutaneous nerve section the neurons of the adjacent DRG (which will undergo collateral sprouting) have increased levels of $B d n f$ mRNA (Dr Petruska's seminar). The up-regulated neurotrophin in adjacent intact neurons indicated neurotrophins may promote plasticity (collateral sprouting) following peripheral sensory nerve section. 


\section{CHAPTER II}

\section{BDNF MAINTAINS ADULT TASTE INNERVATION}

\subsection{Introduction}

In adulthood taste bud cells have a limited life-span and so are constantly renewed (Beidler and Smallman, 1965). As a result of taste cell turnover, taste cells need to be reinnervated constantly by gustatory nerve fibers and some for synapses with gustatory nerves (Yang et al., 2000). The constant turnover of taste cells necessitates continuing support for synaptogenesis throughout adulthood. The molecular mechanisms supporting this continued reinnervation are unclear, but obvious possibilities are the same factors that support initial taste bud innervation during development. It is now well-established that neurotrophins play a huge role in establishing initial gustatory innervation patterns during development (Lopez and Krimm, 2006a; Ma et al., 2009; Patel et al., 2010).

The neurotrophin factor, Brain-derived neurotrophic factor (BDNF) is critical for the normal development of the taste system. Specifically, BDNF is produced by developing neurons of the taste (geniculate) ganglion and in taste placodes (Nosrat and Olson, 1995; Nosrat et al., 1996; Huang and Krimm, 2010) during development. $\mathrm{BDNF}$ is also required for geniculate ganglion neuron survival during taste system development (Conover et al., 1995; Liu et al., 1995; Ernfors, 2001). The geniculate ganglion loses nearly $50 \%$ of its neurons in the absence of functional BDNF (Conover et al., 1995; Liu et al., 1995). More importantly, BDNF produced in taste epithelium, regulates the ability of gustatory neurons to locate and innervate their correct targets 
during development (Ma et al., 2009; Hoshino et al., 2010). As a result of both neuron loss and targeting deficits, mutant mice that lack BDNF have reduced innervation to taste bud (Ma et al., 2009). Because nerve fibers support taste buds during postnatal development (Sollars, 2005), the loss of nerve fibers results in a loss of taste bud number and size by birth in mice that lack neurotrophins (Nosrat et al., 1997; Mistretta et al., 1999; Patel et al., 2010). Therefore, BDNF is required for development of both geniculate ganglion neurons and taste buds.

In addition to development, BDNF may also play a crucial role in maintaining the adult taste system due to its high expression in adult mouse geniculate ganglion, hamster fungiform, foliate, and circumvallate taste buds (Nosrat et al., 1997; Ganchrow et al., 2003; Uchida et al., 2003; Yee et al., 2003). In particular, BDNF and the synaptic protein, SNAP-25, are co-expressed in the adult taste cells (Yee et al., 2003), suggesting that BDNF may function to encourage synaptic contacts between taste cell and nerve fibers. As a result, BDNF could maintain sensory innervation and/or direct reinnervation to new taste cells in adulthood (Yee et al., 2003). Consistent with this idea, there is a correlation between loss of neurotrophins and loss of peripheral innervation in aging and neurodegenerative diseases (Bergman et al., 2000; Gardiner et al., 2008; Ola et al., 2013). Because these experiments are correlative, it is still unclear whether it is the loss of neurotrophins that results in the loss of sensory innervation. Additional exogenous neurotrophins induced increases in dermal innervation in adult diabetic mice (Christianson et al., 2007), which indicates that neurotrophins can regulate innervation in adult animals. Therefore, it is possible that loss of neurotrophin will cause loss of innervation in adulthood.

To address whether loss of neurotrophins in the adult will result in the loss of sensory innervation, I used genetic recombination to inducibly reduce BDNF 
expression in adult mice. I found that geniculate ganglion neuron number and taste bud number were unaffected by $B d n f$ gene deletion in adulthood. However, innervation to individual taste buds was reduced by half. Taste buds also had a reduced volume following $B d n f$ gene deletion due to a reduction in taste cell number, probably as a result of the loss of innervation. The timing of this reduced innervation is consistent with the idea that BDNF supports innervation of new taste cells in adulthood. Thus, continued $B d n f$ expression is critical for the normal maintenance of innervation to the adult taste bud.

\subsection{Materials and Method}

\subsubsection{Animals}

Ubc-cre ${ }^{\mathrm{ER}} B d n f^{\text {tox/lox }}$ mice were generated by crossing $B d n f^{\text {fox/lox }}$ mice (JAX, $\# 004339)$ with Ubc-cre ${ }^{\mathrm{ER}}$ mice $(\mathrm{JAX}, \# 007001) . B d n f^{\text {tox/lox }}$ mice possess loxP sites on either side of exon 5 of Bdnf gene (JAX, \#004339) and Ubc-cre ${ }^{\mathrm{ER}}$ mice expresses the $\mathrm{Cre}^{\mathrm{ER}}$ from the human ubiquitin $\mathrm{C}$ promotor. Since ubiquitin is found in almost all tissues of eukaryotic organisms, $\mathrm{Cre}^{\mathrm{ER}}$ is also expressed in all tissues under ubiquitin promoter. $\mathrm{Cre}^{\mathrm{ER}}$ is a fusion protein composed of Cre recombinase and a mutant form of the estrogen receptor ligand-binding domain that is selectively activated only in the presence of tamoxifen (TAM) (Feil et al., 1997). Upon introduction of tamoxifen, the Cre recombinase is able to penetrate the nucleus and remove $B d n f$ in Ubc-cre ${ }^{\mathrm{ER}} B d n f$ lox/lox mice.

In order to increase the probability Bdnf would be successfully removed, Ubc$\mathrm{cre}^{\mathrm{ER}} B d n f^{\text {lox/- }}$ mice were generated by crossing Ubc-cre ${ }^{\mathrm{ER}} B d n f^{\text {lox/lox }}$ with heterozygous Bdnf knockout mice $B d n f^{+/-}(\mathrm{JAX}, \# 002266)$. The end result is an 
experimental animal which lacks a functional $B d n f$ gene on one allele and in which $B d n f$ can be removed inducibly from the other allele. Moreover, three controls were analyzed for three different purposes of comparison. $B d n f^{\text {lox/+ }}$ mice (with tamoxifen) was used to exclude potential effects of tamoxifen administration. Ubc-cre ${ }^{\mathrm{ER}} B d n f$ ${ }^{\text {lox } /+}$ mice (without tamoxifen) when compared to Ubc-cre ${ }^{\mathrm{ER}} B d n f^{\text {lox/- }}$ mice. Ideally, $B d n f^{\text {lox/+ }}$ mice, and Ubc-cre ${ }^{\mathrm{ER}} B d n f^{\text {lox/+ }}$ mice were equivalent to each other because they were expected to produce normal amounts of $B d n f . B d n f^{\text {lox/- }}$ mice (with tamoxifen) controlled for any effects in heterozygous $B d n f$ knockouts.

\subsubsection{Tamoxifen administration}

Tamoxifen was administrated (Sigma, T5648; mixed in peanut oil; $188 \mathrm{ng} / \mathrm{g}$ body weight, once per day for 5 days) by oral gavage (Ruzankina et al., 2007). Initially, two different doses were compared when giving tamoxifen: $6 \mathrm{mg} / \mathrm{g}$ (body/weight) for one day, and $188 \mathrm{ng} / \mathrm{g}$ per day for 5 continuous days. I found the latter dose worked more efficiently than the former one. Intraperitoneal (IP) injection was compared with oral gavage, but IP injection of tamoxifen lead to higher morality. Therefore, oral gavage was used to administer tamoxifen at a dose of $188 \mathrm{ng} / \mathrm{g}$ per day for 5 continuous days, which maximized recombination and decreased the loss of animals through toxicity (Ruzankina et al., 2007). For Real Time RT-PCR, mice were euthanized at two weeks and ten weeks after final tamoxifen administration, and mice used for immunohistochemistry were sacrificed at four weeks and ten weeks after final tamoxifen administration.

2.2.3 Lingual epithelium and geniculate ganglion isolation for Real Time RT-PCR

Mice were scarified by overdose $(4 \mathrm{mg} / \mathrm{kg}$ body/weight) of avertin. The 
anterior tongue rostral to the circumvallate papilla was removed and rinsed with 0.1 M phosphate-buffered saline (PBS) solution $(\mathrm{PH}=7.4)$ and then cut in half evenly under microscope. To isolate the lingual epithelium, the tongue pieces containing fungiform papillae were incubated in sterile dispase I-solution (BD Biosciences, San Jose, California) for 50-60 minutes. After incubation, the epithelial sheets were peeled from the underlying lamina propria. The lingual epithelium from each animal was stored in RNA later (Ambion, Austin, TX) and geniculate ganglia were stored in RNA isolation reagent (Qiagen, Chatsworth, CA) at $80^{\circ} \mathrm{C}$ until RNA extraction.

\subsubsection{RNA Extraction and Real Time RT- PCR}

To determine the success of gene recombination, $B d n f$ mRNA level in tongue epithelium and geniculate ganglion were measured using Real Time RT-PCR. Total RNA from each geniculate ganglion, and the epithelia was extracted using RNeasy micro kit or RNeasy mini kit (Qiagen). DNase I treatment was applied to eliminate traces of DNA during the procedure. After the extraction, RNA was analyzed with RNA 6000 Pico/Nano Chip kits in Bioanalyzer 2100 (Agilent Technologies, Santa Clara, CA) and RNA Integrity Number (RIN) and 28S/18S ratio were used to estimate the RNA quality. Only RNA samples with RNA integrity number (RIN) more than 8.0 were used in this study. Reverse transcription was performed using 200 U Superscript III Reverse Transcriptase (Invitrogen, Carlsbad, CA) and 50ng random hexamers (Invitrogen) in $25 \mathrm{ml}$ reaction volume containing first strand buffer (Invitrogen), 0.5 mM dNTPs, and $40 \mathrm{U}$ of RNase inhibitor. All samples produced sufficient amounts of RNA for Real Time RT-PCR. To control for differences in the amount of RNA isolated from different groups, the same amount of RNA from each sample was used for the geniculate ganglion (3ng) and for the lingual epithelium (50ng). After 
incubation for $50 \mathrm{~min}$ at $50^{\circ} \mathrm{C}$, the reaction was stopped by heating $\left(5 \mathrm{~min}\right.$ at $85^{\circ} \mathrm{C}$ ).

Real Time RT-PCR was performed with the ABI PRISM/7900HT sequence detection system (Applied Biosystems, Foster City, CA), using Taq-Man Universal PCR kit (Applied Biosystems), and oligonucleotide primer/probe sets, which were designed from the sequences in the GenBank database using Beacon Designer software (Premier Biosoft International, Atlanta GA). When it was possible, the primers were chosen to span an intron to avoid the detection of any contamination of genomic DNA. TaqMan probes were labeled at the 50-end with a fluorescent reporter dye (FAM) and at the 30-end with a quencher dye (TAMRA). The Real Time RT-PCR reaction (Table 1) were conducted using $10 \mathrm{ml}$ total volume with Master Mix, 720/200 Nm primer/probe sets (TaqMan PCR kit) and the same amount of target cDNA across different time periods. For normalization of cDNA loading, all samples were run in parallel with the housekeeping gene, 18S ribosomal RNA, and mouse glyceraldehyde 3 phosphate dehydrogenase (GAPDH). Each assay was carried out in triplicate. Amplification of cDNA was performed for 40 cycles of $95^{\circ} \mathrm{C}$ for $15 \mathrm{sec}$ and $60^{\circ} \mathrm{C}$ for $1 \mathrm{~min}$.

\subsubsection{Tissue preparation for Immunohistochemistry}

The mice were scarified by avertin overdose $(4 \mathrm{mg} / \mathrm{kg}$ body/weight) and perfused through the heart using 4\% paraformaldehyde (PFA). The anterior two-thirds of the tongue was separate from the circumvallate papillae, rinsed with $0.1 \mathrm{M}$ phosphate-buffered saline (PBS) solution $(\mathrm{PH}=7.4)$ and then cut in half evenly under microscope. The geniculate ganglia were dissected under a microscope. Both the anterior tongue and geniculate ganglia were fixed in $4 \%$ paraformaldehyde for 2 hours, rinsed with PBS, and then transferred to $30 \%$ sucrose at $4{ }^{\circ} \mathrm{C}$ overnight. These 
tissues were frozen the next day in OCT and stored at $-80{ }^{\circ} \mathrm{C}$ until sectioned on a cryostat. Serial sagittal sections of tongue (20um) and geniculate ganglion (50um) were mounted on glass slides for quantification.

\subsubsection{Immunohistochemistry}

To visualize taste buds and innervation, slides containing tongue sections were first dried on a slide warmer $\left(37^{\circ} \mathrm{C}\right)$ overnight. The next day they were rehydrated, placed into Citric Acid buffer (10mM Citric Acid, 0.05\% Tween 20, $\mathrm{PH}=6.0$ ), heated to $98-100{ }^{\circ} \mathrm{C}$ for approximately 15 minutes in boiling bath, and allowed to cool for 20 minutes at room temperature for antigen retrieval. Slides were washed in PBS $(\mathrm{PH}=7.4)$ and incubated overnight at room temperature in anti-cytokerain- 8 antibody in PBS (Table 2). Following the incubation with the anti-cytokeratin-8 antibody the slides were rinsed in PBS and incubated for 1.5 hours with Alexa 488 anti-rat secondary antibody (1:500; Invitrogen). After washing in PBS, the slides were incubated for 2 hours in blocking solution (5\% NGS 2\% Triton X-100 made in $1 \mathrm{X}$ PBS) followed by rabbit anti-P2X3 (1:500; Table 2), mouse anti-TUJ1 (1:500; Table 2 in blocking solution in room temperature overnight. Following the overnight incubation, the slides were rinsed in PBS ( 4 X 5 minutes), and the tissue was incubated for 1.5 hours at room temperature in Alexa 555 anti-rabbit secondary antibody (1:500; Invitrogen), and Alexa 647 anti-mouse secondary antibody (1:500; Invitrogen) in blocking solution. The slides were then rinsed in PBS (3 X 5 minutes) and stained with DAPI (4,6-diamidino-2-phenylindole, dihydrochloride, 2ul/50ml ddH2O, Life technologies, Foster City, CA) for 15 minutes. After a rinse in PBS (3 X 5 mins.), the slides were mounted with Fluoromount-G (SouthernBiotech, Birmingham, AL). 
To label PLC $\beta 2$ containing taste cells the immunohistochemistry procedure was the same as the one for nerve fibers except, the slides were incubated with rabbit anti-PLC $\beta 2$ (1:500; Table 2) in 0.1\% triton X-100/PBS solution in room temperature overnight, instead of anti-P2X3.

\subsubsection{Taste bud counts}

Taste bud are defined as having a visible taste pore and span the entire height of the lingual epithelium from the surface to the basement membrane with Troma-1 staining. Taste buds were counted in 20-um serial sections of the immunofluorescent sagittal section of tongue using enabled Leica DMLB microscope.

\subsubsection{Stereology}

Stereological methods were used to count the total number of geniculate ganglion neurons. Fixed ganglia were serial sectioned $(50 \mu \mathrm{m})$, mounted on slides, and stained with cresyl violet for $15 \mathrm{mins}$. To maintain section thickness, sections were not dehydrated and were mounted in Dako glycergel mounting medium (Dako North America, Carpinteria, CA) for stereological quantification. Using Stereo Investigator software (MBF Bioscience), an experimenter blind to the genotype of the animals traces a contour around the geniculate ganglion (20X). Every section containing the ganglion was traced, and a total of at least 4 sections were quantified. Within each traced contour of the geniculate ganglion, the computer randomly determined the placement of the counting frames. The depth of the counting frame was equal to minimal thickness of the section, minus a total guard zone of $10 \mu \mathrm{m}(5 \mu \mathrm{m}$ from the top and bottom of the section). Geniculate ganglion neurons were counted (100X mag) by each counting frame $\left(15 \mu \mathrm{m}^{2}\right)$. Neurons were counted only when they first came into 
focus (cell top) so that each cell was counted only once. Based on these measurements, the total cell number in the ganglion was estimated for the entire volume of the ganglion using the optical fractionator probe (MBF Bioscience).

\subsubsection{Microscopic analysis of imaging}

To minimize variability, the analysis of individual taste buds was limited to the dorsal tongue tip (Figure 1). Immunofluorescent images consisting of multiple images planes (step size $1 \mu \mathrm{m}$ ) were obtained with an Olympus Fluoview FV1000Laser scanning confocal microscope (LSI3-FV1000-Inverted). During both image capture and analysis the experimenter was blind to the genotype of animals. For each triplelabel immunohistochemical image, the four channels were collected separately, with single wavelength excitation and then merged to produce the composite image. Serial optical sections were captured every $1 \mu \mathrm{m}$ in labeled whole taste buds under $60 \mathrm{X}$ lens at 3.5 zoom. A single taste bud from an intact tongue was typically found in 2-3 physical sections (i.e. 36-60um); all 2-3 sections containing the taste bud were captured so that the entire taste bud could be quantified.

2.2.10 Taste bud analysis: Quantification of taste bud size, innervation and taste cells

Each physiological section contains $15-20$ optical images. Each $1 \mu \mathrm{m}$ optical image was traced and the area measured using Neurolucida imaging software (MicroBrightField). Total area was summed and multiplied by the total number of optical images in all physical sections to yield taste bud volume.

The volume of anti-P2X3 and anti-TUJ1 immunostaining with in the taste bud was measured using MBF ImageJ software (ImageJ 1.47) (Jensen, 2013). ImageJ software set an unbiased threshold automatically, and pixels were analyzed for every 
single section. Finally, the number of labeled pixels inside of taste bud was measured for each section and summed up to obtain the total amount of nerve fibers for one taste bud.

Taste cell number was quantified by counting DAPI staining within the keratin 8 defined taste buds. DAPI labeled nuclei were followed through the optical sections, such that each nucleus was only counted once. Because each taste bud was more than one physical section, the number of cells was added for each physical section. A few cells may have been counted twice due to split nuclei.

\subsubsection{Statistics}

All the measurements within the same group of mice were determined to have equal variance (using Levene's test for homogeneity of variance, $P>0.05$ ). When comparing $B d n f$ mRNA level, one-way ANOVA was applied to analyze the difference between genotypes. For taste bud volumes, nerve innervation, taste cell number, taste bud number and ganglion cell numbers, two-way ANOVA's were used for analysis. After overall significance was determined, a Tukey post-hoc test was used to identify which groups within the analysis were significant. The mean value representing each group derived from 4-5 mice and mean value of each mouse was derived from 5-6 taste buds/mouse. For all the above measurements, 5 mice were analyzed in Ubccre $^{\mathrm{ER}} B d n f^{\text {lox/- }}$ group, while 4 mice in $B d n f^{\text {lox/+ }}$ mice, Ubc-cre ${ }^{\mathrm{ER}} B d n f^{\text {lox/+ }}$ mice, and $B d n f^{\text {lox } /+}$ mice. The significance level was set at $\mathrm{p}<0.05$ for all statistical comparisons.

\subsection{Results}

2.3.1 Tamoxifen induced $B d n f$ gene recombination in adulthood reduces $B d n f$ 
expression to barely detectable levels.

In the mouse taste system, BDNF continues to be expressed during postnatal development and adulthood (Yee et al., 2003). Therefore, it is possible that BDNF maintains the peripheral gustatory system in adult mice. To study its function, $B d n f$ was inducibly removed in all cells of adult mice using the Cre-LoxP system to observe how geniculate ganglion neurons, gustatory innervation and taste bud size would respond. To test the efficiency of gene recombination, Real Time RT-PCR was used to measure $B d n f$ expression at two weeks and ten weeks following tamoxifen introduction.

In mice where $B d n f$ was inducibly removed (Ubc-cre ${ }^{\mathrm{ER}} B d n f^{\text {lox/- }}$ mice), $B d n f$ expression was dramatically reduced in tongue epithelium two weeks after the last tamoxifen administration when compared to the three control genotypes ( $B d n f^{\text {lox/+ }}$ mice $(\mathrm{p}<0.001)$, Ubc-cre ${ }^{\mathrm{ER}} B d n f^{\text {lox/+ }}$ mice $(\mathrm{p}<0.001)$ and $B d n f^{\text {lox/- }}$ mice $(\mathrm{p}=0.001$; Figure 2A)). By comparing $B d n f^{\text {lox/+ }}$ mice (with tamoxifen administration) and Ubc$\mathrm{cre}^{\mathrm{ER}} B d n f^{\text {lox/t+}}$ mice (without tamoxifen administration), I determined there was no effect of tamoxifen administration on $B d n f$ expression. Heterozygous $B d n f$ mutant mice $\left(B d n f^{\text {lox/- }}\right.$ mice) showed $30 \%-40 \%$ reduction in $B d n f$ expression compared to $B d n f^{\text {lox/+ }}$ mice $(\mathrm{p}<0.05)$ and Ubc-cre ${ }^{\mathrm{ER}} B d n f^{\text {lox/t}}$ mice $(\mathrm{p}<0.01)$. In order to verify that $B d n f$ expression remained reduced throughout my experiment, $B d n f$ expression was examined at ten weeks following the last tamoxifen administration. $B d n f$ expression in tongue epithelium of $\mathrm{Ubc}-\mathrm{cre}^{\mathrm{ER}} B d n f^{\text {lox/- }}$ was dramatically reduced when compared to $B d n f^{\mathrm{lox} /+}$ mice $(\mathrm{p}<0.05), \mathrm{Ubc}-\mathrm{cre}^{\mathrm{ER}} B d n f^{\mathrm{lox} /+}$ mice $(\mathrm{p}<0.01)$ and $B d n f^{\mathrm{lox} /-}$ mice $(\mathrm{p}<0.05$; Figure 2A). Similar to the results obtained two-weeks following tamoxifen, control genotypes injected with tamoxifen $\left(B d n f^{\text {lox/- }}\right.$ mice) and without tamoxifen (Ubc-cre ${ }^{\text {ER }}$ $B d n f^{\text {lox/+ }}$ mice) were not different in level of $B d n f$ expression, ruling out an effect of 
tamoxifen on $B d n f$ expression. $B d n f^{\text {lox/- }}$ mice did not show a statistically reliable decrease in $B d n f$ expression levels compared to $B d n f^{\text {lox/+ }}$ mice and Ubc-cre ${ }^{\mathrm{ER}} B d n f$ ${ }^{\text {lox } /+}$ mice. This finding indicates that one functional $B d n f$ allele ( $B d n f^{\text {lox/- }}$ mice) produces as much $B d n f$ mRNA as two alleles in the lingual epithelium. Together these data demonstrate that $B d n f$ expression in the tongue epithelium is successfully reduced to $5 \%$ of normal levels in the experimental animals following tamoxifen administration and will remain reduced for the duration of the experiment.

In addition to the lingual epithelium, $B d n f$ expression level in geniculate ganglion remained very low at both two weeks and ten weeks after tamoxifen administration. Specifically, in the geniculate ganglion of mice where the $B d n f$ gene was inducibly removed (Ubc-cre ${ }^{\mathrm{ER}} B d n f^{\text {lox/- }}$ mice), $B d n f$ expression was reduced to $5 \%$ of $B d n f^{\text {lox/+ }}$ mice $\left(\mathrm{p}<0.001\right.$, two weeks; $\mathrm{p}<0.005$, ten weeks), Ubc-cre ${ }^{\mathrm{ER}} B d n f$ ${ }^{\text {lox } /{ }^{+}}$mice $\left(\mathrm{p}=0.001\right.$, two weeks; $\mathrm{p}<0.01$, ten weeks) and $B d n f^{\text {lox/- }}$ mice $(\mathrm{p}<0.005$, two weeks; $p<0.05$, ten weeks; Figure $2 \mathrm{~B}$ ). Similar to findings in the lingual epithelium, comparing $B d n f^{\text {lox/+ }}$ mice (with tamoxifen administration) and Ubc-cre ${ }^{\mathrm{ER}} B d n f^{\text {lox/+ }}$ mice (without tamoxifen administration), no difference was observed. Moreover, $B d n f$ ${ }^{\text {lox/- }}$ mice did not show a significant reduction in Bdnf expression compared to Bdnf ${ }^{\text {lox } /+}$ mice and Ubc-cre ${ }^{\mathrm{ER}} B d n f^{\text {lox/+ }}$ mice. These findings confirmed tamoxifen does not affect $B d n f$ expression and $B d n f$ expression in the ganglion is the same regardless of the number of functional alleles. In summary, following tamoxifen administration in Ubc-cre ${ }^{\mathrm{ER}} B d n f^{\text {lox/- }}$ mice, $B d n f$ expression levels were reduced to approximately $4 \%$ of normal levels in the geniculate ganglion and remained low throughout the duration of the experiment.

Deletion of $B d n f$ from the hypothalamus of adult mice results in hyperphagic behavior and obesity (Unger et al., 2007). Since the Ubiquitin promoter is expressed 
in all cells, weight gain in the Ubc-cre ${ }^{\mathrm{ER}} B d n f^{\text {lox/- }}$ mice following tamoxifen deletion would be evidence of effective gene recombination. Consistently, Ubc-cre ${ }^{\mathrm{ER}} B d n f^{\text {lox/- }}$ mice appeared to be fatter than the littermate control mice (Figure 3A, B). To quantify this difference, I measured bodyweight before tamoxifen injection and at the time of sacrifice. Before tamoxifen administration, the average body weight of all four genotypes was approximately 20 grams, and there was no difference between genotypes (Figure 3C, D). Four weeks after tamoxifen administration, the average body weight of Ubc-cre ${ }^{\mathrm{ER}} B d n f^{\text {lox/- }}$ mice reached 40 grams while the other three control groups $\left(B d n f^{\text {lox/+ }}\right.$ mice $(\mathrm{p}<0.001)$, Ubc-cre ${ }^{\mathrm{ER}} B d n f^{\text {lox } /+}$ mice $(\mathrm{p}<0.001)$, and $B d n f^{\text {lox/- }}$ mice $\left.(\mathrm{p}<0.001)\right)$ only had an average body weight of approximately 25 grams (Figure 3C). Ten weeks after tamoxifen administration, the body weights of Ubc-cre ${ }^{\mathrm{ER}} B d n f^{\text {lox/- }}$ mice reached an average of 50 grams, while the other three control groups had an average body weight of around 30 grams (Bdnf ${ }^{\text {lox/+ }}$ mice $(\mathrm{p}<0.001)$, Ubc-cre ${ }^{\mathrm{ER}} B d n f^{\mathrm{lox} /+}$ mice $(\mathrm{p}<0.001)$, and $B d n f^{\text {lox/- }}$ mice $(\mathrm{p}<0.001$; Figure. 3D). In addition to weight gain, I noticed an increase of circling behavior in Ubc-

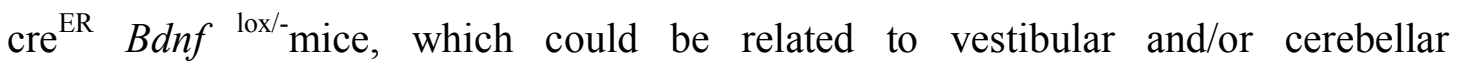
dysfunction.

Culture studies have demonstrated that both BDNF and neurotrophin-4 (NT-4) function through a common TrkB receptor to support the survival of distinct subsets of peripheral sensory neurons (Davies et al., 1993). Neurotrophin-3 (NT-3) primarily binds and activates TrkC; however, strong evidence suggests that NT-3 may also function through TrkA and TrkB receptors (Farinas et al., 1998). Therefore, following BDNF deletion these factors could have increased expression and compensate for the missing BDNF. To test this idea, expression of these neurotrophic factors was detected at 10 weeks after tamoxifen administration. I found no difference in Nt3 or Nt4 
expression within the tongue epithelium (Figure 4A) or the geniculate ganglion (Figure 4B) across genotypes. In conclusion, $N t 3$ and $N t 4$ expression did not increase to compensate for reduced $B d n f$ expression in taste system.

2.3.2 Geniculate ganglion neuron number and taste bud number were unaffected by $B d n f$ gene deletion.

Brain derived neurotrophic factor (BDNF) is required for the survival of gustatory neurons and maintenance of taste buds during development (Zhang et al., 1997; Patel et al., 2010). However, whether $B d n f$ is also required to support geniculate neuron survival and/or maintain taste bud number in adulthood is unknown. To answer these questions, the number of geniculate neurons and the number of taste buds on the anterior two-thirds of the tongue containing the fungiform taste field were counted. Geniculate ganglion neuron number did not change following $B d n f$ gene deletion (Ubc-cre ${ }^{\mathrm{ER}} B d n f^{\text {lox/- }}$ mice) compared to mice without $B d n f$ gene deletion $\left(B d n f^{\text {lox/+ }}\right.$ mice, Ubc-cre ${ }^{\mathrm{ER}} B d n f^{\text {lox/+}}$ mice, $B d n f^{\text {lox/- }}$ mice) at either four weeks or ten weeks after tamoxifen administration. All four genotypes had approximately 800-900 neurons in the geniculate ganglion at both four weeks and ten weeks after tamoxifen administration (Figure 5A). Moreover, when compared to control genotypes (Bdnf $f^{\text {lox/+ }}$ mice, Ubc-cre ${ }^{\mathrm{ER}} B d n f^{\text {lox/+}}$ mice, and $B d n f^{\text {lox/- }}$ mice), the number of taste buds following $B d n f$ deletion (Ubc-cre ${ }^{\mathrm{ER}} B d n f^{\text {lox/- }}$ mice) was not reduced. All four groups had around 70-80 taste buds at both four weeks and ten weeks after tamoxifen administration (Figure 5B). Therefore, geniculate ganglion neuron number and taste bud number were not sensitive to BDNF deprivation in adulthood.

2.3.3 Neural innervation of the taste bud was reduced by half following $B d n f$ gene deletion. 
During development, brain derived neurotrophic factor (BDNF) is required for the innervation of gustatory epithelium (Lopez and Krimm, 2006b; Ma et al., 2009). However, whether neurotrophins are required for the maintenance of the proper amount of gustatory innervation in adulthood is still unknown. To answer this question, I labeled nerve fibers using two markers, anti-P2X3 (red) and anti-TUJ1 (blue) and analyzed them within a taste bud defined by cytokeratin 8 (green). P2X3 is an ATP channel that is required for neural responses to taste stimuli (Finger et al., 2005; Murata et al., 2010; Taruno et al., 2013) and in the tongue is specific to taste fibers coming from geniculate ganglion (Finger et al., 2005; Ishida et al., 2009). TUJ1 (anti-neuron specific beta III tubulin) is a general marker of nerve innervation and most nerve fibers. While both antibodies clearly labeled nerve fibers within the taste bud (Figure 6), there was only a small amount of overlap between the labels (Figure 6 C, G, K, O). This indicates that neither marker labels $100 \%$ of the innervation within the taste bud and that many TUJ1 positive fibers lack P2X3, while P2X3 positive fibers lack TUJ1. No obvious difference was observed between the four genotypes in the amount of $\mathrm{P} 2 \mathrm{X} 3$ or TUJ1 positive staining within the taste bud at four weeks after tamoxifen administration (Figure 6). However, at ten weeks after tamoxifen administration, mice with reduced $B d n f$ expression (Ubc-cre ${ }^{\mathrm{ER}} B d n f^{\text {lox/- }}$ mice) appeared to have fewer labeled nerve fibers and smaller taste buds than the other three genotypes (Figure 7).

In order to quantify these observations, I analyzed the volume of P2X3 and TUJ1-positive nerve fibers inside the taste bud. Mice with the $B d n f$ gene deleted (Ubc-cre ${ }^{\mathrm{ER}} B d n f^{\text {lox/- }}$ mice) did not show any difference in the mean volume of $\mathrm{P} 2 \mathrm{X} 3$ staining inside the taste bud at four weeks after tamoxifen administration, when compared to genotypes with normal levels of $B d n f$ expression $\left(B d n f^{\text {lox/+ }}\right.$ mice, Ubc- 
cre $^{\mathrm{ER}} B d n f^{\text {lox/+ }}$ mice, and $B d n f^{\text {lox/- }}$ mice) (Figure $8 \mathrm{~A}$ ). These results demonstrate that four weeks of $B d n f$ gene deletion does not influence innervation to the taste bud. There was no difference in the volume of P2X3-labeled fibers in the taste bud between $B d n f^{\text {lox/+ }}$ and Ubc-cre ${ }^{\mathrm{ER}} B d n f^{\text {lox/+ }}$ which demonstrates that tamoxifen did not influence P2X3-positive taste innervation. Furthermore, comparing $B d n f^{\text {lox/+ }}$ with $B d n f^{\text {lox/- }}$ indicated that heterozygous Bdnf knockout mice have normal amounts of P2X3-positive taste bud innervation. However, by ten weeks after tamoxifen administration, mice with $B d n f$ gene deletion (Ubc-cre ${ }^{\mathrm{ER}} B d n f^{\text {lox/- }}$ mice) showed a significant reduction of $\mathrm{P} 2 \mathrm{X} 3$ positive staining compared to $B d n f^{\text {lox/+ }}$ mice $(\mathrm{p}<0.01)$, Ubc-cre ${ }^{\mathrm{ER}} B d n f^{\text {lox/+ }}$ mice $(\mathrm{p}<0.01)$ and $B d n f^{\text {lox/- }}$ mice $(\mathrm{p}<0.01$; Figure $8 \mathrm{~A})$. Consistent with our findings at four weeks, no difference among the three controls was observed, confirming that neither tamoxifen administration nor a single allele $B d n f$ mutation influence taste bud innervation. Therefore, $B d n f$ is required for the long-term maintenance of normal P2X3-positive taste bud innervation in adulthood. As a control, to verify that $\mathrm{P} 2 \mathrm{X} 3$ expression level was not affected by $B d n f$ gene deletion, I used Real-Time RT-PCR to detect P2X3 expression level in the geniculate ganglion ten weeks after tamoxifen administration. There was no difference in P2X3 expression level in geniculate ganglion of mice (Ubc-cre ${ }^{\mathrm{ER}} B d n f^{\text {lox/- }}$ mice, mean (normalized $B d n f$ expression level) $=0.78 \pm 0.08$ ) compared to other three genotypes $\left(B d n f^{\text {lox } /+}\right.$ mice: mean $=1 \pm 0.17 ;$ Ubc- cre $^{\mathrm{ER}} B d n f^{\text {lox } /+}$ mice: mean $=1.09 \pm 0.13 ; B d n f$ lox/- mice: mean $=0.92 \pm 0.13$ ).

Similar results were also found with TUJ1 (anti-neuron specific beta III tubulin)-positive nerve fibers. At four weeks after tamoxifen administration, there was no difference across genotypes in the volume of TUJ1 positive nerve fibers within the taste bud (Figure $8 \mathrm{~B}$ ). However, at ten weeks after tamoxifen, Ubc- cre ${ }^{\mathrm{ER}} B d n f^{\text {lox/- }}$ 
mice showed a reduction of around $40 \%$ of labeled fibers when compared to $B d n f^{\text {lox/+ }}$ mice $(\mathrm{p}<0.01)$, Ubc-cre ${ }^{\text {ER }} B d n f^{\text {lox/+ }}$ mice $(\mathrm{p}<0.01)$, and $B d n f^{\text {lox/- }}$ mice $(\mathrm{p}<0.01$; Figure.8B). Finally, there was no difference among the three control genotypes at either four weeks or ten weeks after tamoxifen, ruling out any effect of either tamoxifen or a single allele $B d n f$ mutation on volume of TUJ1-labeled nerve fibers in the taste bud. Thus, BDNF is required for the long-term maintenance TUJ1-labeled nerve fibers in the taste bud.

I used two different markers of nerve fibers and limited our analysis to the taste bud, because there are no perfect labels for taste innervation. Because much of the label was non-overlapping, I compared the two nerve markers (P2X3 and TUJ1) to determine if changes in one label predicted changes in the other. In general, individual taste buds containing more P2X3 positive stained fibers also contained more TUJ1 positive staining fibers $(r=.822, p<0.001, N=81)$. Therefore, the two nerve markers (P2X3 and TUJ1) had a consistent trend inside of taste bud. Because two different markers of nerve innervation produced similar results, I conclude that BDNF is required to maintain the normal levels of innervation to each taste bud during adulthood.

\subsubsection{The changes in innervation predicted changes in taste bud size}

Since loss of innervation at adulthood can result in loss of the normal morphological appearance of the taste bud (Guth, 1957, 1958; Oakley et al., 1993), I wondered whether the reduced innervation following $B d n f$ gene deletion could change the morphological appearance of the taste bud. At four weeks after tamoxifen administration, no obvious difference was observed in taste bud size among the four genotypes (Figure 9). However, at ten weeks, taste buds appeared smaller in mice 
lacking BDNF (Ubc-cre ${ }^{\mathrm{ER}} B d n f^{\text {lox/- }}$ mice) compared to the other three genotypes $\left(B d n f^{\text {lox/+ }}\right.$ mice, Ubc-cre ${ }^{\mathrm{ER}} B d n f^{\mathrm{lox} /+}$ mice, $B d n f^{\text {lox/- }}$ mice $(\mathrm{p}<0.01)$; Figure 9).

Because taste buds appeared smaller following $B d n f$ gene deletion, I measured taste bud volume and cell number. Taste bud size was defined by staining with an anti- cytokeratin 8 antibody, which is a marker for simple epithelium and labels most columnar taste cells of fungiform taste buds. All nuclei (DAPI) within the cytokeratin 8 border were quantified, so that cell number was not limited to cytokeratin 8 positive taste cells. There was no difference in taste bud volume or cell number across the four genotypes (Figure 10A) four weeks after gene recombination. However, ten weeks after tamoxifen administration, mice that underwent $B d n f$ gene deletion (Ubc-cre ${ }^{\text {ER }}$ $B d n f^{\text {lox/- }}$ mice) showed a $30 \%$ reduction in taste bud volume compared to the other three genotypes $\left(B d n f^{\text {lox/+ }}\right.$ mice $(\mathrm{p}<0.01)$, Ubc-cre ${ }^{\mathrm{ER}} B d n f^{\text {lox/+ }}$ mice $(\mathrm{p}<0.01)$ and $B d n f$ ${ }_{\text {lox/- }}$ mice $(p<0.01$; Figure $10 \mathrm{~A})$. Consistent with changes in taste bud volume, at ten weeks after tamoxifen, mice lacking BDNF (Ubc- $\mathrm{cre}^{\mathrm{ER}} B d n f^{\text {lox/- }}$ mice) showed a loss of around $30 \%$ of the taste cells per bud when compared to the other three genotypes $B d n f^{\text {lox } /+}$ mice $(\mathrm{p}<0.01)$, Ubc-cre ${ }^{\mathrm{ER}} B d n f^{\text {lox } /+}$ mice $(\mathrm{p}<0.01)$, and $B d n f^{\text {lox } /-}$ mice $(\mathrm{p}$ $<0.01$; Figure 10B). No difference among the three control genotypes was observed at either four weeks or ten weeks in taste bud volume or cell number, ruling out any effects of tamoxifen or a single $B d n f$ gene loss on taste bud size. When the taste buds of all four genotypes are considered together, larger taste buds mostly contained more taste cells, and vice versa $(\mathrm{r}=.887, \mathrm{p}<0.001, \mathrm{~N}=81)$. In conclusion, $\mathrm{BDNF}$ is required for the maintenance of normal taste bud volume in adulthood and decreases in taste bud volume in mice lacking BDNF is due to a loss of taste cells.

2.3.5 Correlation between nerve innervation, taste bud size, and cell number.

The amount of innervation a taste bud receives during early development 
predicts the size of the taste bud will become by adulthood (Krimm and Hill, 1998b, a, 2000). It is unclear whether this relationship can be reestablished in adulthood following manipulations of innervation. In fact this relationship appears to be easily disrupted by environmental manipulations like sodium derivation (Krimm and Hill, 1999) and nerve section (Shuler et al., 2004). Therefore, it is not clear that this relationship would be maintained following BDNF recombination. Since Ubc-cre ${ }^{\text {ER }}$ $B d n f^{\text {lox/- }}$ mice have reduced innervation to taste buds and smaller taste buds at ten weeks after tamoxifen administration, I wondered if there was also corresponding relationship between these traits in individual taste buds. When the taste buds of all four genotypes are considered together, larger taste buds with more taste cells had greater amounts of innervation, while smaller taste buds with fewer taste cells contained less innervation $(r=0.734, p<0.001, N=81$, Figure.11A; $r=0.746, p<0.001$, $\mathrm{N}=81$, Figure.11B; $\mathrm{r}=.834, \mathrm{p}<.001, \mathrm{~N}=81$, Figure.11C; $\mathrm{r}=.839, \mathrm{p}<0.001, \mathrm{~N}=81$; Figure 11D). In conclusion, the reduction of taste bud size and reduced cell number in Ubc$\mathrm{cre}^{\mathrm{ER}} B d n f^{\mathrm{lox} /-}$ mice could be predicted for each taste bud by loss of innervation.

2.3.6 Taste bud cell loss may be specific to a subtype of cells following Bdnf gene deletion.

Taste buds contain the transduction mechanisms for multiple taste stimuli and many of these stimuli are transduced by separate taste cell subtypes (Farbman, 1965; Kinnamon et al., 1985; Ruiz et al., 2001). Since I found that taste cell number decreased following $B d n f$ gene deletion in adulthood, it would be interesting to know if this loss occurs across all taste cell subtypes or was specific to particular groups of taste cells. PLC $\beta 2$ (phospholipase C $\beta 2$ ), a principal GPCR effector, electively expressed in taste cells that respond to sweet, amino acid, and bitter taste stimuli 
(Hoon et al., 1999; Miyoshi et al., 2001; Finger, 2005). I counted the number of PLC $\beta 2$ - positive taste cells in $B d n f^{\text {lox/+ }}$ mice, Ubc-cre ${ }^{\mathrm{ER}} B d n f^{\text {lox/+ }}$ mice, $B d n f^{\text {lox/- }}$ mice and Ubc-cre ${ }^{\mathrm{ER}} B d n f^{\text {lox/- }}$ mice, at ten weeks after tamoxifen administration. I found no change in PLC $\beta 2$ cell number across the four genotypes (Figure 12, DAPI blue, PLC $\beta 2$ red, anti-cytokeratin 8 green; Figure 13A). However, since the total taste cell number is reduced with $B d n f$ gene deletion, the percentage of PLC $\beta 2$ cells increased in Ubc- cre ${ }^{\mathrm{ER}} B d n f^{\text {lox/- }}$ mice compared to $B d n f^{\mathrm{lox} /+}$ mice $(\mathrm{p}<0.05)$, Ubc-cre ${ }^{\mathrm{ER}} B d n f$ ${ }^{\text {lox } /+}$ mice $(\mathrm{p}<0.05)$, and $B d n f^{\text {lox } /-}$ mice $(\mathrm{p}<0.05$; Figure 13B $)$. Therefore, taste cell loss is not uniform across the various taste cell types and future experiments need to determine which taste cells are lost.

\subsection{Discussion}

BDNF was found to play an important role in taste development, but its role in adult taste system was unknown. I successfully bred inducible BDNF knockout mice to reveal BDNF's role in the adult taste system. My results demonstrated that BDNF is required to maintain normal amounts of gustatory innervation and taste bud size in adult mice.

Removing BDNF in adulthood resulted in a $50 \%$ loss of innervation to the taste bud indicating that BDNF plays an important role in maintaining innervation in adulthood. However, this effect was not measurable until some point between four and ten weeks following tamoxifen administration, even though $B d n f$ mRNA was reduced by two weeks following tamoxifen administration. It is unclear why it would take so long after the reduction in $B d n f$ mRNA to observe an anatomical effect. One possibility is that complete degradation of BDNF protein might take a longer time than deletion of Bdnf mRNA. The remaining small levels of BDNF may be able to support taste innervation for a while following gene recombination. 
A more likely explanation for the slow loss of innervation is that BDNF in the adult taste system may not be required to maintain existing innervation. Instead, BDNF may function to support the formation of new taste cell-nerve fiber connections. Taste cells turn over in the adult and need to be constantly reinnervated by gustatory nerve fibers (Beidler and Smallman, 1965). Some of these taste cells (BDNF expressing taste cells, not PLC $\beta 2$ taste cells) synapse with gustatory nerves (Yang et al., 2000), which necessitates continuing support for synaptogenesis throughout adulthood. In the central nervous system, BDNF has been shown to regulate and facilitate synaptogenesis (Aguado et al., 2003; Cohen-Cory et al., 2010). Therefore, BDNF may function to support the formation of new taste cell-nerve fiber connections in gustatory system, too. If this is the case, in the absence of BDNF, newly-formed taste cells would fail to become innervated resulting in a loss of nerve fibers over time - exactly what we observed.

The length of time required to eliminate innervation following $B d n f$ gene deletion is likely further enhanced by the longer cycle of BDNF-expressing taste cells. Taste bud cells are constantly renewed and have a limited life-span at the average of $250 \pm 50$ hours (Beidler and Smallman, 1965). Some taste cells that express PLC $\beta 2$ turn over with half life time of 8 days, while other taste cells (defined by 5-HT) have the slowest turnover rate with half life time of 22 days (Perea-Martinez et al., 2013). This later population of taste cells are the ones thought to form synapse and coexpress with BDNF and 5-HT (Yee et al., 2003). Because of the longer cycle of BDNF expressing taste cells, these taste cells take a longer time to be eliminated from the taste bud. This would increase the time it takes for newly developed BDNFexpressing taste cells to fail to reconnect to nerve fibers following $B d n f$ gene resulting in fiber loss. 
After Bdnf gene deletion, geniculate ganglion cell number remained unchanged, which indicates that these neurons do not depend on BDNF for survival in adulthood. This finding is consistent with in vitro studies which demonstrate that adult sensory neurons do not depend on neurotrophins (Grothe and Unsicker, 1987; Lindsay, 1988; Putcha et al., 2000). Specifically, adult rat dorsal root ganglion neurons can survive in vitro for more than 3-4 weeks in the absence of BDNF and NGF (Lindsay, 1988). Therefore, it is possible that neuron survival is not dependent on neurotrophins at all by adulthood. The reason why the mature neuron can survive independent of neurotrophins may relate to neurotrophin's ability to inhibit apoptotic signaling cascades (BAX signaling). It has been shown that BAX signaling was triggered and activated in immature sympathetic neurons after NGF withdrawal, but not in mature sympathetic neurons (Putcha et al., 2000). If these results were extrapolated to the taste system, BDNF may not be crucial for survival of taste neurons in adulthood, even though BDNF does regulate geniculate ganglion neuron survival during development (Hoshino et al., 2010).

$B d n f$ gene deletion did not lead to a complete loss of gustatory innervation ten weeks after tamoxifen administration. Specifically, $50 \%$ of the innervation to the taste bud remained. There are several possible explanations for the remaining innervation. First, innervation may remain because ten weeks is not long enough to observe a complete loss. Secondly, the small amount of BDNF remaining in the taste bud could maintain the remaining innervation in taste buds. Third, in situ hybridization shows not all neurons in geniculate ganglion express the primary receptor for $B d n f, \operatorname{Trk} B$ in postnatal and adult ages (Cho and Farbman, 1999; Matsumoto et al., 2001; Farbman et al., 2004). Specifically, the number of TrkB positive neurons in the geniculate ganglion varies among papers from one-third to "the majority" (Cho and Farbman, 
1999; Matsumoto et al., 2001; Farbman et al., 2004). Therefore some neurons in geniculate are TrkB negative, and may innervate the taste bud independent of $B d n f$ regulation.

My findings that BDNF maintains peripheral sensory innervation, but not neuron number, is consistent with correlative studies in other sensory systems especially in aging and neurodegenerative disease (Bergman et al., 2000; Gardiner et al., 2008; Ola et al., 2013). In aging, decreases NT3 and NT4 were observed and accompanied with a loss of sensory axons into peripheral receptive fields (Bergman et al., 1999; Bergman et al., 2000). In diabetic and other neurodegenerative disease, fungiform papillae or taste sensation are also decreased, accompanied by reduced neurotrophins (Gardiner et al., 2008). These experiments are correlative; while both neurotrophins and sensory innervation are reduced, the causal relationship between the loss of neurotrophins and the loss of innervation was still unclear. In addition, when exogenous neurotrophin was supplied, it induced increases in dermal innervation in adult diabetic mice (Christianson et al., 2007). Consistently, in our study, I found reduced BDNF causes a loss of innervation in the gustatory system of adult mice. Therefore, it is likely that loss of neurotrophins with aging/neurodegenerative disease results in a loss of nerve innervation in many adult sensory systems.

After Bdnf gene deletion, taste bud size is decreased due to a loss of taste cells. This cell loss could be a direct effect, such that BDNF normally supports taste cell survival. The BDNF receptor, TrkB, is present in taste cells of the adult mouse and hamster (Ganchrow et al., 2003; Yee et al., 2003; Huang and Stahler, 2009). Furthermore, BDNF overexpression increases TrkB phosphorylation in taste buds (Nosrat et al., 2012), indicating that BDNF activates TrkB in taste receptor cells. 
These findings suggest that BDNF released from taste cells could have an autocrine effect or could influence other taste cells via a paracrine mechanism. Alternatively, loss of nerve innervation following Bdnf gene deletion could cause taste cell loss. Nerve fibers support taste cells during adulthood. Specifically, the loss of nerve fibers after nerve section results in a loss of taste buds and a reduction in size and cell number of remaining taste buds (Farbman, 1969; Ganchrow and Ganchrow, 1989; Montavon et al., 1996; Guagliardo and Hill, 2007). Taste nerves may support taste buds by releasing a trophic factor of their own (May, 1925; Torrey, 1936).

Taste cells can be sub-grouped into different cell types based on their function, ultrastructure anatomical features or light microscope markers (Farbman, 1965; Kinnamon et al., 1985; Ruiz et al., 2001). Specifically, some taste cells express G-protein-coupled receptors (GPCR) which transduce sweet, bitter or umami stimuli (Ruiz et al., 2001). Phospholipase Cb2 (PLC 32 ), as a principal GPCR effector, is involved with this transduction in taste cells with GPCRs (Ruiz et al., 2001). What's more, another type of taste cells possess specialized chemical synapses and coexpresses some synaptic proteins like SNAP-25 (Yang et al., 2000). We found that the total number of taste cells decreased following $B d n f$ gene deletion with no PLC $\beta 2$ labeled taste cell loss. Our finding indicates that PLC $\beta 2$ labeled taste cells are not sensitive to $B d n f$ gene deletion. In addition, a clear increase in the number of NCAMpositive cells was observed in the taste buds of mice with overexpressing BDNF (Nosrat et al., 2012). Therefore, it is likely that the reduction of taste cells following $B d n f$ gene deletion does not occur equally across taste cell subtypes, but instead is due to a loss of a specific type of taste cells. 
Table 1

\begin{tabular}{|c|c|c|}
\hline \multicolumn{3}{|l|}{ Gene } \\
\hline GenBank Accession\# & Sequence 5'-3' & ze (bp) \\
\hline BDNF (X55573) & $\begin{array}{l}\text { Forward primer TGCAGGGGCATAGACAAAAGG } \\
\text { Reverse primer CTTATGAATCGCCAGCCAATTCTC }\end{array}$ & 110 \\
\hline NT4 (NM_198190) & $\begin{array}{l}\text { Forward primer AGCGTTGCCTAGGAATACAGC } \\
\text { Reverse primer GGTCATGTTGGATGGGAGGTATC }\end{array}$ & 95 \\
\hline 18S rRNA (X00686) & $\begin{array}{l}\text { Forward primer CAGGATTGACAGATTGATAGCTCTTTC } \\
\text { Reverse primer ATCGCTCCACCAACTAAGAACG }\end{array}$ & 76 \\
\hline GAPDH (NM_008084) & $\begin{array}{l}\text { Forward primer AATGTGTCCGTCGTGGATCTG } \\
\text { Reverse primer CAACCTGGTCCTCAGTGTAGC }\end{array}$ & 130 \\
\hline Beta-Actin (NM_007393) & $\begin{array}{l}\text { Forward primer CTGGGACGACATGGAGAAGATC } \\
\text { Reverse primer GTCTCAAACATGATCTGGGTCATC }\end{array}$ & 144 \\
\hline TrkB (X17647) & $\begin{array}{l}\text { Forward primer AAGGACTTTCATCGGGAAGCTG } \\
\text { Reverse primer TCGCCCTCCACACAGACAC }\end{array}$ & 86 \\
\hline Krt8 (NM_031170) & $\begin{array}{l}\text { Forward primer TCTTCTGATGTCGTGTCCAAGTG } \\
\text { Reverse primer GATCCTCGGACGGGTCTCTAG }\end{array}$ & 130 \\
\hline Nefl (NM_010910) & $\begin{array}{l}\text { Forward primer CAGCAGAACAAGGTCCTGGAA } \\
\text { Reverse primer AGCGGGAAGGCTCAGAGTG }\end{array}$ & 69 \\
\hline NT3 ( NM-001164034 ) & $\begin{array}{l}\text { Forward primer CAGAACATAAGAGTCACCGAGG } \\
\text { Reverse primer TGTCCCCGAATGTCAATGG }\end{array}$ & 94 \\
\hline Bdnf exn IV ( NM-001048141) & $\begin{array}{l}\text { Forward primer CGCCATGCAATTCCACTATCAATAATTTAAC } \\
\text { Reverse primer CGCCTTCATGCAACCGAAGTATG| }\end{array}$ & 274 \\
\hline
\end{tabular}

Table 1 Sequence of Primer Pairs Used For Real-Time RT-PCR. 
Table 2

\begin{tabular}{|c|c|c|c|c|}
\hline Antigen & Dilution & $\begin{array}{l}\text { Host } \\
\text { species }\end{array}$ & Source & Catalog no. \\
\hline Cytokeratin-8 & $\begin{array}{l}1: 50 \text { of } \\
\text { concentrate }\end{array}$ & rat & $\begin{array}{l}\text { Deveopmental } \\
\text { studies } \\
\text { Hybridoma } \\
\text { Bank }\end{array}$ & Troma-1-s \\
\hline $\mathrm{P} 2 \mathrm{X} 3$ & $1: 500$ & rabbit & Millipore & AB5895 \\
\hline TUJ1 & $1: 500$ & mouse & Covance & MMS-435P \\
\hline PLC $\beta 2$ & $1: 500$ & rabbit & Santa cruz & C0811 \\
\hline
\end{tabular}

Table 2 Primary antibodies used in the study. 
Figure 1
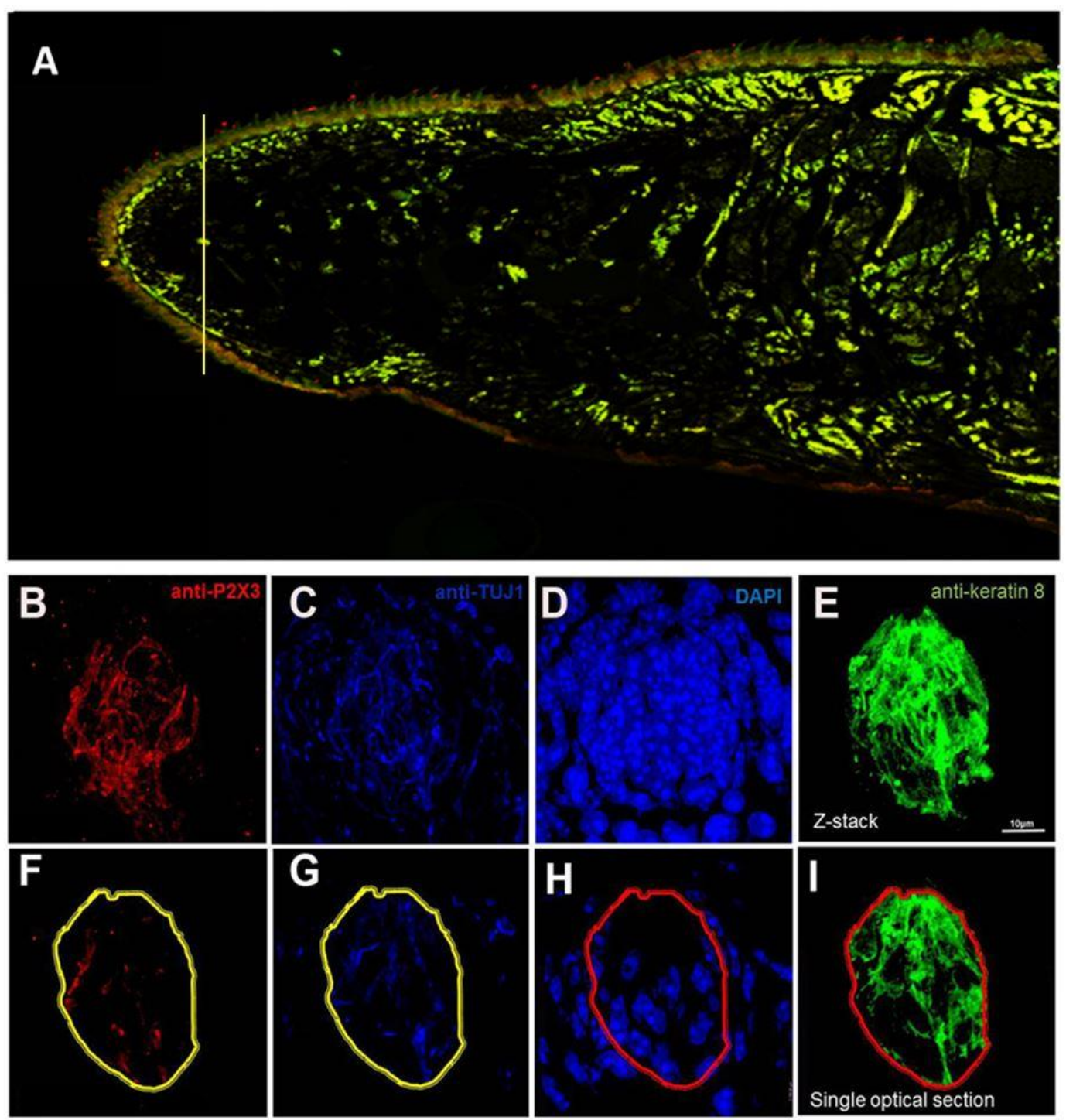
Figure 1. Method of taste bud quantification. An image of whole tongue section labeled with anti-Troma1, anti-P2X3, anti-TUJ1 staining comes from wild type mice. Analyzed taste buds were taken from the tip of tongue rostral of the white line (A). Merged z-stack of the entire physical section of a taste bud as shown in (B-E). For analysis, the taste bud edge was defined in single optic sections by anti-Keratin 8 labeling. In each optical section the number of pixels occupied by $\mathrm{P} 2 \mathrm{X} 3$ positive fibers (F), or TUJ1 positive fibers $(\mathrm{G})$, and the number of DAPI stained nuclei $(\mathrm{H})$, and the volume of anti-Keratin 8 labeled (I) were determined. These data were summed through all optical and physical sections in one taste bud. The scale bar is $=10$ $\mu \mathrm{m}$ and applies to all. 
Figure 2
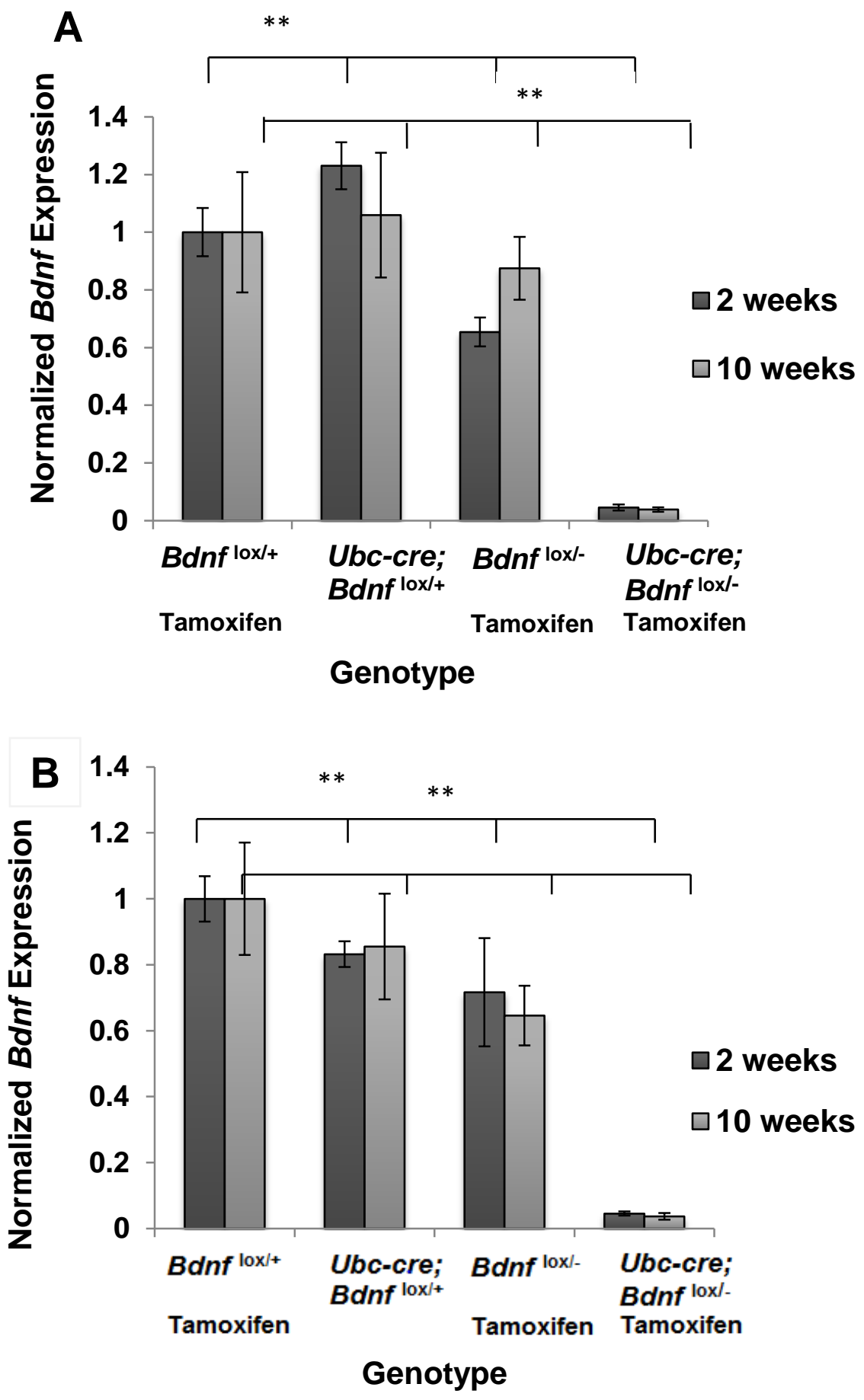
Figure 2. $B d n f$ expression is successfully reduced following gene recombination. $B d n f$ expression in tongue epithelium is reduced in Ubc-cre ${ }^{\mathrm{ER}} B d n f^{\text {lox/- }}$ mice $(\mathrm{n}=4)$ at both two and ten weeks after tamoxifen administration, compared to $B d n f^{\text {lox/+ }}$ mice $(\mathrm{n}=4)$, and Ubc-cre ${ }^{\mathrm{ER}} B d n f^{\text {lox/+ }}$ mice $(\mathrm{n}=4)$ and $B d n f^{\text {lox/- }}$ mice $(\mathrm{n}=4)(\mathrm{A})$. In the geniculate ganglion, $B d n f$ expression was reduced at two and ten weeks following tamoxifen administration in Ubc-cre ${ }^{\mathrm{ER}} B d n f^{\text {lox/- }}$ mice $(\mathrm{n}=4)$, compared to $B d n f^{\mathrm{lox} /+}$ mice $(\mathrm{n}=4)$, Ubc-cre ${ }^{\mathrm{ER}} B d n f^{\text {lox/+ }}$ mice $(\mathrm{n}=4)$, and $B d n f^{\text {lox/- }}$ mice $(\mathrm{n}=4)(\mathrm{B}) .{ }^{*} \mathrm{p}<0.05,{ }^{*} \mathrm{p}<0.01$ 
Figure 3
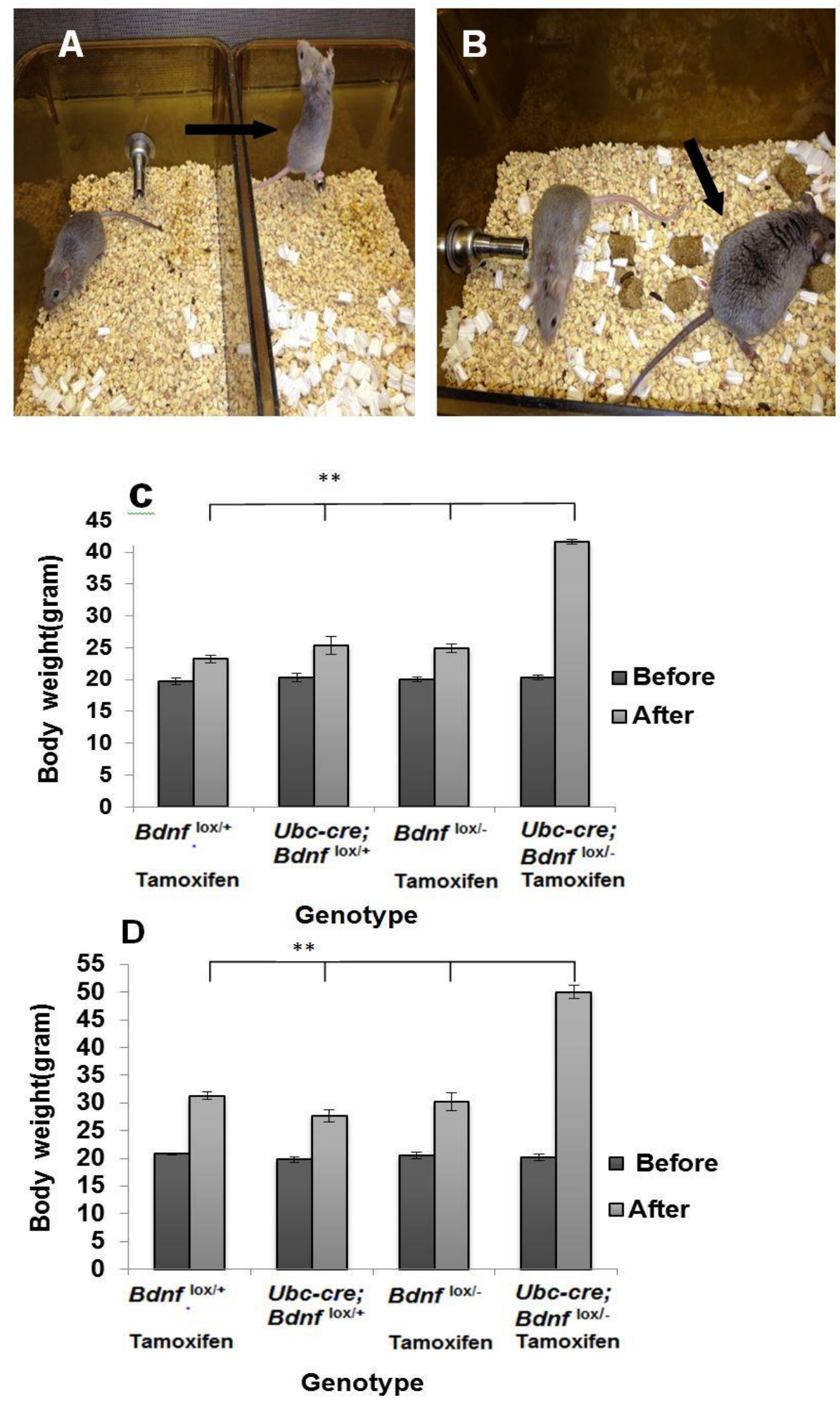
Figure $3 B d n f$ gene recombination results in increased body weight. $B d n f^{\text {lox/+ }}$ mice and Ubc-cre ${ }^{\mathrm{ER}} B d n f^{\text {lox/- }}$ mouse (arrow) look similar before tamoxifen injection (A). However, ten weeks after tamoxifen administration, the Ubc-cre ${ }^{\mathrm{ER}} B d n f^{\text {lox/- }}$ mouse (arrow) was much bigger than the $B d n f^{\text {lox/+ }}$ mouse (B). Mean body weight of Ubccre $^{\mathrm{ER}} B d n f^{\mathrm{lox} /-}$ mice $(\mathrm{n}=4)$ increased compared to $B d n f^{\mathrm{lox} /+}$ mice $(\mathrm{n}=4), \mathrm{Ubc}-\mathrm{cre}^{\mathrm{ER}} B d n f$ ${ }^{\text {lox } /+}$ mice $(n=4)$ and $B d n f^{\text {lox/- }}$ mice $(n=4)$ at four weeks $(C)$ and ten weeks $(D)$ after tamoxifen administration $(\mathrm{C}, \mathrm{D}) .{ }^{*} \mathrm{p}<0.05, * * \mathrm{p}<0.01$ 
Figure 4
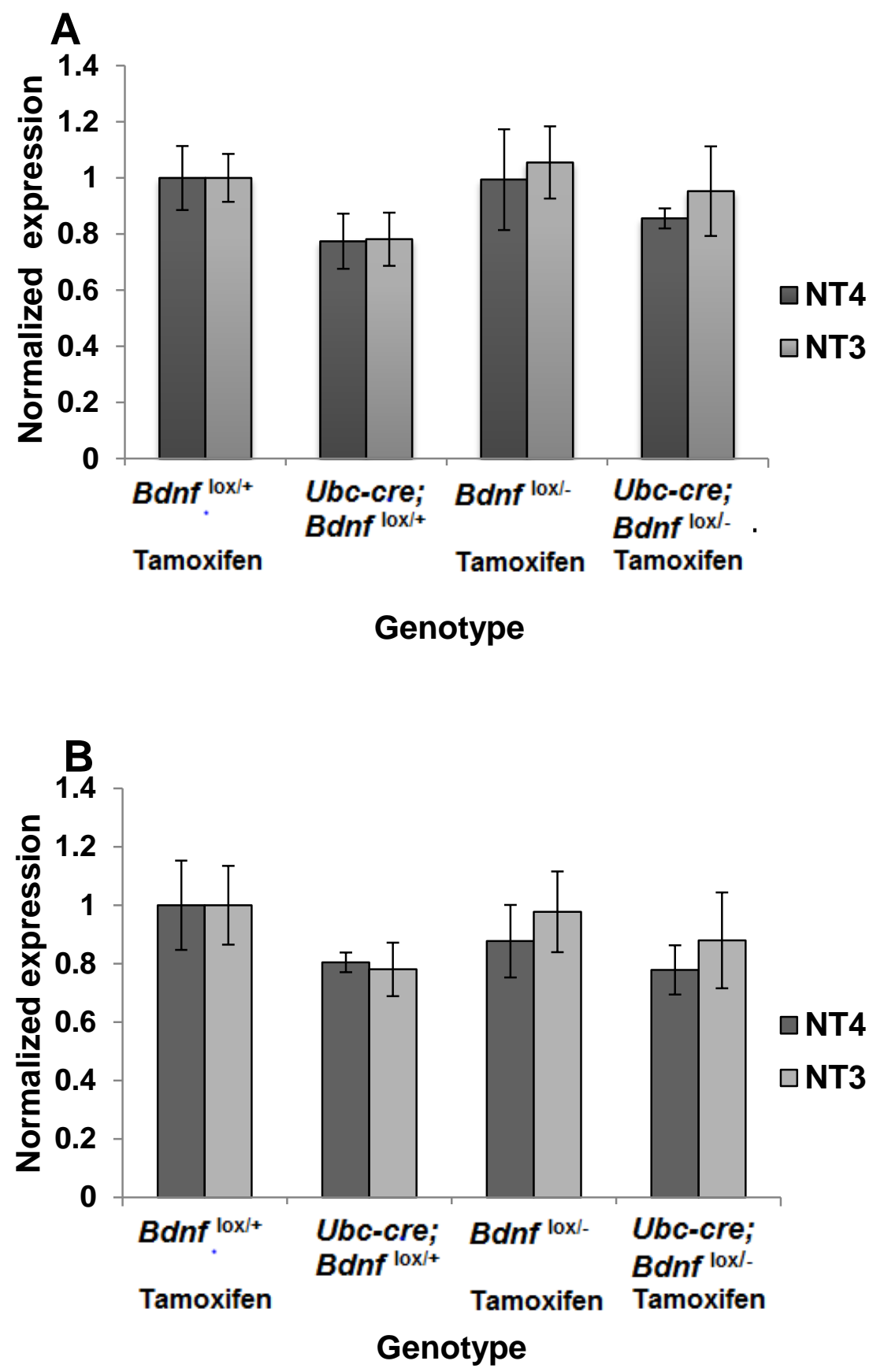
Figure 4. Neither $N t 3$ nor $N t 4$ show altered expression after $B d n f$ gene deletion. In the tongue epithelium (A) and the geniculate ganglion (B), Nt3 and Nt4 expression level was unaltered in Ubc-cre ${ }^{\mathrm{ER}} B d n f^{\text {lox/- }}$ mice $(\mathrm{n}=4)$ compared to $B d n f^{\text {lox/+ }}$ mice $(\mathrm{n}=4)$, Ubc-cre ${ }^{\mathrm{ER}} B d n f^{\text {lox/+ }}$ mice $(\mathrm{n}=4), B d n f^{\text {lox/- }}$ mice $(\mathrm{n}=4)$ at ten weeks after tamoxifen administration. 
Figure 5

A

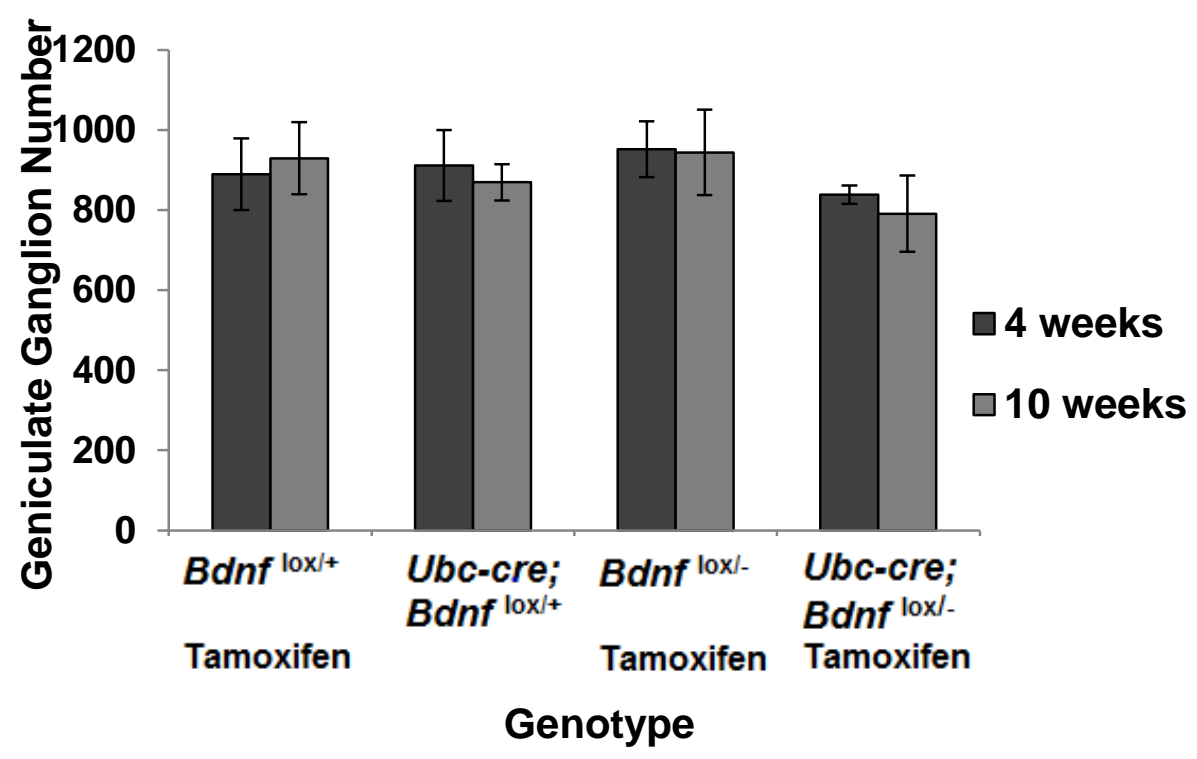

B

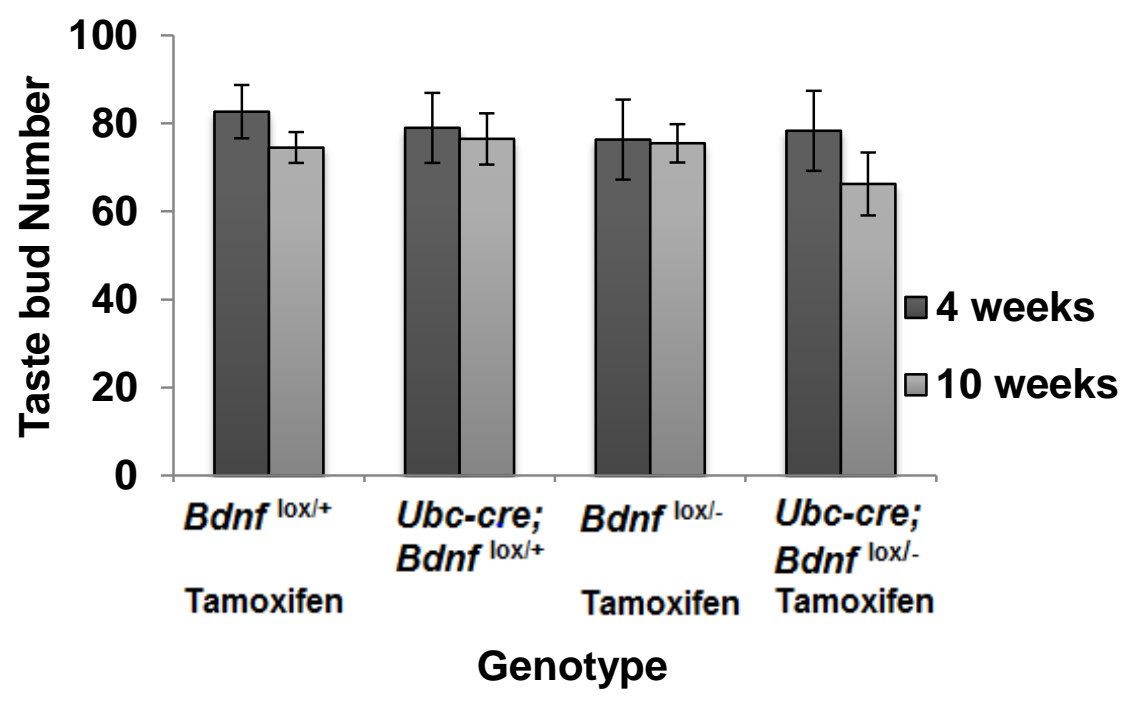


Figure 5. The number of geniculate ganglion neurons and taste buds were not influenced by $B d n f$ gene deletion. The number of geniculate ganglion neurons were not different in Ubc-cre ${ }^{\mathrm{ER}} B d n f^{\text {lox/- }}$ mice $(\mathrm{n}=4)$ compared to $B d n f^{\text {lox/+ }}$ mice $(\mathrm{n}=4)$, Ubccre $^{\mathrm{ER}} B d n f^{\text {lox/+ }}$ mice $(\mathrm{n}=4), B d n f^{\text {lox/- }}$ mice $(\mathrm{n}=4)$ at both four and ten weeks after tamoxifen administration (A). The number of taste buds was not different in Ubccre $^{\mathrm{ER}} B d n f^{\text {lox/- }}$ mice $(\mathrm{n}=4)$ compared to $B d n f^{\text {lox } /+}$ mice $(\mathrm{n}=4), \mathrm{Ubc}-\mathrm{cre}^{\mathrm{ER}} B d n f^{\text {lox } /+}$ mice $(\mathrm{n}=4), B d n f^{\text {lox } / \text { mice }}(\mathrm{n}=4)$ at both four and ten weeks after tamoxifen administration (B). 
Figure 6

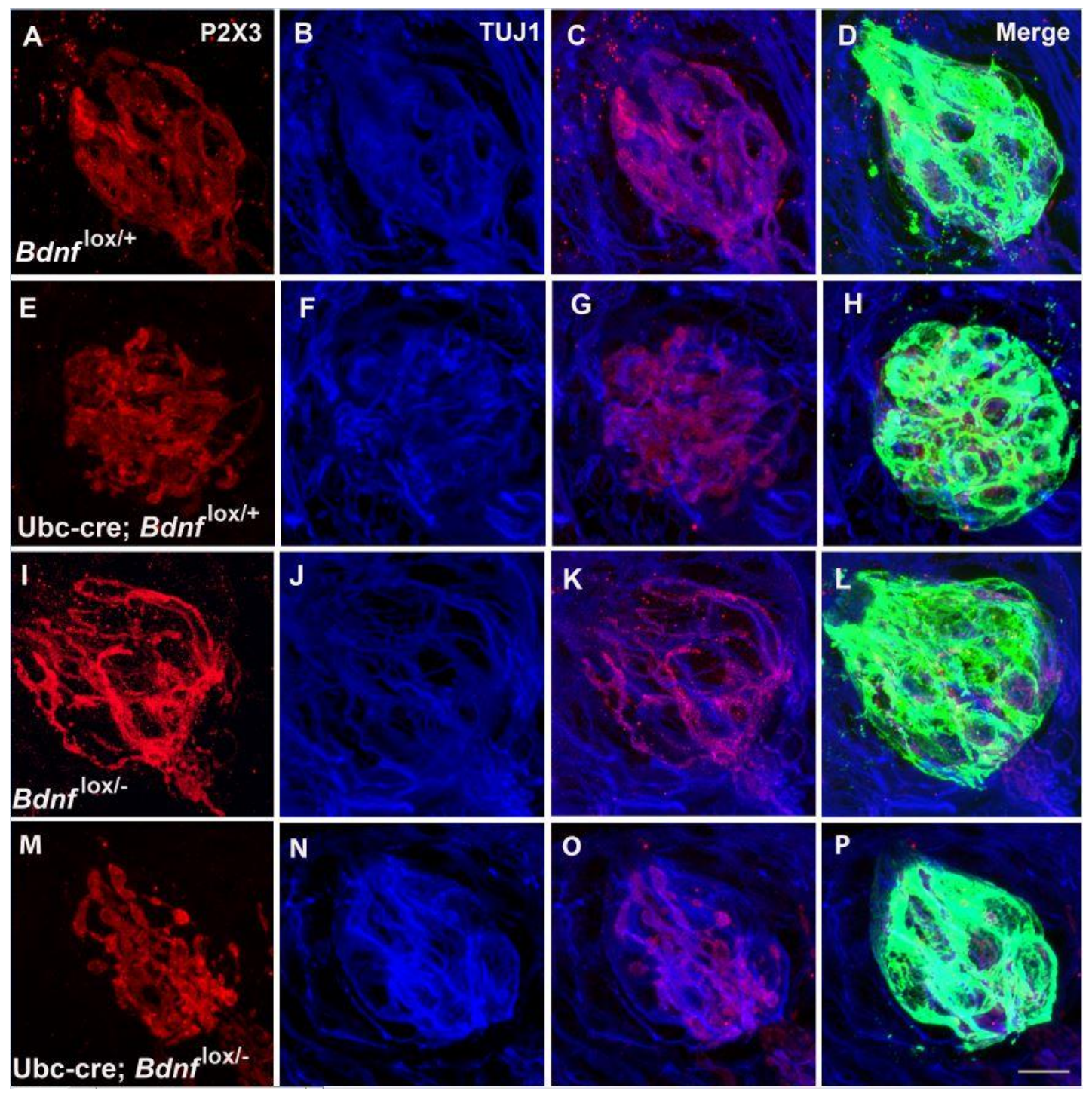


Figure 6. P2X3 and TUJ1 labeled nerve fibers appeared similar across genotypes at four weeks after tamoxifen administration. A-P: Confocal images of innervation within the taste buds of $B d n f^{\text {lox/+ }}$ mice (A-D), Ubc-cre ${ }^{\mathrm{ER}} B d n f^{\text {lox/+ }}$ mice (E-H), $B d n f^{\text {lox/- }}$ mice (I-L) and Ubc-cre ${ }^{\mathrm{ER}} B d n f^{\text {lox/-mice }}(\mathrm{M}-\mathrm{P})$ at four weeks after tamoxifen administration. Anti-P2X3 (nerve fibers, red) and anti-TUJ1 (nerve fibers, blue) were merged $(\mathrm{C}, \mathrm{G}, \mathrm{K}, \mathrm{O})$ to examine overlap in two labels in $B d n f^{\text {lox/+ }}$ mice $(\mathrm{C})$, Ubccre $^{\mathrm{ER}} B d n f^{\text {lox/+ }}$ mice $(\mathrm{G}), B d n f^{\text {lox/- }}$ mice $(\mathrm{K})$ and $\mathrm{Ubc}-\mathrm{cre}^{\mathrm{ER}} B d n f^{\text {lox/- }}$ mice $(\mathrm{O})$. Anticytokeratin 8 (taste bud, green) was used to define the borders of the taste buds in $B d n f^{\text {lox/+ }}$ mice (D), Ubc-cre ${ }^{\mathrm{ER}} B d n f^{\mathrm{lox} /+}$ mice $(\mathrm{H}), B d n f^{\mathrm{lox} /-}$ mice $(\mathrm{K})$ and $\mathrm{Ubc}-\mathrm{cre}^{\mathrm{ER}} B d n f$ lox/- mice (P). There was no obvious difference between these four genotypes in the amount of innervation to the taste bud. The scale bar is $=10 \mu \mathrm{m}$ and applies to all. 
Figure 7

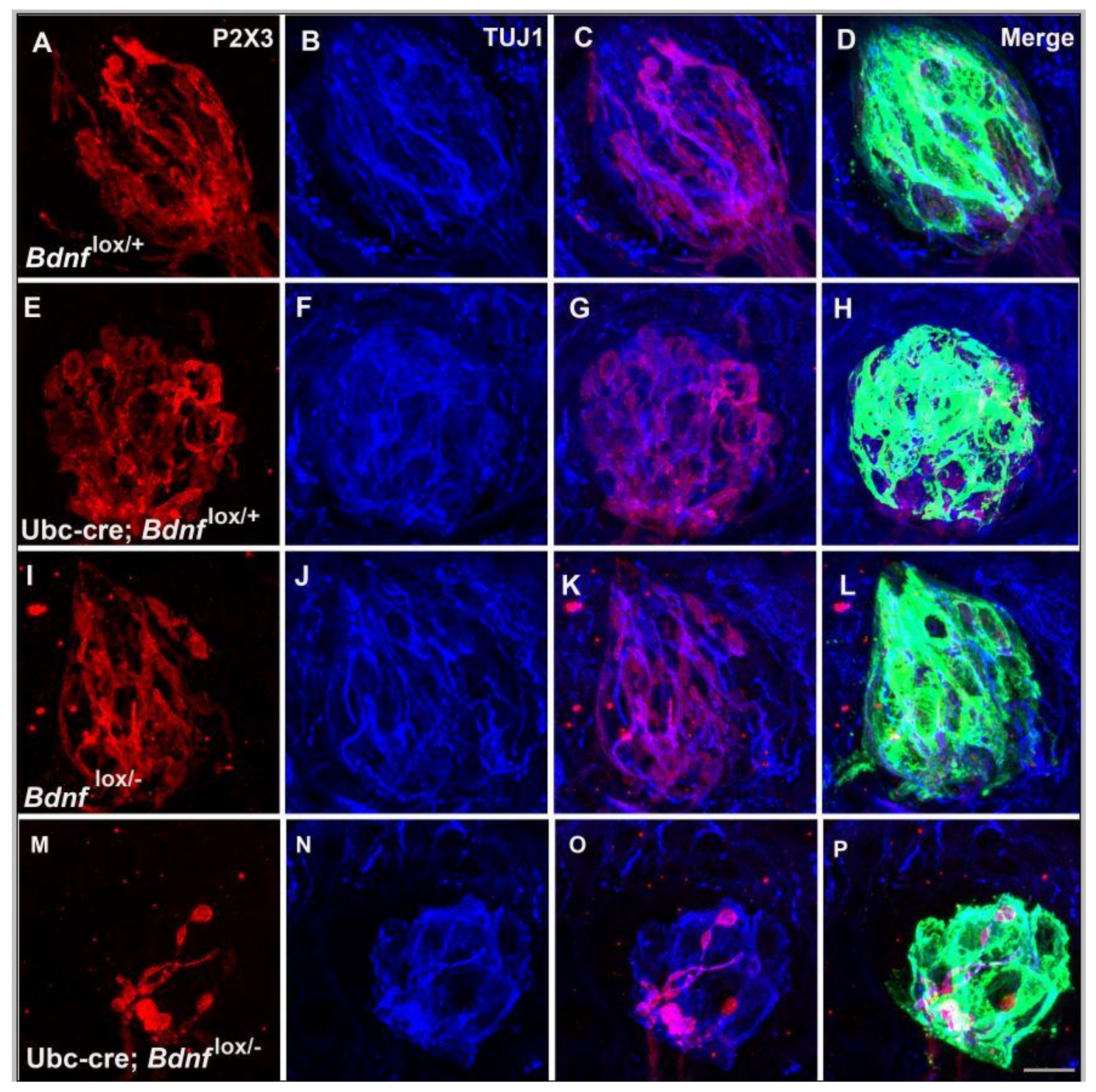


Figure 7: Taste buds appeared to contain fewer P2X3 and TUJ1 labeled nerve fibers at ten weeks after tamoxifen administration. A-P: Confocal images of innervation within the taste buds of $B d n f^{\text {lox/+ }}$ mice (A-D), Ubc-cre ${ }^{\mathrm{ER}} B d n f^{\text {lox/+ }}$ mice (E-H), $B d n f^{\text {lox/- }}$ mice (I-L) and Ubc-cre ${ }^{\mathrm{ER}} B d n f^{\text {lox/- }}$ mice (M-P) at ten weeks after tamoxifen administration. Anti-P2X3 (nerve fibers, red) and anti-TUJ1 (nerve fibers, blue) were merged (C, G, $\mathrm{K}, \mathrm{O})$ to observe the degree to which these two measures of innervation overlap in $B d n f^{\text {lox/+ }}$ mice $(\mathrm{C}), \mathrm{Ubc}-\mathrm{cre}^{\mathrm{ER}} B d n f^{\mathrm{lox} /+}$ mice $(\mathrm{G}), B d n f^{\mathrm{lox} /-}$ mice $(\mathrm{K})$ and Ubc-cre ${ }^{\mathrm{ER}} B d n f$ lox/- mice (O). Anti-cytokeratin 8 (taste bud, green), anti-P2X3 (nerve fibers, red) and anti-TUJ1(nerve fibers, blue) were merged to visualize taste bud and taste nerve fibers in in $B d n f^{\text {lox/+ }}$ mice (D), Ubc-cre ${ }^{\mathrm{ER}} B d n f^{\text {lox/+ }}$ mice $(\mathrm{H}), B d n f^{\text {lox/- }}$ mice $(\mathrm{K})$ and Ubccre $^{\mathrm{ER}} B d n f^{\text {lox/- }}$ mice $(\mathrm{P})$. Innervation to the taste bud in $\mathrm{Ubc}-\mathrm{cre}^{\mathrm{ER}} B d n f^{\mathrm{lox} /}$ mice was reduced compared to other three genotypes. The scale bar=10 $\mu \mathrm{m}$ and applies to all. 
Figure 8

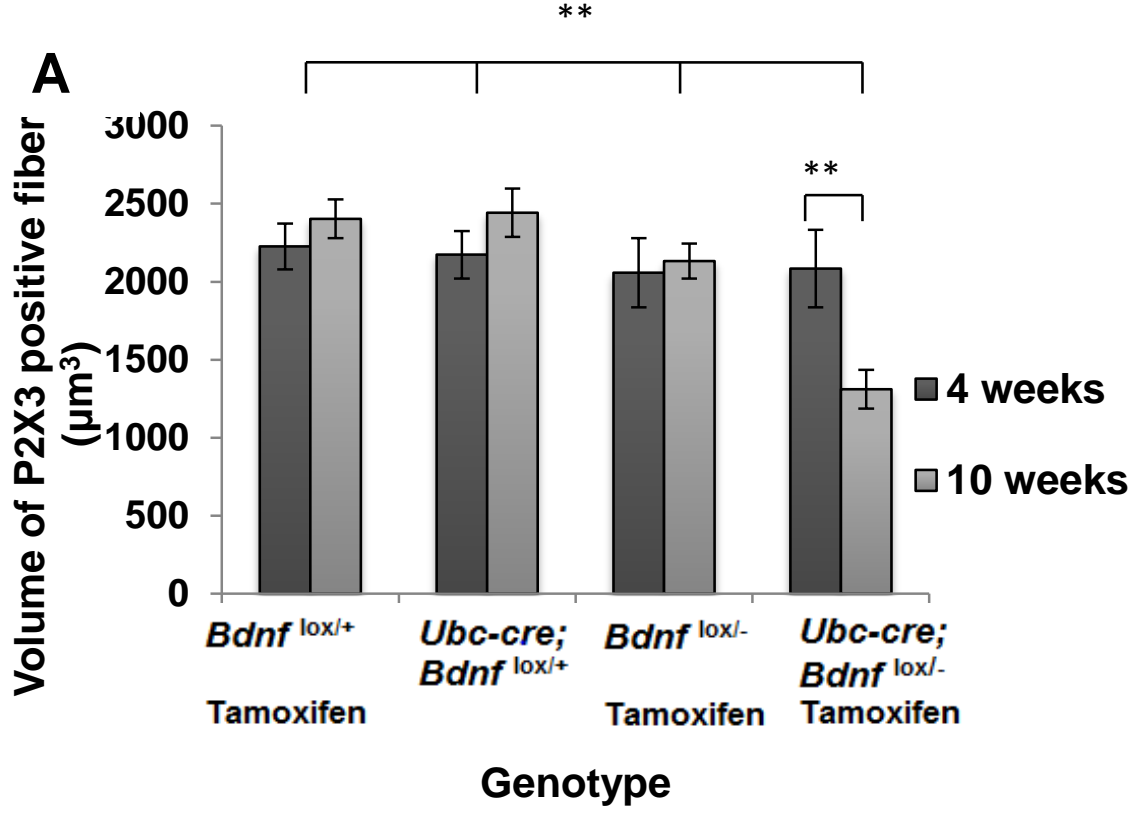

B

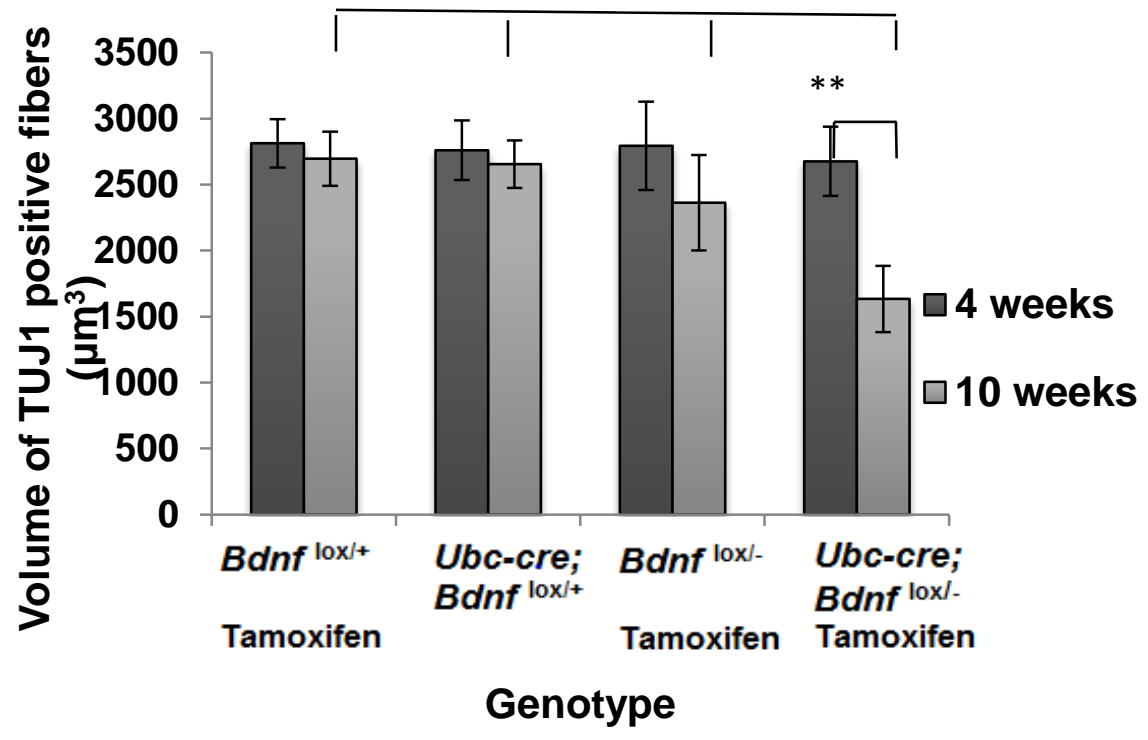


Figure 8. Quantification of P2X3 and TUJ1 labeled nerve fibers confirmed a 50\% reduction in innervation to the taste bud ten weeks after $B d n f$ gene recombination. At four weeks after tamoxifen administration, there were no differences in volume of P2X3 label within the taste bud in $B d n f^{\text {lox } /+}$ mice $(\mathrm{n}=3)$, Ubc-cre ${ }^{\mathrm{ER}} B d n f^{\text {lox/+ }}$ mice $(\mathrm{n}=3), B d n f^{\text {lox/- }}$ mice $(\mathrm{n}=3)$ and Ubc-cre ${ }^{\mathrm{ER}} B d n f^{\text {lox/- }}$ mice $(\mathrm{n}=3)$. However, ten weeks after tamoxifen administration, the volume of P2X3-labeled fibers is reduced by approximately $50 \%$ in Ubc-cre ${ }^{\mathrm{ER}} B d n f^{\text {lox/- }}$ mice $(\mathrm{n}=4)$, compared to $B d n f^{\text {lox } /+}$ mice $(\mathrm{n}=4)$, Ubc-cre ${ }^{\mathrm{ER}} B d n f^{\text {lox } /+}$ mice $(\mathrm{n}=4)$, and $B d n f^{\text {lox/- }}$ mice $(\mathrm{n}=4)$. There was no difference in the three control genotypes (A). At four weeks after tamoxifen administration, there were no differences in the volume of TUJ1 (anti-neuron specific beta III tubulin) label nerve fibers among $B d n f^{\text {lox/+ }}$ mice $(\mathrm{n}=3)$, Ubc-cre ${ }^{\mathrm{ER}} B d n f^{\mathrm{lox} /+}$ mice $(\mathrm{n}=3), B d n f^{\text {lox/- }}$ mice $(\mathrm{n}=3)$ and Ubc-cre ${ }^{\mathrm{ER}} B d n f^{\text {lox/- }}$ mice $(\mathrm{n}=3)$. While ten weeks after tamoxifen administration, the volume of TUJ1 labeled fibers in the taste bud was reduced by approximately $40 \%$ in Ubc-cre ${ }^{\mathrm{ER}} B d n f^{\text {lox/- }}$ mice $(\mathrm{n}=4)$, compared to $B d n f$ ${ }^{\text {lox } /+}$ mice $(\mathrm{n}=4), \mathrm{Ubc}-\mathrm{cre}^{\mathrm{ER}} B d n f^{\mathrm{lox} /+}$ mice $(\mathrm{n}=4)$, and $B d n f^{\text {lox/- }}$ mice $(\mathrm{n}=4)$. There was no difference in the three control genotypes (A, B). ${ }^{*} \mathrm{p}<0.05,{ }^{* *} \mathrm{p}<0.01$. 
Figure 9
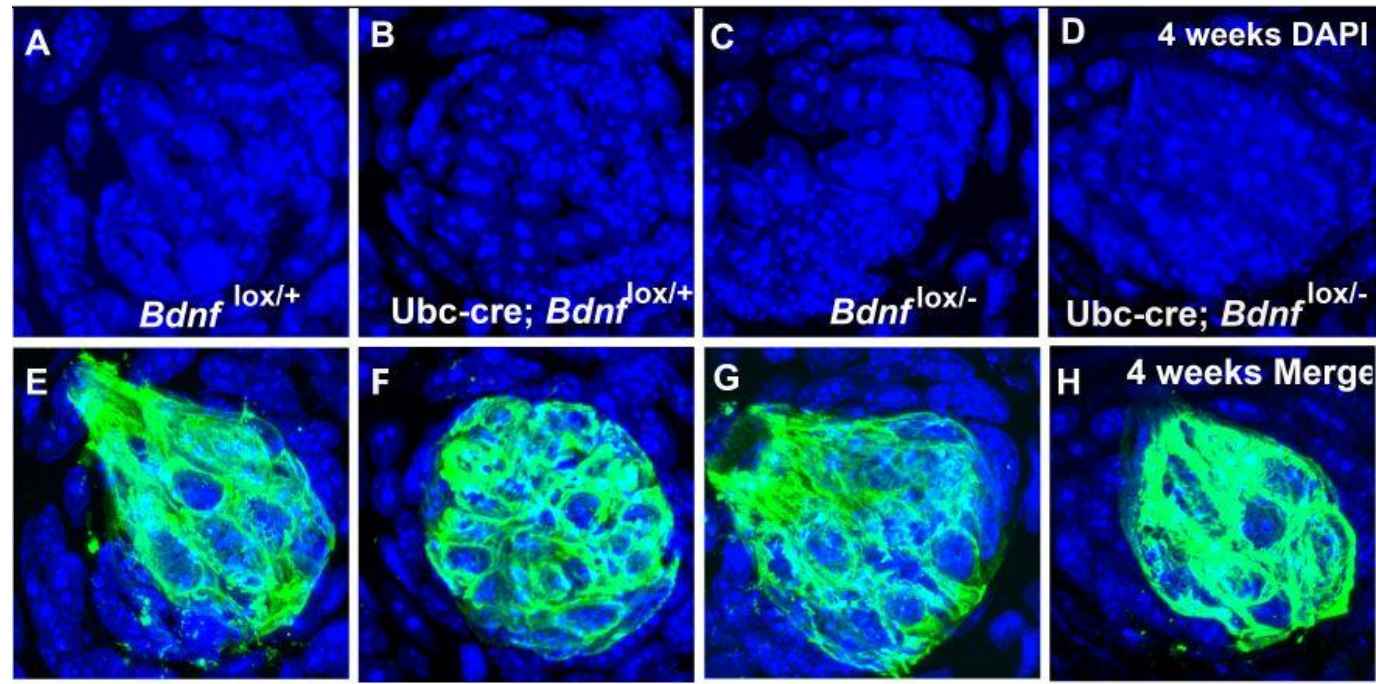

H 4 weeks Merge
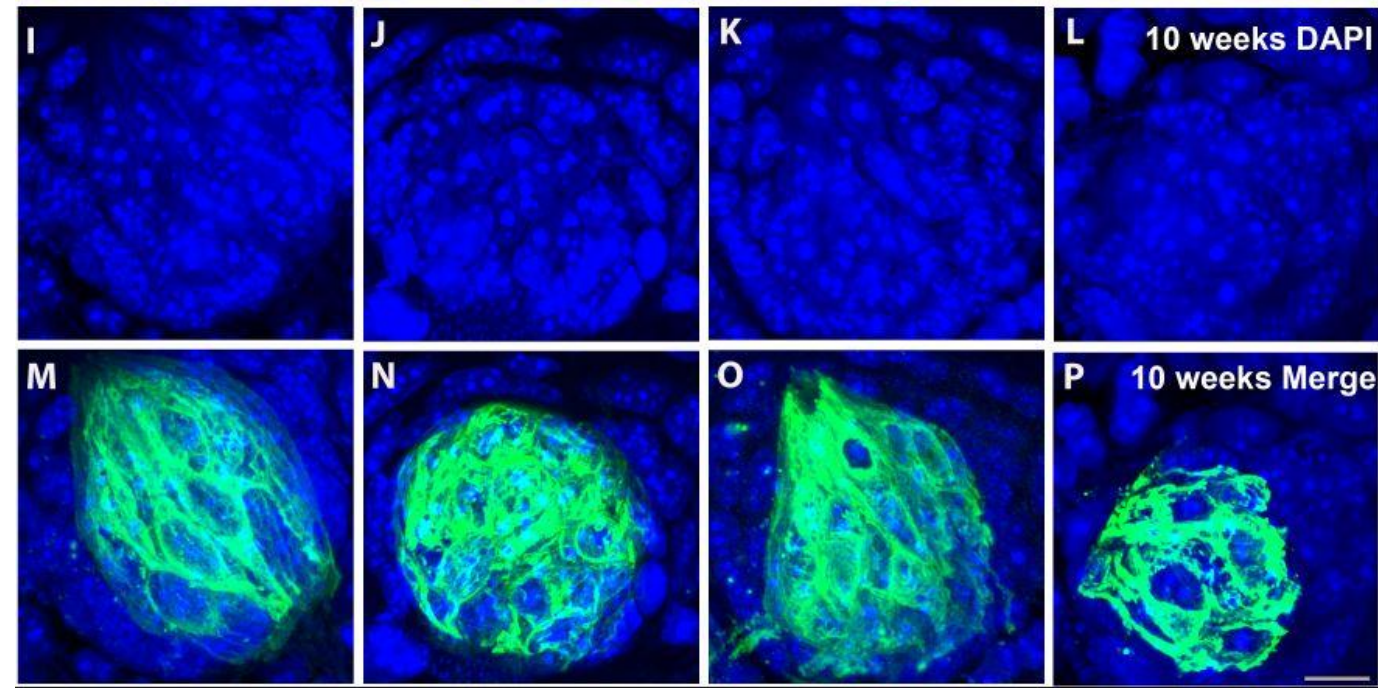
Figure 9. Taste buds appear smaller at ten weeks, but not four weeks following BDNF induced gene recombination. (A-H) Confocal images of taste buds (anti-troma 1, green) and taste cell (DAPI, blue) in $B d n f^{\text {lox/+ }}$ mice (A,E,I,M), Ubc-cre ${ }^{\mathrm{ER}} B d n f$ ${ }^{\text {lox/+ }}$ mice $(\mathrm{B}, \mathrm{F}, \mathrm{J}, \mathrm{N})$ and $B d n f^{\text {lox/- }}$ mice $(\mathrm{C}, \mathrm{G}, \mathrm{K}, \mathrm{O})$ and $\mathrm{Ubc}-\mathrm{cre}^{\mathrm{ER}} B d n f^{\text {lox/- }}$ mice $(\mathrm{D}, \mathrm{H}, \mathrm{L}, \mathrm{P})$ at four weeks and ten weeks after tamoxifen administration. Anticytokeratin 8, DAPI were merged to visualize nuclei within the taste bud in $B d n f^{\text {lox/+ }}$ mice (E), Ubc-cre ${ }^{\mathrm{ER}} B d n f^{\mathrm{lox} /+}$ mice $(\mathrm{F}), B d n f^{\mathrm{lox} /-}$ mice $(\mathrm{G})$ and $\mathrm{Ubc}-\mathrm{cre}^{\mathrm{ER}} B d n f^{\mathrm{lox} /-}$ mice (H) at four weeks after tamoxifen administration and in $B d n f^{\text {lox } /+}$ mice $(\mathrm{M})$, Ubccre $^{\mathrm{ER}} B d n f^{\text {lox/+ }}$ mice $(\mathrm{N}), B d n f^{\text {lox/- }}$ mice $(\mathrm{O})$ and Ubc-cre ${ }^{\mathrm{ER}} B d n f^{\text {lox/- }}$ mice $(\mathrm{P})$ at ten weeks after tamoxifen administration. There was no obvious difference in taste bud size and/or cell number between these 4 genotypes at four weeks after tamoxifen administration. At ten weeks after tamoxifen administration, Ubc-cre ${ }^{\mathrm{ER}} B d n f^{\text {lox/- }}$ mice (P) had smaller taste buds and fewer taste cells/bud compared to $B d n f^{\text {lox/+ }}$ mice (M), Ubc-cre ${ }^{\mathrm{ER}} B d n f^{\text {lox/+ }}$ mice $(\mathrm{N}), B d n f^{\text {lox/- }}$ mice $(\mathrm{O})$. There was no difference in taste bud size and taste cell number among the 3 control genotypes $\left(B d n f^{\text {lox/+ }}\right.$ mice, Ubc$\mathrm{cre}^{\mathrm{ER}} B d n f^{\mathrm{lox} /+}$ mice and $B d n f^{\text {lox/- }}$ mice .Scar bar $=10 \mu \mathrm{m}$ and applies to all figures. 
Figure 10
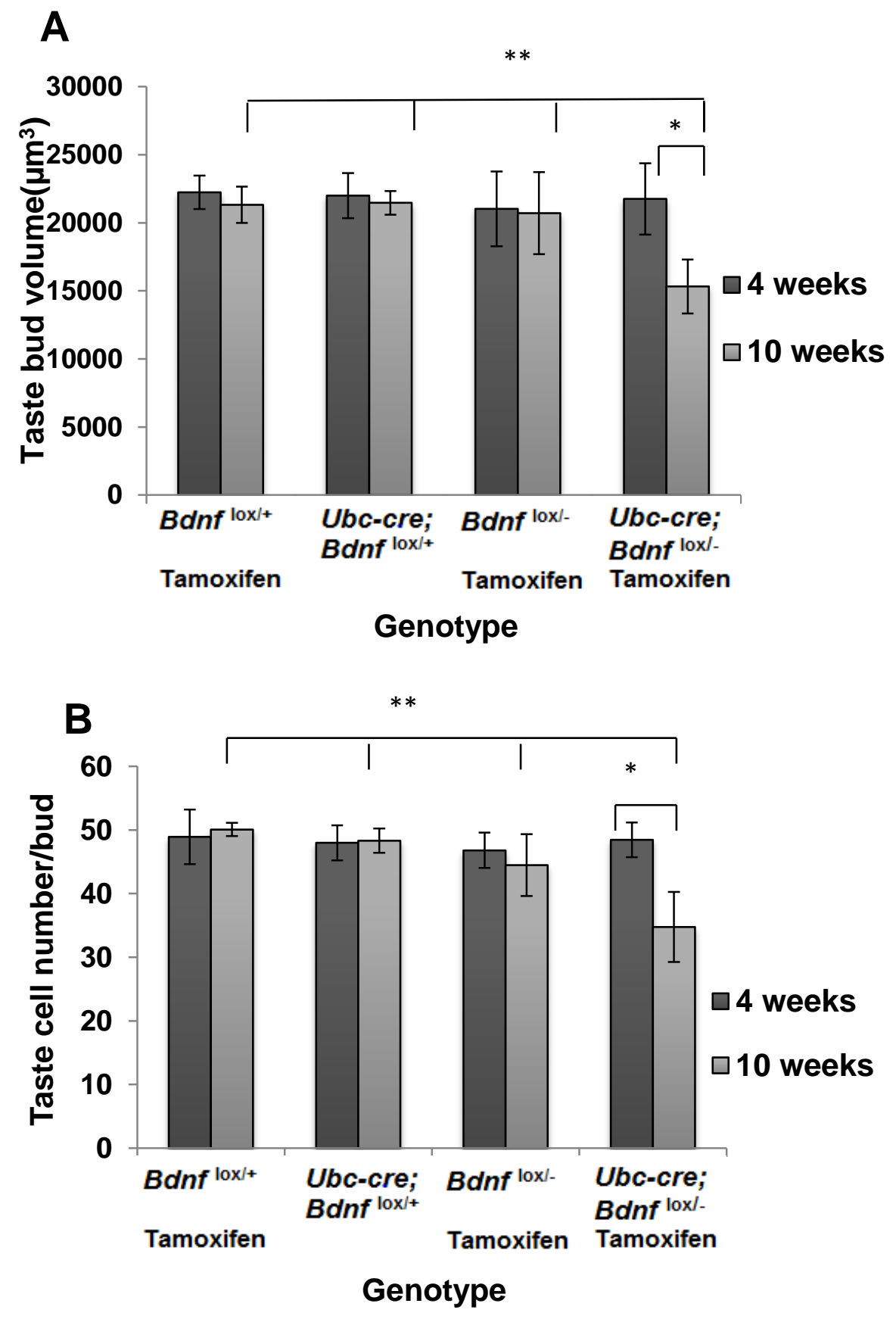
Figure 10. There were no differences in taste bud size and cell number at four weeks after tamoxifen administration, while ten weeks after tamoxifen administration, taste bud size and cell number was reduced by Bdnf gene deletion. Four weeks after tamoxifen administration, there were no differences in taste bud size among $B d n f^{\text {lox } /+}$ mice $(\mathrm{n}=3), \mathrm{Ubc}_{-} \mathrm{cre}^{\mathrm{ER}} B d n f^{\mathrm{lox} /+}$ mice $(\mathrm{n}=3), B d n f^{\mathrm{lox} /-}$ mice $(\mathrm{n}=3)$ and Ubc-cre ${ }^{\mathrm{ER}} B d n f$ lox/- mice $(\mathrm{n}=3)$. However, ten weeks after tamoxifen administration, taste bud size was reduced by approximately $30 \%$ in Ubc-cre ${ }^{\mathrm{ER}} B d n f^{\text {lox/- }}$ mice $(\mathrm{n}=4)$, compared to $B d n f^{\text {lox/+ }}$ mice $(\mathrm{n}=4)$, Ubc-cre ${ }^{\mathrm{ER}} B d n f^{\mathrm{lox} /+}$ mice $(\mathrm{n}=4)$, and $B d n f^{\text {lox/- }}$ mice $(\mathrm{n}=4)$. There was no difference in the three control genotypes (A). The data for number of taste cells per bud mimicked the data for taste bud volume (B), indicating that taste buds are smaller because they lose taste cells. There was no difference in the three control genotypes (A, B). *p<0.05, ** $\mathrm{p}<0.01$. 
Figure 11
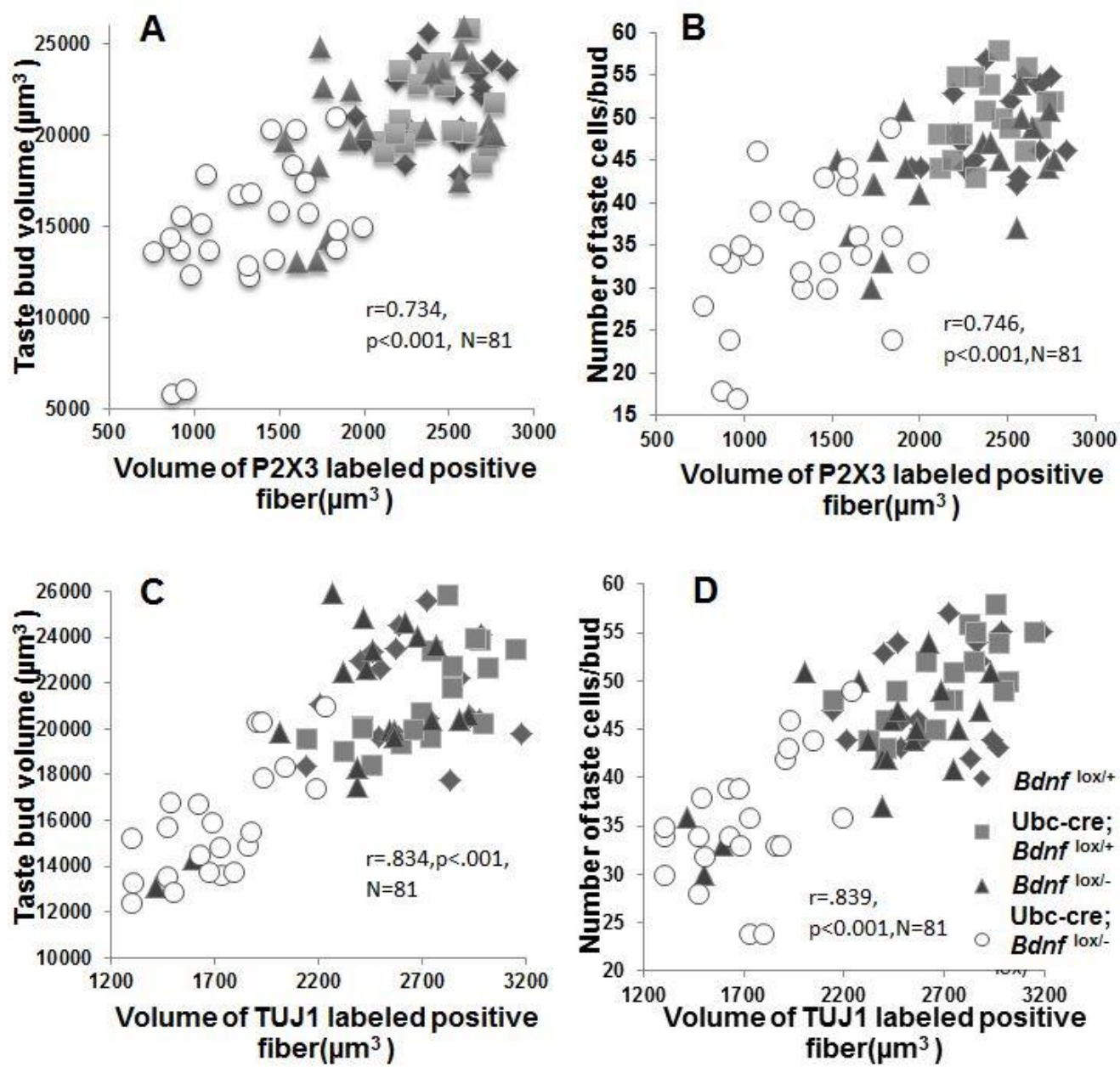
Figure 11. At ten weeks after tamoxifen administration, reductions in innervation predict loss of taste bud size and cell number across individual taste buds. Taste bud volume and cell number were plotted against the volume of $\mathrm{P} 2 \mathrm{X} 3$ positive fibers for individual taste buds from $B d n f^{\mathrm{lox} /+}$ mice $(\mathrm{n}=4), \mathrm{Ubc}-\mathrm{cre}^{\mathrm{ER}} B d n f^{\mathrm{lox} /+}$ mice $(\mathrm{n}=4), B d n f$ ${ }_{\text {lox/- }}$ mice $(n=4)$ and Ubc-cre ${ }^{\mathrm{ER}} B d n f^{\text {lox/- }}$ mice $(\mathrm{n}=4)(\mathrm{A}, \mathrm{B})$. Taste bud volume and taste cell number are plotted against the volume of TUJ1 positive fibers for individual taste buds from $B d n f^{\text {lox/+ }}$ mice $(\mathrm{n}=4), \operatorname{Ubc}-\mathrm{cre}^{\mathrm{ER}} B d n f^{\text {lox/+ }}$ mice $(\mathrm{n}=4), B d n f^{\text {lox/- }}$ mice $(\mathrm{n}=4)$ and Ubc-cre ${ }^{\mathrm{ER}} B d n f^{\text {lox/- }}$ mice $(\mathrm{n}=4)(\mathrm{C}, \mathrm{D})$. In general, smaller taste buds contain fewer taste cells, and have reduced innervation. 
Figure 12

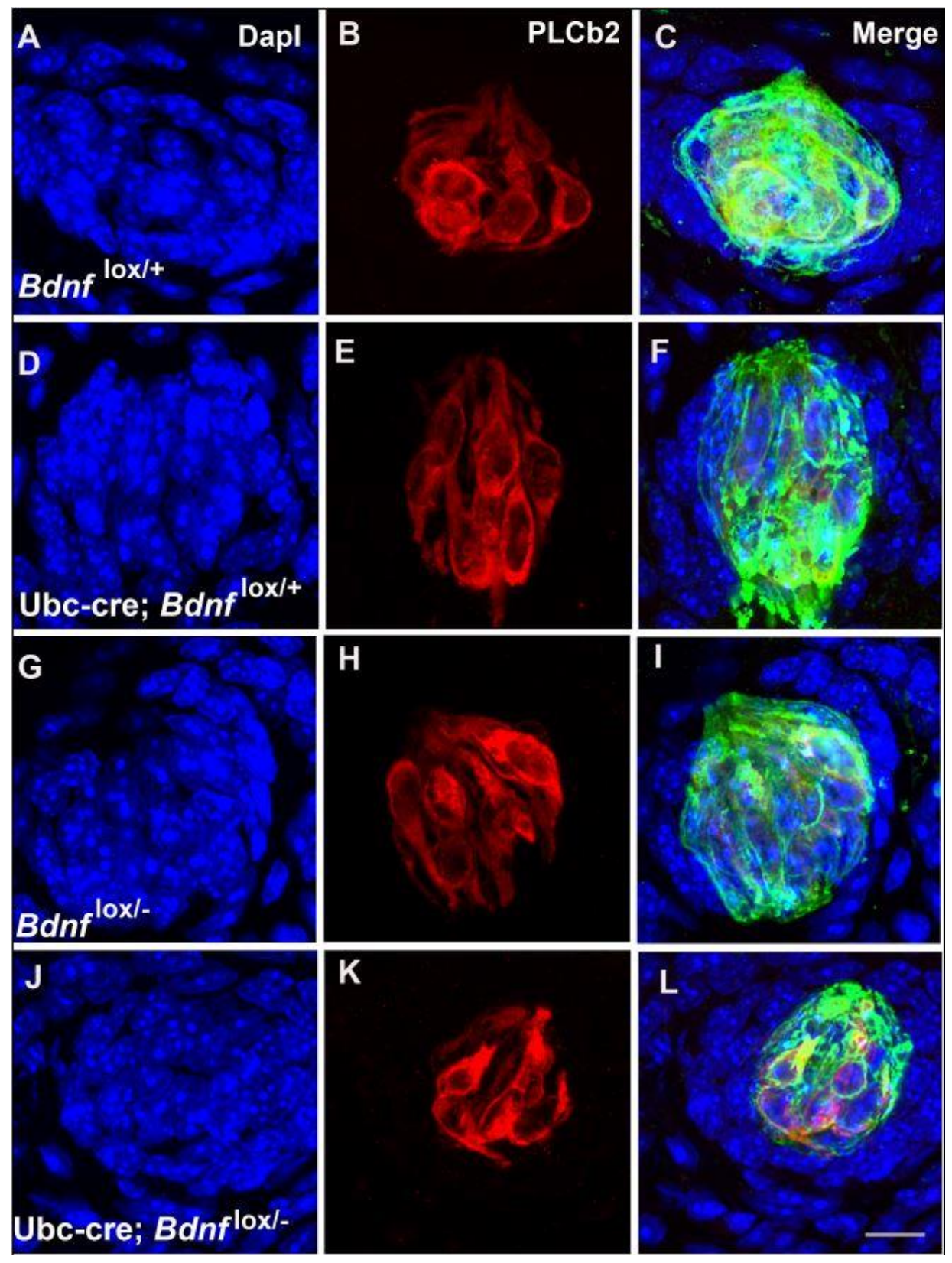


Figure 12. PLC $\beta 2$ cell number was not affected by $B d n f$ gene deletion. A-K: Confocal images of taste buds labeled with anti-cytokeratin 8 (green), DAPI (blue) and PLC $\beta 2$ (red) in $B d n f^{\text {lox/+ }}$ mice (A-C), Ubc-cre ${ }^{\mathrm{ER}} B d n f^{\text {lox/+ }}$ mice (D-F), $B d n f^{\text {lox/- }}$ mice (G-I) and Ubc-cre ${ }^{\mathrm{ER}} B d n f^{\text {lox/- }}$ mice $(\mathrm{J}-\mathrm{L})$ at ten weeks after tamoxifen administration. There was no obvious difference in the number of PLC $\beta 2$-postive cells between genotypes, $B d n f$ ${ }^{\text {lox } /+}$ mice (B), Ubc-cre ${ }^{\mathrm{ER}} B d n f^{\text {lox } /+}$ mice $(\mathrm{E}), B d n f^{\text {lox/- }}$ mice $(\mathrm{H})$ and Ubc-cre ${ }^{\mathrm{ER}} B d n f^{\text {lox } /-}$ mice (K). Scar bar=10 $\mu \mathrm{m}$ and applies to all. 
Figure 13

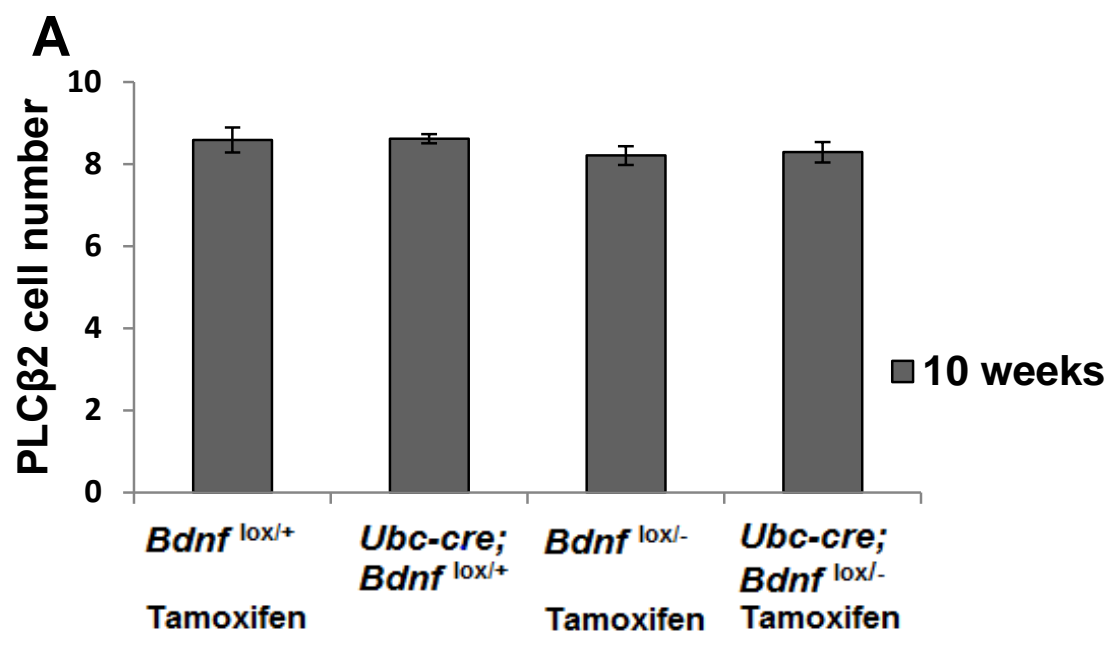

\section{Genotype}

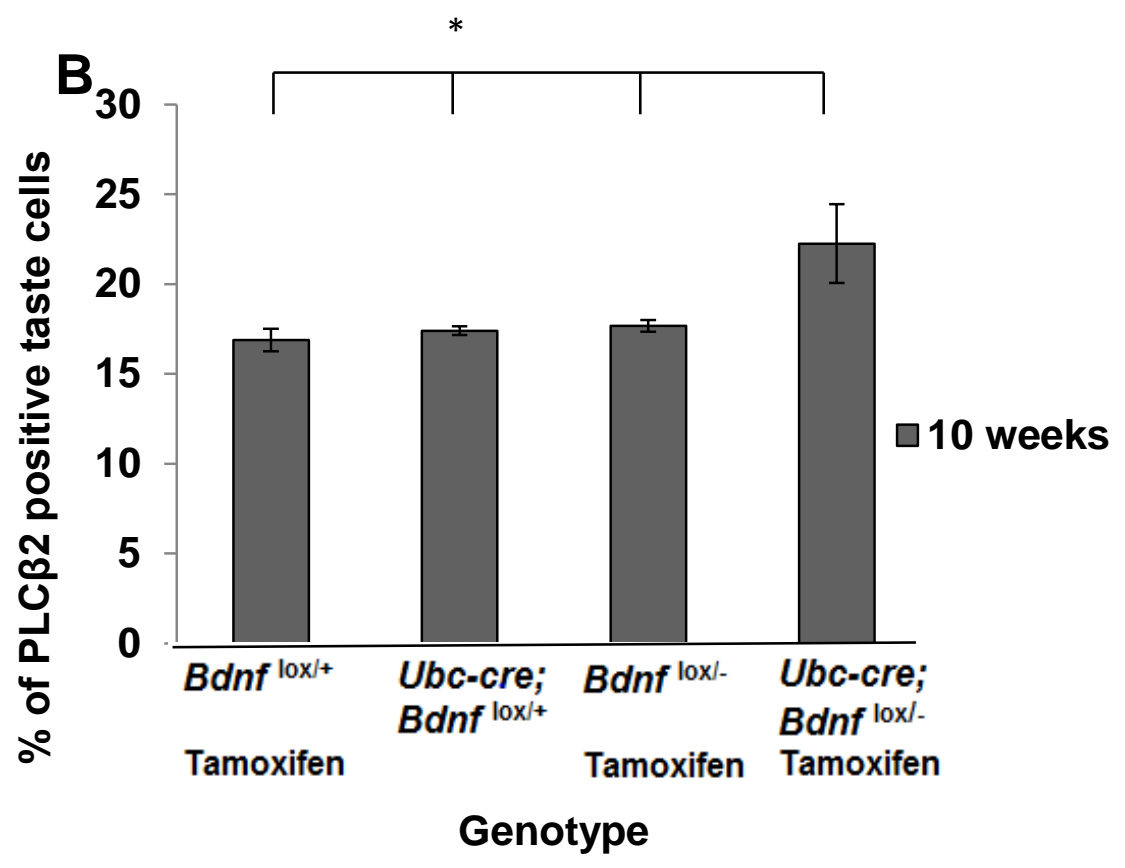


Figure 13. The number of PLC $\beta 2$-positive cells change following $B d n f$ gene deletion indicating that taste cell lost is not evenly distributed among taste cell subtypes. Ten weeks after tamoxifen administration, the number of PLC 32 -positive cells remained unchanged among $B d n f^{\text {lox } /+}$ mice $(\mathrm{n}=4), \mathrm{Ubc}-\mathrm{cre}^{\mathrm{ER}} B d n f^{\text {lox } /+}$ mice $(\mathrm{n}=4), B d n f^{\text {lox/- }}$ mice $(\mathrm{n}=4)$ and Ubc-cre ${ }^{\mathrm{ER}} B d n f^{\text {lox/- }}$ mice $(\mathrm{n}=4)(\mathrm{A})$. Therefore, the mean percentage of PLC $\beta 2$ cells within the taste bud increased in Ubc-cre ${ }^{\mathrm{ER}} B d n f^{\text {lox/- }}$ mice $(\mathrm{n}=4)$ compared to $B d n f^{\text {lox } /+}$ mice $(\mathrm{n}=4), \mathrm{Ubc}-\mathrm{cre}^{\mathrm{ER}} B d n f^{\text {lox/+ }}$ mice $(\mathrm{n}=4), B d n f^{\text {lox/- }}$ mice $(\mathrm{n}=4)$ at ten weeks after tamoxifen administration (B). This finding indicated that PLC $\beta 2$ cells were unaffected by $B d n f$ gene deletion and that another taste cell type must be reduced instead. ${ }^{*} \mathrm{p}<0.05,{ }^{* *} \mathrm{p}<0.01$. 


\section{CHAPTER III}

\section{BDNF IS REQUIRED FOR TASTE NERVE REGENERATION}

\section{AFTER INJURY}

\subsection{Introduction}

The peripheral taste system is extremely plastic in adulthood; taste cells turn over and are constantly reinnervated by nerve fibers (Beidler and Smallman, 1965). Thus, reinnervation does not just occur following nerve injury, but instead is part of normal biology of the taste system. This may be why after nerve injury, regeneration of the taste system is robust (Guth, 1958; Oakley et al., 1993). In addition, to constantly reinnervating taste buds, neurons support the taste bud. Specifically, after taste nerve sectioning, taste buds are lost following a loss of innervation, and taste buds return with innervation (Yee et al., 2005; Guagliardo and Hill, 2007). Therefore, the taste system is a plastic system highly dependent on innervation, with the capacity to regenerate.

Although regeneration has been studied extensively in the taste system (Guth, 1957; Cheal and Oakley, 1977; Cain et al., 1996), none of the factors required for regeneration have been identified. One possibility is that factors that are required for initial nerve innervation of taste buds, like neurotrophins, are also involved in regeneration. This idea is supported by findings demonstrating that nerve injury is frequently accompanied by increasing levels of neurotrophin expression (Popper et al., 1999; Hirsch et al., 2000). In addition, exogenous application of neurotrophins can

enhance regeneration in many systems (Bradbury et al., 1999; Ramer et al., 2000). 
Only a few studies have examined whether neurotrophins are required for peripheral nerve regeneration and the results are conflicting. Specifically, there is evidence that BDNF is required for motor nerve regeneration (Wilhelm et al., 2012), but NGF is not required for sensory nerve regeneration (Diamond et al., 1992b). It is unclear whether differences in these systems (sensory vs motor) or the neurotrophins (BDNF vs NGF), lead to differences the role of these factors in nerve regeneration.

In gustatory system, we speculated that BDNF might regulate taste nerve regeneration for the following reasons. First, BDNF is required for innervation of the taste bud during development (Nosrat et al., 1997; Ma et al., 2009); it regulates geniculate ganglion neuron survival, and targeting of gustatory axons to the correct location (Krimm et al., 2001; Ma et al., 2009; Hoshino et al., 2010; Patel and Krimm, 2010). Second, BDNF continues to be expressed in the adult taste system (Yee et al., 2003; Nosrat et al., 2012), where it appears to regulate innervation to new taste cells as they form in adulthood (Chapter 1). Third, while only a few studies have examined whether neurotrophins are required for regeneration (Diamond et al., 1992; Wilhelm et al., 2012), numerous studies have demonstrated that the addition exogenous neurotrophins can enhance regeneration in systems where nerve regeneration tends to be poor (Bradbury et al., 1999; Ramer et al., 2000). In fact, the continued presence of BDNF in adulthood of this extremely plastic system might be one reason why reinnervation in the taste system is so robust.

The goal in this study was to determine if BDNF is required for regeneration in the gustatory system following chorda tympani nerve section. To answer this question, I sectioned the chorda tympani nerve in inducible BDNF mutants to observe nerve fiber loss two-weeks after nerve section and regeneration of the chorda tympani nerve two months after nerve section. The results show that degeneration occurred at 
the same rate following nerve section regardless of whether BDNF is present. However, chorda tympani nerve regeneration was either slowed or prevented following Bdnf gene deletion, indicating the BDNF is important for peripheral gustatory axon regeneration

3.2 Materials and Methods

\subsubsection{Animals}

For Real time RT-PCR, C57Bl/6J mice were purchased from Jackson laboratories (Bar Harbor, ME). The surgical groups received unilateral chorda tympani nerve transaction at 2 months of age. The geniculate ganglia and the anterior tongues were dissected 2 days $(n=6), 2$ weeks $(n=6), 1$ month $(n=6)$ and 2 months $(n=6)$ following unilateral chorda tympani nerve section (CTX). Control animals were age matched to the surgical animals.

In order to remove $B d n f$ in conjunction with chorda tympani nerve section, Ubc-cre ${ }^{\mathrm{ER}} B d n f^{\text {dox/lox }}$ mice were generated by crossing $B d n f^{\text {dox/lox }}$ mice (JAX, \#004339) with Ubc-cre ${ }^{\mathrm{ER}}$ mice $(\mathrm{JAX}, \# 007001) . B d n f^{\text {lox/lox }}$ mice possess loxP sites on either side of exon 5 of Bdnf gene (JAX, \#004339 description) and Ubc-cre ${ }^{\mathrm{ER}}$ mice expresses the $\mathrm{Cre}^{\mathrm{ER}}$ from the human ubiquitin $\mathrm{C}$ promotor. Since ubiquitin is found in almost all tissues of eukaryotic organisms, $\mathrm{Cre}^{\mathrm{ER}}$ is also expressed in all tissues under ubiquitin promoter. $\mathrm{Cr}^{\mathrm{ER}}$ is a fusion protein composed of Cre recombinase and a mutant form of the estrogen receptor ligand-binding domain that is selectively activated only in the presence of tamoxifen (TAM) (Feil et al., 1997). Upon introduction of tamoxifen, the Cre recombinase is able to penetrate the nucleus and remove $B d n f$ in Ubc-cre ${ }^{\mathrm{ER}} B d n f$ lox/lox mice. 
In order to increase the probability that $B d n f$ would be successfully removed, Ubc-cre ${ }^{\mathrm{ER}} B d n f^{\mathrm{lox} /-}$ mice were generated by crossing Ubc-cre ${ }^{\mathrm{ER}} B d n f^{\text {dox/lox }}$ with heterozygous Bdnf knockout mice $B d n f^{+/-}(\mathrm{JAX}, \# 002266)$. The end result is an experimental animal which lacks a functional $B d n f$ gene on one allele and in which $B d n f$ can be removed inducibly from the other allele. Three controls were analyzed for three different purposes of comparison. $B d n f^{\text {dox/+ }}$ mice (with tamoxifen) were used to exclude potential effects of tamoxifen administration. Ubc-cre ${ }^{\mathrm{ER}} B d n f^{\text {lox/ } /}$ mice (without tamoxifen) when compared to Ubc-cre ${ }^{\mathrm{ER}} B d n f^{\text {lox/- }}$ mice. $B d n f^{\text {lox/- }}$ mice (with tamoxifen) controlled for any effects in heterozygous Bdnf knockouts.

\subsubsection{Tamoxifen administration}

Tamoxifen was administered (Sigma, T5648; mixed in peanut oil; $188 \mathrm{ng} / \mathrm{g}$ body weight, once per day for 5 days) by oral gavage (Ruzankina et al., 2007) which maximized recombination and decreased the loss of animals through toxicity (Ruzankina et al., 2007).

\subsubsection{Chorda tympani nerve transection}

The mice were anesthetized with an intramuscular injection of dexmedetomadine hydrochloride $(0.4 \mathrm{mg} / \mathrm{kg}$ body weight $)$ followed by ketamine hydrochloride (40mg/kg body weight)(Guagliardo and Hill, 2007). The mice were placed in a non-traumatic head holder to provide access to the nerve in the neck via a ventral approach. The chorda tympani nerve was located as it bifurcates from the lingual branch of the trigeminal nerve and was cut without damaging the trigeminal nerve. The wound was sutured, and the mice were allowed to recover on a watercirculating heating pad before being returned to their home cage. Atipamezole 
hydrochloride $(2 \mathrm{mg} / \mathrm{kg}$ body weight) was injected intramuscularly to the mice immediately after surgery to help wake them up.

\subsubsection{Lingual epithelium isolation for Real Time RT-PCR}

Mice were euthanized with Avertin (4mg/kg body weight), and the tongue and geniculate ganglion were collected for Real Time RT-PCR. The tongue was cut gently anterior to circumvallate papillae, removed and rinsed in a $0.1 \mathrm{M}$ phosphatebuffered saline (PBS) solution $(\mathrm{PH}=7.4)$ and then was cut in half evenly under microscope. To isolate the lingual epithelium, half tongues were incubated in sterile dispase I-solution (BD Biosciences) for 50 minutes. After incubation, the epithelial sheets were peeled from the underlying lamina propria. The lingual epithelium from each animal was transferred into a $1.5 \mathrm{ml}$ tube containing RNA later (Ambion, Austin, TX). All samples were stored at $80^{\circ} \mathrm{C}$ until RNA extraction.

3.2.5 Taste bud and ganglion neuron isolation using LCM (laser capture micro dissection)

Geniculate ganglia were quickly dissected under a microscope, and transferred into OCT and frozen immediately on dry ice. All samples are stored at $80^{\circ} \mathrm{C}$ until RNA extraction. Geniculate ganglia and tongues were cut into $10 \mu \mathrm{m}$ thick sections on a cryostat and directly mounted onto glass slides. The sections were then fixed in a solution of $75 \%$ ethyl alcohol (ETOH) for $30 \mathrm{sec}$ and then rinsed in nuclease-free water. The slides dehydrated in alcohol 75\%, 95\%, and 100\% ETOH for 30 sec each, followed by xylene for $5 \mathrm{~min}$. After the slides were removed from xylene and the remaining xylene had evaporated, they were placed onto a laser capture microscope (Arcturus). Geniculate ganglia and taste buds were identified and captured onto CapSure Macro LCM Caps (Molecular Devices, Sunnyvale, CA). For each animal, all 
sections containing the geniculate ganglion and all taste buds in lingual epithelium were collected and captured for RNA isolation. The captured samples were then collected into tubes containing total RNA isolation reagent (Qiagen, Chatsworth, CA) for later RNA isolation.

\subsubsection{RNA Extraction and Real Time RT- PCR}

To determine how $B d n f$ mRNA responds to nerve section, $B d n f$ mRNA level in tongue epithelium and geniculate ganglion were measured using Real Time RTPCR. Total RNA from each geniculate ganglion, and the epithelia was extracted using RNeasy micro kit or RNeasy mini kit (Qiagen). DNase I treatment was applied to eliminate traces of DNA during the procedure. After the extraction, RNA was analyzed with RNA 6000 Pico/Nano Chip kits in Bioanalyzer 2100 (Agilent Technologies, Santa Clara, CA) and RNA Integrity Number (RIN) and 28S/18S ratio were used to estimate the RNA quality. Only RNA samples with RNA integrity number (RIN) more than 8.0 were used in this study. Reverse transcription was performed using 200 U Superscript III Reverse Transcriptase (Invitrogen, Carlsbad, CA) and 50ng random hexamers (Invitrogen) in $25 \mathrm{ml}$ reaction volume containing first strand buffer (Invitrogen), $0.5 \mathrm{mM}$ dNTPs, and $40 \mathrm{U}$ of RNase inhibitor. All samples produced sufficient amounts of RNA for Real Time PCR. To control for differences in the amount of RNA isolated from different groups, the same amount of RNA from each sample was used for the geniculate ganglion (3ng) and for the lingual epithelium (50ng). After incubation for $50 \mathrm{~min}$ at $50^{\circ} \mathrm{C}$, the reaction was stopped by heating $\left(5 \mathrm{~min}\right.$ at $\left.85^{\circ} \mathrm{C}\right)$.

Real Time RT-PCR was performed with the ABI PRISM/7900HT sequence detection system (Applied Biosystems, Foster City, CA), using Taq-Man Universal 
PCR kit (Applied Biosystems), and oligonucleotide primer/probe sets, which were designed from the sequences in the GenBank database using Beacon Designer software (Premier Biosoft International, Atlanta GA). When it was possible, the primers were chosen to span an intron to avoid the detection of any contamination of genomic DNA. TaqMan probes were labeled at the 50-end with a fluorescent reporter dye (FAM) and at the 30-end with a quencher dye (TAMRA). The Real Time RTPCR reaction (Table 1) were conducted using $10 \mathrm{ml}$ total volume with Master Mix, 720/200 Nm primer/probe sets (TaqMan PCR kit) and the same amount of target cDNA across different time periods. For normalization of cDNA loading, all samples were run in parallel with the housekeeping gene, $18 \mathrm{~S}$ ribosomal RNA, and mouse glyceraldehyde 3 phosphate dehydrogenase (GAPDH). Each assay was carried out in triplicate. Amplification of cDNA was performed for 40 cycles of $95^{\circ} \mathrm{C}$ for $15 \mathrm{sec}$ and $60^{\circ} \mathrm{C}$ for $1 \mathrm{~min}$.

For Real Time RT-PCR, the comparative 2-DDCT method was used to determine target gene expression levels (Livak and Schmittgen, 2001). The normalized expression of the target gene was calculated as normalized expression (Etarget) DCT target (control - sample)/ (Eref) DCT ref (control - sample), where Etarget is reaction efficiency of the gene of interest; Eref, reaction efficiency of the reference gene; and DCT, the cycle difference between the control and the sample.

\subsubsection{Tissue preparation for Immunohistochemistry}

Mice were scarified by Avertin overdose $(4 \mathrm{mg} / \mathrm{kg}$ body/weight) and perfused through the heart using 4\% paraformaldehyde (PFA). The anterior two-thirds of the tongue was separated from the circumvallate papillae, rinsed with $0.1 \mathrm{M}$ phosphatebuffered saline (PBS) solution $(\mathrm{PH}=7.4)$ and then cut in half evenly under microscope. The geniculate ganglia were dissected under a microscope (Leica MZFLIII). Both the 
anterior tongue and geniculate ganglia were fixed in 4\% paraformaldehyde for 2 hours, rinsed with $\mathrm{PBS}$, and then transferred to $30 \%$ sucrose at $4^{\circ} \mathrm{C}$ overnight. These tissues were frozen the next day in $\mathrm{OCT}$ and stored at $-80^{\circ} \mathrm{C}$ until sectioned on a cryostat. Serial sagittal sections of tongue (20um) and geniculate ganglion (50um) were mounted on glass slides for quantification.

\subsection{8 $\beta$-Galactosidase histochemistry}

Mice were perfused and then post-fixed in immersion-fixed in ice cold $0.5 \%$ glutaraldehyde in $\mathrm{PBS} / \mathrm{MgCl} 2$ solution (2 $\mathrm{mM} \mathrm{MgCl}_{2}$ in $\mathrm{PBS}$ ) for $1-2 \mathrm{~h}$ in $4{ }^{\circ} \mathrm{C}$. Fixative was removed by multiple washes in ice cold $\mathrm{PBS} / \mathrm{MgCl}_{2}$ and frozen on dry ice in OCT embedding medium and stores in $-80^{\circ} \mathrm{C}$. Tissue sections $(40 \mu \mathrm{m})$ were mounted on SuperFrost/Plus slides and allowed to air-dry for $1 \mathrm{~h}$ at $4{ }^{\circ} \mathrm{C}$. $\beta$ Galactosidase histochemistry was performed on sectioned tissue. Tissue sections (40 $\mu \mathrm{m})$ were washed in ice cold $\mathrm{PBS} / \mathrm{MgCl}_{2}$ to thoroughly remove OCT and then immersed in X-gal staining solution (InvivoGen, San Diego, CA; 0.02\% Igepal, 0.01\% sodium deoxycholate, $5 \mathrm{mM}$ potassium ferrocyanide, $5 \mathrm{mM}$ potassium ferricyanide, and $1 \mathrm{mg} / \mathrm{ml} \mathrm{X}$-gal in $\mathrm{PBS} / \mathrm{MgCl}_{2}$ ) for $2-6 \mathrm{~h}$ in a $37^{\circ} \mathrm{C}$ incubator. Slides were washed in PBS and were allowed to dry on a $37^{\circ} \mathrm{C}$ heater overnight. Sections were mounted in Glycergel mounting medium (Dako North America, Carpinteria, CA, USA) and imaged using a bright field camera.

\subsubsection{Immunohistochemistry}

To visualize taste buds and innervation, slides containing tongue sections were first dried on a slide warmer $\left(37^{\circ} \mathrm{C}\right)$ overnight. The next day they were rehydrated, placed into Citric Acid buffer (10mM Citric Acid, 0.05\% Tween 20, $\mathrm{PH}=6.0$ ), heated to $98-100^{\circ} \mathrm{C}$ for approximately 15 minutes in boiling bath, and allowed to cool for 20 minutes at room temperature for antigen retrieval. Slides were washed in PBS 
$(\mathrm{pH}=7.4)$ and incubated overnight at room temperature in anti-cytokerain- 8 antibody in PBS (Table 2). Following the incubation with the anti-cytokeratin-8 antibody the slides were rinsed in PBS and incubated for 1.5 hours with Alexa 488 anti-rat secondary antibody (1:500; Invitrogen). After washing in PBS, the slides were incubated for 2 hours in blocking solution (5\% NGS 2\% Triton X-100 made in $1 \mathrm{X}$ PBS) followed by rabbit anti-P2X3 (1:500; Table 2), mouse anti-TUJ1 (1:500;Table 2 in blocking solution in room temperature overnight. Following the overnight incubation, the slides were rinsed in PBS ( 4 X 5 minutes), and the tissue was incubated for 1.5 hours at room temperature in Alexa 555 anti-rabbit secondary antibody (1:500; Invitrogen), and Alexa 647 anti-mouse secondary antibody (1:500; Invitrogen) in blocking solution. The slides were then rinsed in PBS (3 X 5 minutes) and stained with DAPI (4, 6-diamidino-2-phenylindole, dihydrochloride, 2ul/50ml ddH2O, Life technologies, Foster City, CA) for 15 minutes. After a rinse in PBS (3 X 5 mins), the slides were mounted with Fluoromount-G (SouthernBiotech, Birmingham, AL).

\subsubsection{Taste bud counts}

Taste buds are defined by cytokeratin 8 florescent staining and span the entire height of the lingual epithelium form the surface to the basement membrane with Troma-1 staining. Taste buds were counted in 20-um serial sections of the immunofluorescent sagittal section of tongue using enabled Leica DMLB microscope. Taste buds were tracked through individual serial sections, so that each taste bud was only counted once.

\subsubsection{Stereology}

Stereological methods were used to count the total number of geniculate ganglion neurons. Fixed ganglia were serial sectioned $(50 \mu \mathrm{m})$, mounted on slides, and 
stained with cresyl violet for 15 mins. To maintain section thickness, sections were not dehydrated and were mounted in Dako glycergel mounting medium for stereological quantification (Dako North America, Carpinteria, CA). Using Stereo Investigator software (MBF Bioscience), an experimenter blind to the genotype of the animals traced a contour around the geniculate ganglion (20X). Every section containing the ganglion was traced, and a total of at least 4 sections were quantified. Within each traced contour of the geniculate ganglion, the computer randomly determined the placement of the counting frames. The depth of the counting frame was equal to minimal thickness of the section, minus a total guard zone of $10 \mu \mathrm{m}(5 \mu \mathrm{m}$ from the top and bottom of the section). Geniculate ganglion neurons were counted (100X mag) in each counting frame $\left(15 \mu \mathrm{m}^{2}\right)$. Neurons were counted only when they first came into focus (cell top) so that each cell was counted only once. Based on these measurements, the total cell number in the ganglion was estimated for the entire volume of the ganglion using the optical fractionator probe (MBF Bioscience).

\subsubsection{Analysis of Individual Taste Buds}

To minimize variability, the analysis of individual taste buds was limited to the dorsal tongue tip (Figure $1 \mathrm{~A}$ ). Immunofluorescent image stacks each consisting of multiple optical image planes (step size $1 \mu \mathrm{m}$ ) were obtained with an Olympus Fluoview FV1000Laser scanning confocal microscope (LSI3-FV1000-Inverted). During both image capture and analysis the experimenter was blind to the genotype of animals. For each triple-labeled immunohistochemical image, the four channels were collected separately, with single wavelength excitation and then merged to produce the composite image. Serial optical sections were captured every $1 \mu \mathrm{m}$ in labeled whole taste buds under $60 \mathrm{X}$ lens at $3.5 \mathrm{zoom}$. A single taste bud from an intact tongue 
was typically found in 2-3 physical sections (i.e. 36-60um); all 2-3 sections containing the taste bud were captured so that the entire taste bud could be quantified.

3.2.13 Analysis of individual taste buds.

Each physiological section contains $15-20$ optical images. Each $1 \mu \mathrm{m}$ optical image was traced and the area measured using Neurolucida imaging software (MicroBrightField). Total area was summed and multiplied by the total number of optical images in all physical sections to yield taste bud volume.

The volume of anti-P2X3 and anti-Tuj1 immunostaining with in the taste bud was measured using MBF ImageJ software (ImageJ 1.47) (Jensen, 2013). ImageJ software set an unbiased threshold automatically, and the number of labeled pixels inside the taste buds was measured for each optical section. The perimeter of the taste bud was defined by cytokeratin 8 label. Pixels were converted to volume and summed to obtain the total volume occupied by nerve fibers with in one taste bud.

Taste cell number was quantified by counting DAPI stained nuclei within the keratin 8 defined taste buds. DAPI labeled nuclei were followed through the optical sections, such that each nucleus was only counted once. Because each taste bud was in more than one physical section, the number of cells was summed physical sections. A few cells may have been counted twice due to split nuclei across physical sections.

\subsubsection{Statistics}

All the measurements within the same group of mice were determined to have equal variance (using Levene's test for homogeneity of variance, $P>0.05$ ). When comparing Bdnf mRNA level in RT-PCR Real Time, one-way ANOVA was applied to analyze the difference between genotypes. For taste bud volumes, nerve 
innervation, taste cell number, taste bud number and ganglion cell numbers, two-way ANOVA's were used for analysis. After overall significance was determined, a Tukey post-hoc test was used to identify which groups within the analysis were significant. The mean value representing each group derived from 4-5 mice and mean value of each mouse was derived from 5-6 taste buds/mouse. For all the above measurements, 5 mice were analyzed in Ubc-cre ${ }^{\mathrm{ER}} B d n f^{\text {lox/- }}$ group, while 4 mice in $B d n f^{\text {lox/+ }}$ mice, Ubc-cre ${ }^{\mathrm{ER}} B d n f^{\text {lox/t}}$ mice, and $B d n f^{\text {lox/+ }}$ mice. The significance level was set at $\mathrm{p}<0.05$ for all statistical comparisons.

\subsection{Results:}

3.3.1 Bdnf expression did not change following nerve section in the geniculate ganglia or lingual epithelium.

Neurotrophins may participate in promoting nerve regeneration to support their innervated area after nerve section. In the gustatory system, following section of the chorda tympani nerve, the number of taste buds and the size of remaining taste buds is decreased (Guagliardo and Hill, 2007). Since BDNF is primarily expressed by taste buds (Yee et al., 2003), BDNF could be reduced along with taste bud loss following nerve section. If BDNF is no longer present in the taste buds or the geniculate ganglion after nerve section, it seems unlikely that it would important for regeneration of the chorda tympani nerve following sectioning. To determine if this was the case, $B d n f$ expression was examined using Real Time RT-PCR in geniculate ganglion at 2 days, 14 days, 30 days and 60 days after unilateral chorda tympani nerve section. I found that $B d n f$ expression did not change in geniculate ganglion after unilateral chorda tympani nerve (Figure 14A). Neurofilament expression was the same across all groups, indicating that relatively equal number of neurons were 
isolated from each geniculate ganglion $(\mathrm{p}>0.05)$. I examined other neurotrophins involved in taste system development and found that $N t 3$ expression did not change 14 days after nerve section in geniculate ganglion (The relative mRNA level for intact ganglion $=1 \pm 0.14$; from cut side $=0.94 \pm 0.08)$ and $N t 4$ was expressed at undetectable levels in adult geniculate ganglion. $\operatorname{Trk} B$ (receptor for $B d n f$ ) expression was unchanged 14 days after nerve section $(\mathrm{p}>0.05)$. These results indicated that expression of neither the neurotrophins $(B d n f, N t 3$, and $N t 4)$ nor their primary receptor, $\operatorname{Trk} B$, in geniculate ganglion was influenced by chorda tympani nerve section.

Following chorda tympani nerve section, taste buds are lost (Guagliardo and Hill, 2007). Since $B d n f$ is primarily expressed by taste buds in lingual epithelium (Yee et al., 2003), I expected $B d n f$ level might be significantly reduced. However, $B d n f$ continued to be expressed at roughly the same level in the lingual epithelium on the section side at 2 days, 14 days, 30 days and 60 days after unilateral chorda tympani nerve section (Figure 14B). These data indicated that there is $B d n f$ remaining in tongue epithelium, which could support nerve regeneration. Consistent with a loss of taste buds, I found that the expression of a taste bud specific protein - cytokertatin-8 decreased at 14 days $(\mathrm{p}<0.01)$ and 30 days $(\mathrm{p}<0.01)$ following nerve section (Figure 14C). There are two possible explanations for why keratin-8 is decreased in the lingual epithelium while $B d n f$ did not: 1) Expression of $B d n f$ in the remaining taste cells following chorda tympani section was increased. 2) Bdnf expression outside of taste buds in lingual epithelium could be high enough to compensate for loss of $B d n f$ expression loss due to taste bud degeneration.

To examine the first possibility, remaining individual taste buds were isolated using laser capture micro-dissection (LCM) at 14 days following nerve section and 
$B d n f$ expression was analyzed using Real Time RT-PCR. Bdnf and keratin 8 expression within the taste bud decreased on the sectioned side $(\mathrm{p}<0.01$; Figure 15A, B) compared to taste buds from non-surgical controls. The decrease in both Bdnf and Krt8 expression is likely due to the reduction in size of the remaining taste buds (Guagliardo and Hill, 2007). When Bdnf expression is plotted relative to Krt8 expression which takes into account the reduction in taste bud size, relative $B d n f$ expression is increased at 14 days after nerve section $(\mathrm{p}<0.05$; Figure $15 \mathrm{C})$. This finding suggests that remaining taste cells produce more $B d n f$, perhaps to compensate for the loss of BDNF producing taste cells.

To examine the possibility that $B d n f$ is expressed outside the taste bud, nontaste regions of the lingual epithelium were isolated using LCM and Bdnf mRNA was analyzed by Real Time RT-PCR. The lamina propria, and filiform papillae expressed $B d n f$ in wild type mice, and there is no change in the level of $B d n f$ expression in these regions 14 days after nerve section (Figure $16 \mathrm{E}, \mathrm{F}$ ). $\beta$ gal staining in $B d n f^{\mathrm{lacZ} /+}$ mice confirmed that $B d n f$ is expressed both in taste and non-taste tissue (Figure 16 A,B,C,D). I conclude that $B d n f$ expression remains the same in the lingual epithelium following chorda tympani nerve section because remaining taste cells increase their $B d n f$ expression and $B d n f$ expression outside of the taste bud contributes to total lingual $B d n f$ expression. Bdnf expression in the remaining geniculate ganglion neurons, taste cells, and lingual epithelium following chorda tympani nerve section may support nerve regeneration.

3.3.2 Bdnf gene deletion prevented or delayed recovery of taste bud number.

Since $B d n f$ continues to be expressed in the geniculate ganglion, the lingual epithelium, and remaining taste cells after chorda tympani nerve section, I 
hypothesized that BDNF supports nerve regeneration after injury. Taste buds are dependent on nerve innervation (Oakley et al., 1993; Guagliardo and Hill, 2007). Therefore, $68 \%$ taste buds are lost following nerve section and return when the nerve regrows to the target (Guagliardo and Hill, 2007). To address whether BDNF is necessary for regeneration after surgery, the $B d n f$ gene was deleted from adult mice (using the Cre-LoxP system) followed by chorda tympani nerve section. Efficiency of gene recombination was demonstrated by Real Time RT-PCR in aim 1.

Taste buds were quantified at two and eight weeks following nerve section. The number of taste buds between control genotypes injected with tamoxifen ( $B d n f$ ${ }^{\text {lox/- }}$ mice) and without tamoxifen (Ubc-cre ${ }^{\mathrm{ER}} B d n f{ }^{\text {lox/+ }}$ mice) were not different, ruling out an effect of tamoxifen on taste bud number (Figure 17). Compared to $B d n f^{\text {lox/+ }}$ mice and Ubc-cre ${ }^{\mathrm{ER}} B d n f^{\text {lox/+ }}$ mice, $B d n f^{\text {lox/- }}$ mice did not lose taste buds, ruling out effects of a heterozygous $B d n f$ mutation on taste bud number (Figure 17). Taste bud number decreased by almost half in all four genotypes two weeks after chorda tympani nerve section $(\mathrm{p}<0.01$; Figure 17$)$, indicating that $B d n f$ gene deletion did not influence taste bud loss following nerve section. Taste bud number did not return to normal for any genotype at eight weeks after nerve section $(p<0.01$; Figure 17), indicating that regeneration is not yet complete. Eight weeks post-surgery, taste bud number increased by $40 \%(\mathrm{p}<0.01)$ in control genotypes $\left(B d n f^{\text {lox/+ }}\right.$ mice, Ubc-cre ${ }^{\mathrm{ER}}$ $B d n f^{\text {lox/+ }}$ mice) and heterozygous $B d n f$ mutant mice (Bdnf ${ }^{\text {lox/- }}$ mice), when compared to two weeks post-surgery, demonstrating substantial recovery in mice without $B d n f$ gene deletion. Alternatively, mice with reduced levels of Bdnf (Ubc-cre ${ }^{\mathrm{ER}} B d n f^{\text {lox/- }}$ mice) did not show recovery of taste bud number, compared to two weeks postsurgery ( $\mathrm{p}>0.05$; Figure 17). In conclusion, Bdnf gene deletion does not influence 
taste bud loss soon after nerve section, but it delays or prevents recovery of taste bud number eight weeks after surgery.

\subsubsection{Bdnf gene deletion prevented or delayed taste bud re-innervation.}

Since taste buds did not recover eight weeks after chorda tympani nerve section in mice with reduced $B d n f$, and taste bud maintenance is highly dependent on nerve innervation, it is likely that reinnervation was also impaired. To determine if this was the case, I examined nerve fibers inside of Keratin 8-defined taste buds (green) using two markers, anti-P2X3 (red) and anti-TUJ1 (neuron specific beta III Tubulin) (blue). P2X3 is an ATP channel that is required for neural responses to taste stimuli (Finger et al., 2005; Murata et al., 2010) and primarily labels taste fibers (Finger et al., 2005; Ishida et al., 2009). Neuron specific beta III Tubulin is present in all nerve fibers. Two weeks after nerve section nearly all taste buds lack P2X3 positive fibers in all four genotypes, confirming earlier studies that $\mathrm{P} 2 \mathrm{X} 3$ primarily labels taste fibers (Ishida et al., 2009). There were a few TUJ1 positive fibers left inside of taste bud in all four genotypes, which may come from trigeminal nerve (Figure 18). There was no difference in innervation across genotypes at two weeks after surgery, indicating BDNF did not influence nerve fiber loss after chorda tympani nerve section. Eight weeks after nerve section, nerve regeneration did not return to normal levels in the control genotypes. Mice with reduced levels of Bdnf (Ubc-cre ${ }^{\mathrm{ER}}$ $B d n f^{\text {lox/- }}$ mice) appeared to have much less re-innervation of taste buds than the other three genotypes (Figure 19).

Since taste bud number is affected by chorda tympani nerve section, I quantified these results by calculating the percentage of remaining taste buds that contained innervation. No difference among the three control genotypes was observed, 
ruling out any effects of tamoxifen or a single $B d n f$ gene mutation on the percentage of remaining taste buds with $\mathrm{P} 2 \mathrm{X} 3$ positive innervation (Figure 20A). All taste buds in non-surgical control animals contained P2X3 positive fibers (Figure 20A), while two weeks after chorda tympani nerve section no taste buds contained $\mathrm{P} 2 \mathrm{X} 3$ positive innervation regardless of genotype or tamoxifen treatment $(p<0.01$; Figure $20 \mathrm{~A})$. Eight weeks after nerve section, mice in all four genotypes still had fewer taste buds containing P2X3 positive fibers $(\mathrm{p}<0.05$; Figure 20A), compared to non-surgical controls. This finding demonstrates that taste innervation did not completely recover even when $B d n f$ levels were normal. However, most taste buds (nearly $70 \%$ ) regained $\mathrm{P} 2 \mathrm{X} 3$ positive fibers in mice without $B d n f$ gene deletion $\left(B d n f^{\text {lox/+ }}\right.$ mice, Ubc-cre ${ }^{\mathrm{ER}}$ $B d n f^{\text {lox/+ }}$ mice $)$ and heterozygous $B d n f$ mutant mice $\left(B d n f^{\text {lox/- }}\right.$ mice $)(\mathrm{p}<0.01$; Figure 20A), while only $7.8 \%$ of the taste buds regained $\mathrm{P} 2 \mathrm{X} 3$ positive fibers in mice following Bdnf gene deletion (Ubc-cre ${ }^{\mathrm{ER}} B d n f^{\text {lox/- }}$ mice) ( $\mathrm{p}>0.05$; Figure 20A). Thus, the percentage of taste buds regaining $\mathrm{P} 2 \mathrm{X} 3$ positive fibers in Ubc-cre ${ }^{\mathrm{ER}} B d n f^{\text {lox/- }}$ mice was much lower than the three control mice $(p<0.001$; Figure 20A). These findings indicate that $B d n f$ gene deletion prevented or slowed chorda tympani nerve reinnervation.

I also analyzed the volume of $\mathrm{P} 2 \mathrm{X} 3$ positive fibers within individual taste buds to determine if the degree reinnervation in those taste buds that regained innervation was impacted by Bdnf removal. Eight weeks after nerve section, all four genotypes still had reduced $\mathrm{P} 2 \mathrm{X} 3$ innervation in the taste buds that were reinnervated, compared to non-surgical controls ( $<<0.01$; Figure $20 \mathrm{~B}$ ). Thus, taste innervation did not recover to normal levels. Also, those few taste buds that regained P2X3 innervation, following $B d n f$ gene deletion (Ubc-cre ${ }^{\mathrm{ER}} B d n f^{\text {lox/- }}$ mice) had fewer P2X3 fibers compared to mice without $B d n f$ gene deletion $\left(B d n f^{\text {lox/+ }}\right.$ mice, Ubc-cre ${ }^{\mathrm{ER}} B d n f^{\text {lox/+ }}$ mice) and 


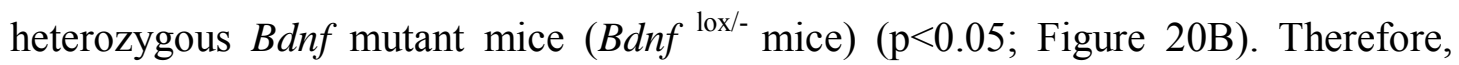
$B d n f$ gene deletion prevented those taste buds that regained innervation from acquiring their full complement of $\mathrm{P} 2 \mathrm{X} 3$ positive fibers.

In order to verify the findings with anti-P2X3 using an additional marker, I counted the number of taste buds containing anti-TUJ1 (neuron specific beta III Tubulin) positive fibers. All taste buds from non-surgical mice contained TUJ1 positive fibers regardless of genotype (Figure 21A). Two weeks after chorda tympani nerve section, nearly all TUJ1 positive fibers were gone, only $50 \%$ of the remaining taste buds had any remaining TUJ1 positive fibers. There were no differences in the percentage of taste buds containing TUJ1 positive innervation across genotype or tamoxifen treatment $(\mathrm{p}<0.05$; Figure $21 \mathrm{~A})$, indicating that $B d n f$ gene deletion did not influence nerve loss after nerve section. Eight weeks after nerve section, the percentage of remaining taste buds that contained TUJ1 positive fibers in all four genotypes was lower than non-surgical control mice $(\mathrm{p}<0.01$; Figure $21 \mathrm{~A})$, indicating nerve regeneration did not recover to normal levels. Eight weeks after nerve section, the percentage of remaining taste buds that contained TUJ1 positive fibers in mice following Bdnf gene deletion (Ubc-cre ${ }^{\mathrm{ER}} B d n f^{\text {lox/- }}$ mice) was lower than mice with in mice without Bdnf gene deletion levels of $B d n f$ expression $\left(B d n f^{\text {lox/+ }}\right.$ mice, Ubc-cre ${ }^{\mathrm{ER}}$ $B d n f^{\text {lox/+ }}$ mice, $)$ and heterozygous $B d n f$ mutant mice $\left(B d n f^{\text {lox/- }}\right.$ mice $)(\mathrm{p}<0.05$; Figure 21A). This finding indicates that $B d n f$ gene deletion delayed or prevented nerve regeneration by TUJ1 positive fibers.

I also analyzed the volume of TUJ1 positive fibers within each taste bud. Two weeks after chorda tympani nerve section, the volume of TUJ1 positive fibers was reduced by nearly $85 \%$ regardless of genotype or tamoxifen treatment $(p<0.01$; Figure 21B). This finding indicates that BDNF does not influence the degree of nerve loss 
after nerve section. Eight weeks after nerve section, all four genotypes still had a lower volume of TUJ1 positive fibers, compared to non-surgical controls $(\mathrm{p}<0.01$; Figure 21B). This finding means that taste innervation did not recover to normal levels by eight weeks after nerve section. For taste buds regaining TUJ1 innervation, the volume of TUJ1 fibers increased by eight weeks post-surgery in taste buds compared to mice without $B d n f$ gene deletion $\left(B d n f^{\text {lox/+ }}\right.$ mice, Ubc-cre ${ }^{\mathrm{ER}} B d n f^{\text {lox/+ }}$ mice $)(\mathrm{p}<0.01)$, and heterozygous $B d n f$ mutant mice $\left(B d n f^{\text {lox/- }}\right.$ mice $)(\mathrm{p}<0.01)$, but not in mice following $B d n f$ gene deletion (Ubc-cre ${ }^{\mathrm{ER}} B d n f^{\text {lox/- }}$ mice $)(\mathrm{p}>0.05$; Figure $21 \mathrm{~B})$. This finding means that $B d n f$ gene deletion in adult mice prevented or slowed the regeneration of the chorda tympani nerve.

In conclusion gustatory nerve degeneration occurs two weeks after chorda tympani nerve section and was unaffected by $B d n f$ expression level. By eight weeks after nerve section, reinnervation of most taste buds had occurred but regeneration is still incomplete even when $B d n f$ levels are normal. Following $B d n f$ gene deletion few taste buds were reinnervated, indicating that regeneration was either severely delayed or completely prevented.

3.3.4 Uninnervated taste buds failed to regain size and cell number.

Taste bud size is dependent on the gustatory innervation in adulthood (Guagliardo and Hill, 2007). Since I observed a lack of innervation inside of the taste buds that failed to be reinnervated, particularly following $B d n f$ gene deletion, I speculated that taste buds that were not reinnervated would also lack normal taste bud morphology. Taste buds were defined by staining with anti-cytokeratin 8 (Figure 22; anti-cytokeratin 8-green), which labels many of the taste cells particularly for fungiform taste buds and a nuclear label (DAPI). Two weeks after nerve section, taste buds appeared to be smaller in all four genotypes (Figure 22; anti-cytokeratin 8-green, 
DAP1-blue). Eight weeks after nerve section, most taste buds appeared to regain their normal size except for those in mice that underwent Bdnf gene deletion (Ubc-cre ${ }^{\mathrm{ER}}$ $B d n f^{\text {lox/- }}$ mice) (Figure 22; anti- cytokeratin 8-green, DAP1-blue).

To quantify taste bud size, I measured taste bud volume from confocal image stacks. No difference among the three control genotypes was observed, ruling out any effects of tamoxifen or a single Bdnf gene mutation on taste bud volume (Figure 23A). Two weeks after nerve section, taste bud volume decreased to one-half of nonsurgical controls in all four genotypes $(\mathrm{p}<0.01$; Figure $23 \mathrm{~A}$ ). These data indicate that all taste buds are reduced in size to the same degree regardless of BDNF level. By eight weeks after nerve section many taste buds are reinnervated, I defined those taste buds that regain $\mathrm{P} 2 \mathrm{X} 3$ innervation as innervated taste buds, while those taste buds still lacking P2X3 innervation as uninnervated taste buds. Eight weeks after nerve section, innervated taste buds recovered to a normal size in all four genotypes, while uninnervated taste buds remained smaller $(\mathrm{p}<0.05)$ (Figure 23A). Reinnervated taste buds in mice without $B d n f$ gene deletion ( $B d n f^{\text {lox/+ }}$ mice, Ubc-cre ${ }^{\mathrm{ER}} B d n f^{\text {lox/+ }}$ mice), and heterozygous $B d n f$ mutants ( $B d n f^{\text {lox/- }}$ mice) are larger than in mice where the $B d n f$ gene was deleted (Ubc-cre ${ }^{\mathrm{ER}} B d n f^{\text {lox/- }}$ mice) $(\mathrm{p}<0.05)$. Alternatively, uninnervated taste buds remain small regardless of genotype (Figure 23A). I conclude that $B d n f$ gene deletion in adult mice prevented the recovery of taste bud size even in the few reinnervated taste buds that were present in mice following $B d n f$ gene deletion (Ubccre $^{\mathrm{ER}} B d n f^{\text {lox/- }}$ mice).

In order to determine if the loss of taste bud volume was due to cell loss, I quantified taste cell number from confocal image stacks. The nuclear label (DAPI) was used to count the number of cells in the taste bud, so that cell number was not limited to cytokeratin 8 positive taste cells. No difference among the three control 
genotypes was observed in taste cell number, ruling out any effects of tamoxifen or a single Bdnf gene mutation (Figure 23B). Two weeks after nerve section, taste cell number decreased to one-half in all four genotypes regardless of genotype $(p<0.01$, Figure 23B). These data indicate that the loss of taste bud volume following nerve section was due to a loss of taste cells. Eight weeks after nerve section, the number of taste cells increased for innervated taste buds to pre-nerve cut levels in the three control genotypes (Bdnf ${ }^{\text {lox/+ }}$ mice, $\mathrm{p}<0.01$; Ubc-cre ${ }^{\mathrm{ER}} B d n f^{\text {lox } /+}$ mice, $\mathrm{p}<0.01 ; B d n f^{\text {lox/- }}$ mice, $p<0.01$ ), while the number of cells in uninnervated taste buds did not $(p<0.05$; Figure 23B). Alternatively, innervated taste buds do not regain taste cells and are not different from uninnervated taste buds in mice lacking $B d n f\left(\mathrm{Ubc}-\mathrm{cre}^{\mathrm{ER}} B d n f^{\text {lox/- }}\right.$ mice; Figure 23B). These data indicate that the $B d n f$ gene is necessary for the recovery of taste bud cell number following nerve section.

In conclusion taste bud size was reduced by half due to a loss of taste cells following chorda tympani nerve section and this reduction in taste bud size was unaffected by level of $B d n f$ expression. Because chorda tympani nerve regeneration was impaired by Bdnf gene deletion, taste bud volume and cell number did not recover.

3.3.5 Correlation between nerve innervation, taste bud size and cell number.

The amount of innervation a taste bud receives during early development predicts the size of the taste bud will become by adulthood (Krimm and Hill, 1998b, a, 2000). It is unclear whether this relationship can be reestablished in adulthood following manipulations of innervation. In fact this relationship appears to be easily disrupted by environmental manipulations like sodium derivation (Krimm and Hill, 1999) and nerve section (Shuler et al., 2004). To determine if taste buds regain a size commensurate with the returning innervation, I examined the relationship between 
taste bud size and innervation for individual taste buds. This relationship was not as obvious as normal mice without surgery (chapter 2), but regenerated taste buds with a larger size generally have regained more innervation than smaller taste buds $(\mathrm{r}=0.830$, $\mathrm{p}<0.001, \mathrm{~N}=66$, Figure 24A; $\mathrm{r}=0.686, \mathrm{p}<0.001, \mathrm{~N}=66$, Figure 24B). Therefore, the relationship between innervation and taste bud size may be reestablished in adulthood following nerve section.

3.3.6 Bdnf gene deletion did not increase geniculate ganglion neuron death after nerve section.

Since taste nerve regeneration was delayed or prevented by Bdnf gene deletion, I wanted to know whether the loss of innervation was caused by a loss of geniculate neurons. To determine if geniculate neuron number is affected by $B d n f$ gene deletion, geniculate neuron number was counted for all treatment groups. Compared to nonsurgical controls, geniculate neuron number did not decrease two weeks after nerve section groups for any genotype or treatment ( $\mathrm{p}>0.05$; Figure 25). Therefore, there was no loss of neurons two weeks after nerve section and no effect of $B d n f$ gene deletion. Eight weeks after nerve section, $22 \%$ of geniculate neurons were lost in the two genotypes with normal $B d n f$ levels $\left(B d n f^{\text {lox/+ }}\right.$ mice $U b c-c r e^{\mathrm{ER}} B d n f^{\text {lox/+ }}$ mice) when compared to non-surgical controls ( $\mathrm{p}<0.05$; Figure 25). However, mice lacking $B d n f$ (Ubc-cre ${ }^{\mathrm{ER}} B d n f^{\text {lox/- }}$ mice) did not lose additional neurons when compared to other three genotypes (Figure 25), indicating that $B d n f$ gene removal did not cause neuron loss after nerve section. Therefore, BDNF is import for adult axon growth or reinnervation of the taste bud and not neuron survival following chorda tympani nerve section. 


\subsection{Discussion}

Exogenous BDNF can promote peripheral nerve regeneration after nerve injury (Tom et al., 2013); however, whether it is necessary for regeneration in gustatory system is still unclear. I sectioned the chorda tympani unilaterally in inducible Bdnf knockout mice to reveal BDNF's role in regeneration. My results demonstrated that BDNF is required for taste buds to become reinnervated normally after chorda tympani nerve section.

Reinnervation did not completely recover by eight weeks after chorda tympani nerve section even when $B d n f$ levels were normal. It is unclear whether nerve innervation would recover completely given more time. In general full anatomically recovery appears to be slow. For example, functional responses in the chorda tympani nerve to salt and sweet stimuli have already returned to normal by 3-5 weeks following nerve surgery when only a few fibers are present in the taste bud (Yasumatsu et al., 2005; Yasumatsu et al., 2007). Remyelination also takes longer than functional recovery; specifically, there is a $67 \%$ loss in myelinated fibers in the regenerated chorda tympani nerve 16 weeks after nerve crush (Cain et al., 1996), yet the relative response magnitudes to taste stimuli ( sucrose) are close to normal in half that time (Cain et al., 1996). Therefore, functional recovery of the chorda tympani responses does not require complete anatomical recovery. I found that eight weeks after nerve surgery, half of the missing taste buds returned and more than half of the taste buds were innervated; therefore, it is likely that some functional recovery has also occurred by this time. Given that functional regeneration improves with time after surgery (Yasumatsu et al., 2007), it is likely that anatomy also continues to recover. Thus it is likely that extending recovery time would result some additional reinnervation of taste buds in mice still expressing normal levels of $B d n f$. 
Although additional anatomical recovery with time is likely in the normal mice, complete regeneration is unlikely no matter how long I wait after surgery. I found that $22 \%$ of the geniculate ganglion neurons were lost at eight weeks after nerve section, which is consistent with the $20 \%$ loss of geniculate ganglion neurons observed by others at 50 days after chorda tympani nerve section (Whitehead et al., 1995; Shuler et al., 2004). The geniculate ganglion consists of three subpopulations: neurons of chorda tympani nerve (innervating taste buds in the fungiform papillae and anterior foliate papillae); neurons of the greater superficial petrosal nerve (innervating taste buds in the incisive papilla and soft palate); and neurons of the posterior auricular nerve (innervating the skin of the external ear) (Mistretta and Hill, 1994; Krimm, 2007). Since I counted total number of geniculate neurons, it is likely that the neurons of chorda tympani nerve decreased far more than $20 \%$. Since the loss of neurons is probably permanent, it is likely that some reduction in innervation to the taste bud is also permanent.

Taste buds are supported by gustatory innervation in adulthood (Guth, 1957; Cheal and Oakley, 1977; Segerstad et al., 1989; Oakley et al., 1993). Two weeks after unilateral chorda tympani nerve section, I found that $50 \%$ of the taste buds remained. This finding is consistent with earlier studies finding that nearly half of the taste buds with pores remained following chorda tympani nerve section in mice (Yasumatsu et al., 2007). Why some taste buds are lost and others remain is unclear. Remaining taste buds may be supported by the trigeminal nerve (Ishida et al., 2009). Consistent with this idea, more taste buds are lost with the combined sectioning of the chorda tympani nerve and the lingual nerve compared to chorda tympani nerve section alone. Specifically, only one-third of the taste buds remained 15 days after chorda-lingual 
nerve section (Guagliardo and Hill, 2007). Therefore, in addition to chorda tympani nerve, the trigeminal nerve also supports a few taste buds.

I found that $B d n f$ gene deletion disrupted the chorda tympani nerve's ability to regenerate. It is unclear whether or not regeneration is completely prevented or delayed. Interestingly, a few taste buds were reinnervated in the absence of BDNF. Therefore, it is possible that more taste buds will regain innervation if I waited a longer time after nerve section. At eight weeks post-surgery there is a large difference in the number of taste buds reinnervated between mice lacking BDNF (7.8\%) and normal mice $(70 \%)$. Therefore, if reinnervation continues at the same rate, reinnervation would take a very long time. In addition, not all mice lacking BDNF had reinnervated taste buds. Half of knockout mice have no regeneration at all, while the other half had a few reinnervated taste buds. The difference between mice could be due to differences in the effectiveness of $B d n f$ gene recombination. For those mice in which some taste buds were reinnervated, some Bdnf expression could remain. Given the severity of the effect on regeneration and the fact inducible gene recombination in adulthood is never complete; I think it unlikely that regeneration would ever be regained to wild type levels in the mice lacking BDNF.

Much like initial axon guidance and growth during development, nerve regeneration is a complicated process which is likely coordinated by numerous factors at different stages. I found that BDNF is required for normal chorda tympani regeneration; however, it is unclear what aspect of regeneration is impacted by $B d n f$ removal. I found that when the chorda tympani nerve is sectioned, $B d n f$ deletion did not cause more geniculate ganglion neurons to die. Therefore, I did determine that geniculate neuron survival after nerve section does not depend on BDNF. This is consistent with findings from other systems that adult sensory neurons do not depend 
on neurotrophins (Grothe and Unsicker, 1987; Lindsay, 1988; Putcha et al., 2000). Therefore, the chorda tympani nerve did not fail to regenerate following $B d n f$ deletion because of neuron death. It is more likely that axon growth from proximal stump after nerve section is prevented or slowed. Since BDNF is important for nerve outgrowth during the development (Ringstedt et al., 1999), it is possible BDNF still surpports nerve outgrowth in adult mice. In the absence of BDNF, axons may not grow across cut site, leading to failure of regeneration (English et al., 2005). BDNF may also prevent nerve regeneration by disturbing axon targeting. During development, BDNF is required for gustatory axons to locate and innervate taste buds (Ma et al., 2009). In the adult, BDNF may function in the same way. In chapter 2, I already provided evidence that taste fibers need BDNF to continue to innervate new taste cells even when the nerve is not cut. In the absence of BDNF axons may grow some distance but fail to reach the taste bud.

In this study Cre recombinase was under the control Ubiquitin promoter which should reduce $B d n f$ expression in all tissues. Therefore, the source of BDNF required for chorda tympani regeneration is unclear. It could come from taste buds, geniculate neurons and/or Schwann cells (Zhang et al., 2000). I found that after nerve section, $B d n f$ expression remained in lingual epithelium and geniculate ganglion, which could supply the BDNF needed for nerve regeneration. In addition, remaining taste cells appear to produce more $B d n f$ two weeks after nerve section, indicating that taste cells may be an important source of BDNF for regeneration. Schwann cells may be another important source of BDNF to support nerve regeneration (Wilhelm et al., 2012). All these sources producing BDNF may contribute to nerve regeneration after injury. 
Figure 14

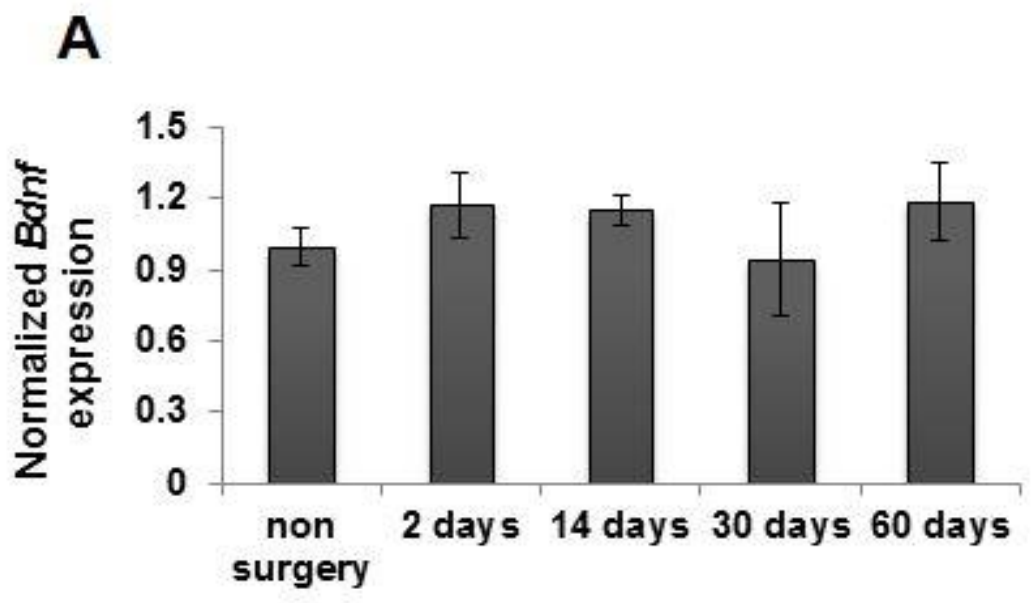

B

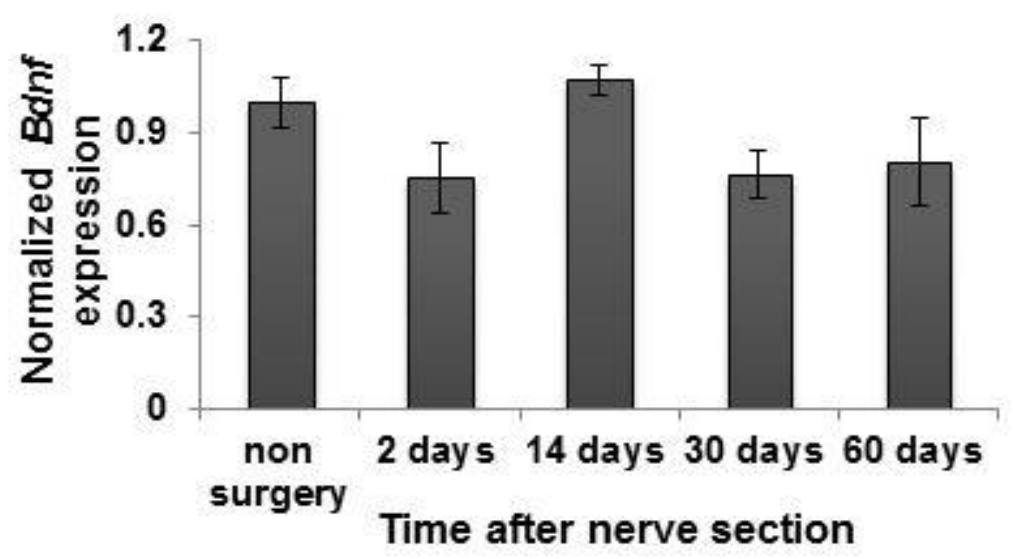

C

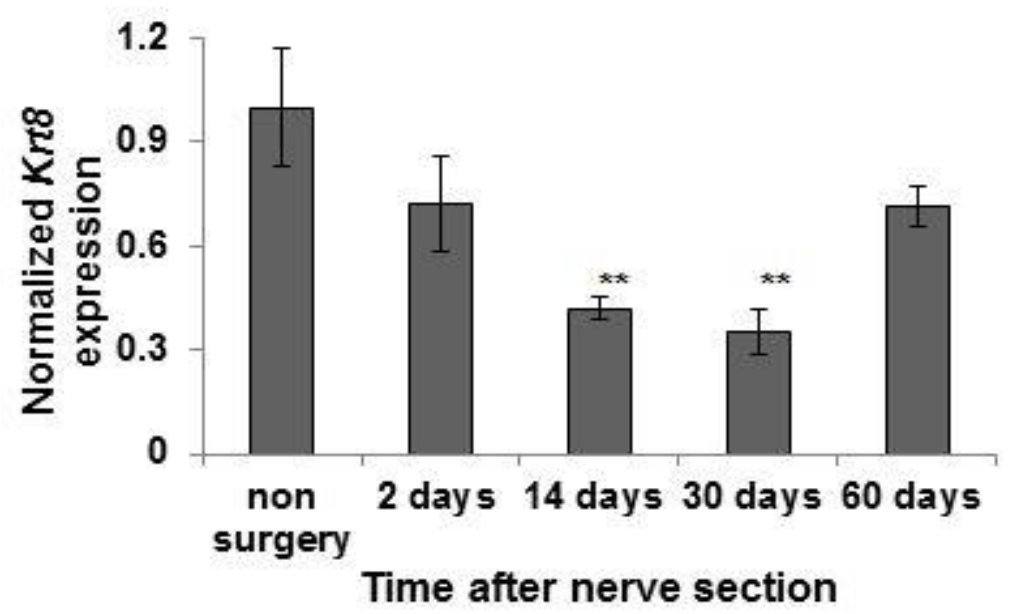


Figure 14. Bdnf continues to be expressed in the geniculate ganglion and lingual epithelium after chorda tympani nerve section, while expression of the taste bud marker $K r t 8$ is decreased. Bdnf expression (normalized to non-surgical controls) did not change at 2 days $(n=6), 14$ days $(n=6), 30$ days $(n=6)$ and 60 days $(n=6)$ after nerve section in the geniculate ganglia (A) and the lingual epithelium (B). Alternatively, normalized $k r t 8$ expression in epithelium decreased at 14 days $(n=6)$ and 30 days $(n=6)$ after nerve section $(\mathrm{C})$. This finding is consistent with a loss and recovery of taste buds following nerve section, with no loss of $B d n f$ expression. ${ }^{*} \mathrm{p}<0.05,{ }^{* *} \mathrm{p}<0.01$ 
Figure 15
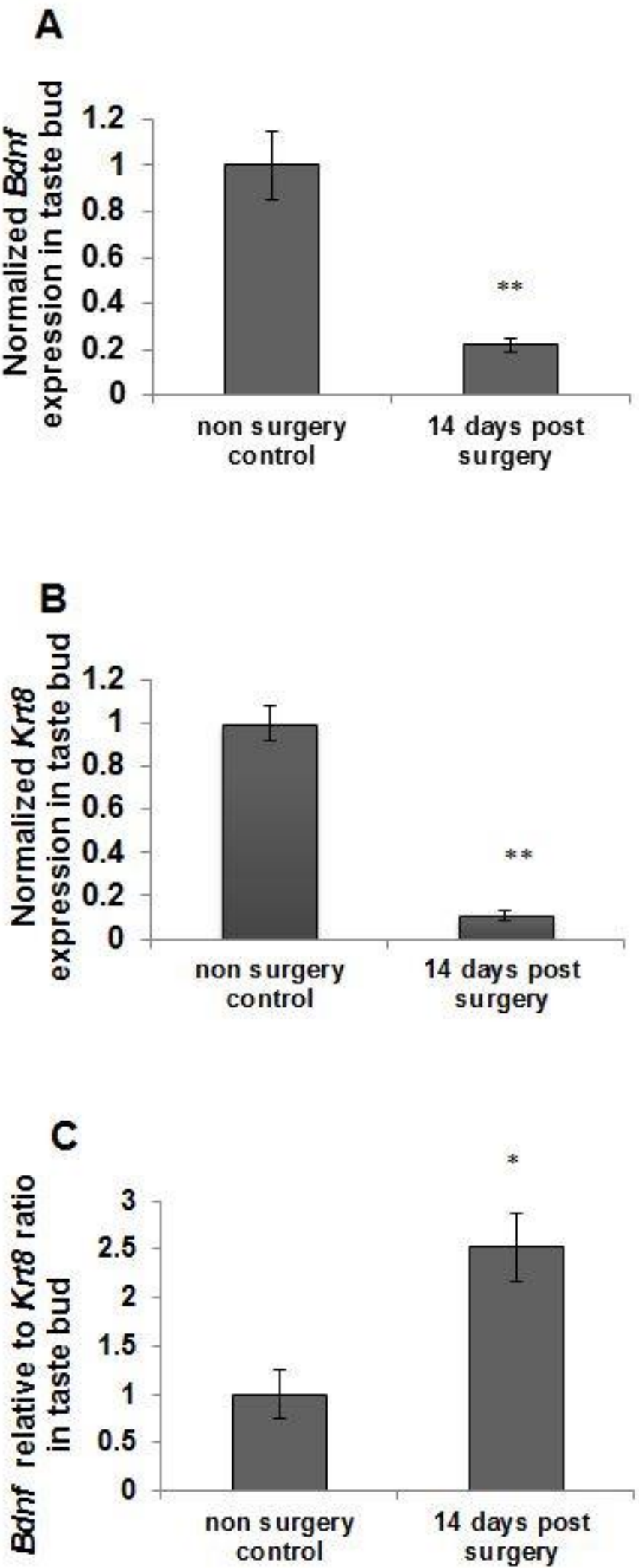
Figure 15. While both $B d n f$ and $K r t 8$ expression with in taste buds decreased at 14 days after nerve section, this decrease was greater for Krt8 than for $B d n f$. Bdnf expressed in taste buds decreased at 14 days after nerve section (n=3) (A). Krt8 (marker for taste bud) expression decreased at 14 days after nerve section $(n=3)(B)$. Reduction of both Krt8 and Bdnf expression are consistent with a loss of Krt8 expressing taste cells 14 days after nerve section. When $B d n f$ expression is plotted relative to $K r t 8$ in order to control for this loss of taste tissue, the amount of $B d n f$ expressed for a given amount of taste tissue is increased at 14 days after nerve section $(\mathrm{n}=3)(\mathrm{C})$. The relatively higher level of $B \operatorname{dnf}$ expression compared to $K r t 8$ following nerve section is consistent with either an increase in Bdnf expression per taste cell or a greater loss of taste cells that do not produce $B d n f .{ }^{*} \mathrm{p}<0.05^{* *} \mathrm{p}<0.01$ 
Figure 16

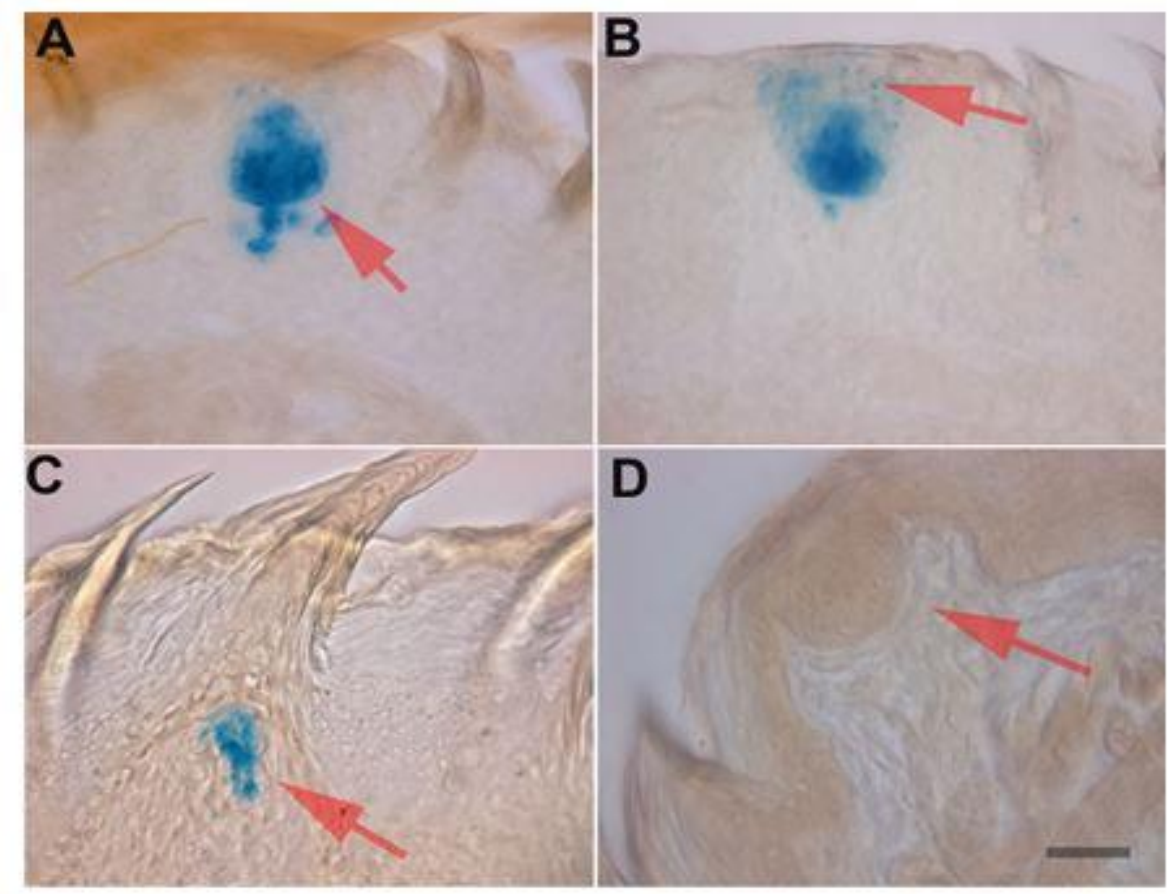

E
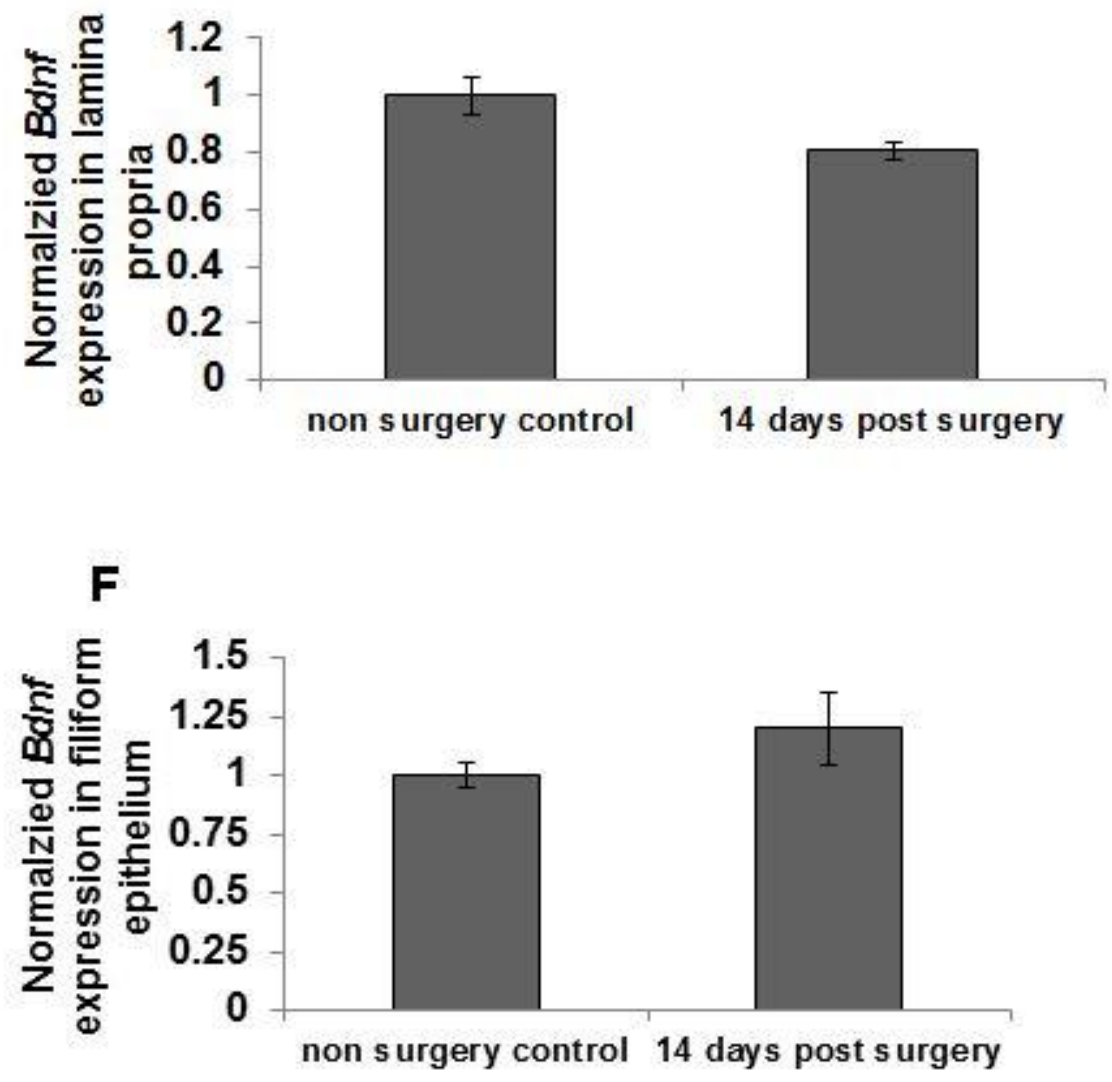
Figure 16. $B d n f$ expression occurs in both taste and non-taste cells in the tongue and $B d n f$ expression in non-taste cells is unaffected by nerve section. A section through a fungiform papilla $(40 \mu \mathrm{m})$ from a $B d n f^{\mathrm{Lacz} /+}$ mouse. Bgal reaction product can be seen in the taste bud and in the lamina propria ventral to the taste bud (arrow point to; $n=3$ ) (A). Another section through a fungiform papilla $(40 \mu \mathrm{m})$ from a $B d n f^{\mathrm{Lacz} /+}$ mouse shows Bgal staining in fungiform epithelium outside of the taste bud (arrow point to; $n=3$ ) (B). A section of the lingual epithelium $(50 \mu \mathrm{m})$ from a $B d n f^{\mathrm{Lacz} /+}$ mouse, shows ßgal reaction product in filiform epithelium (arrow point to; $n=3$ ) (C). Negative controls (wild type mice) consistently show no ßgal reaction product (arrow point to; $\mathrm{n}=3$ ) (D). The scale bar $=50 \mu \mathrm{m} . B d n f$ expression in lamina propria remained unchanged 14 days after nerve section (n=3) (E). Bdnf expression in filiform epithelium remained unchanged 14 days after nerve section $(n=3)(F)$. 
Figure 17

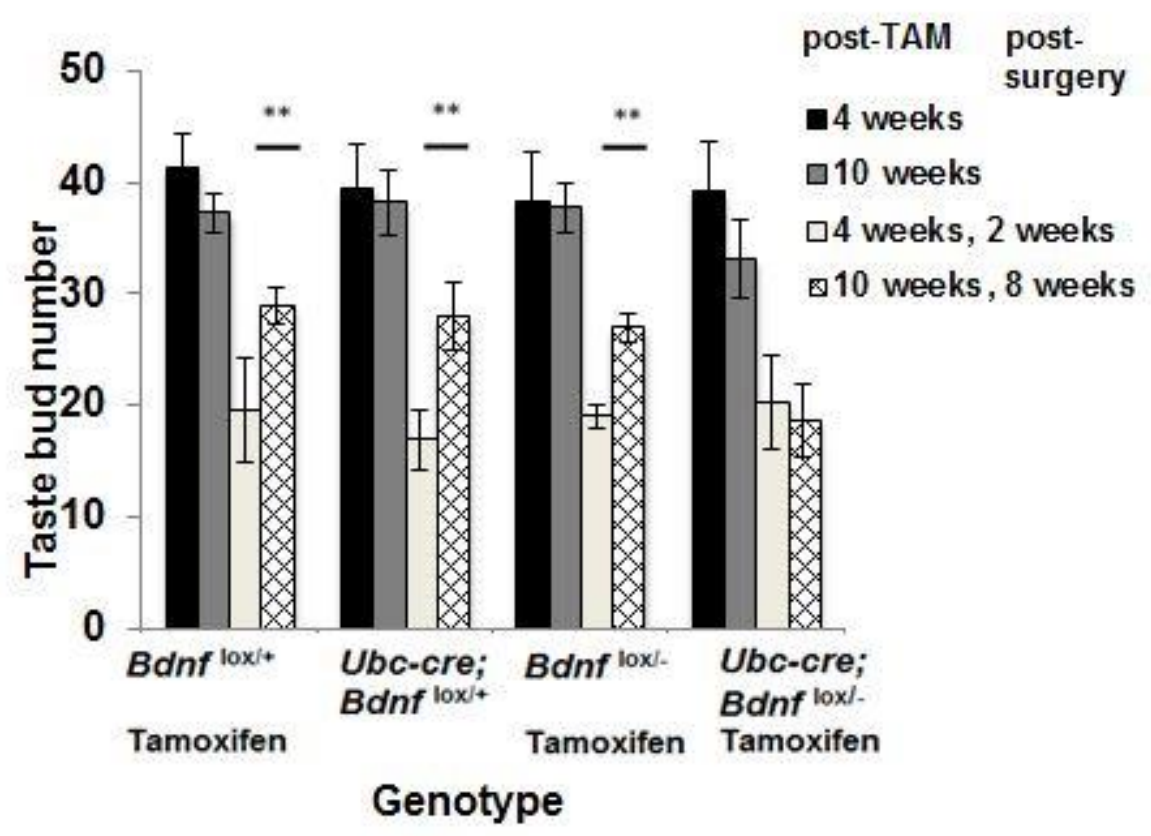


Figure 17 Bdnf removal had no influence on taste bud loss two weeks after chorda tympani nerve section, but it slowed or prevented recovery of taste bud number eight weeks after nerve section. Two weeks after nerve section, the number of taste buds decreased by half in all four genotypes: $B d n f^{\text {lox } /+}$ mice $(\mathrm{n}=3)$, Ubc-cre ${ }^{\mathrm{ER}} B d n f^{\text {lox } /+}$ mice $(\mathrm{n}=3), B d n f^{\text {lox/- }}$ mice $(\mathrm{n}=3)$, and Ubc-cre ${ }^{\mathrm{ER}} B d n f^{\text {lox/- }}$ mice $(\mathrm{n}=3)$ compared to nonsurgical control groups. At eight weeks after nerve section, taste buds returned in $B d n f$ ${ }^{\text {lox } /+}$ mice $(\mathrm{n}=3), \mathrm{Ubc}-\mathrm{cre}^{\mathrm{ER}} B d n f^{\text {lox/+ }}$ mice $(\mathrm{n}=3)$ and $B d n f^{\text {lox/- }}$ mice $(\mathrm{n}=4)$, but not in Ubc-cre ${ }^{\mathrm{ER}} B d n f^{\text {lox/- }}$ mice $(\mathrm{n}=4)$. There was no difference between the three control genotypes. These data demonstrate that normal Bdnf levels are required for taste bud recovery following nerve section. ${ }^{*} \mathrm{p}<0.05, * * \mathrm{p}<0.01$. 
Figure 18

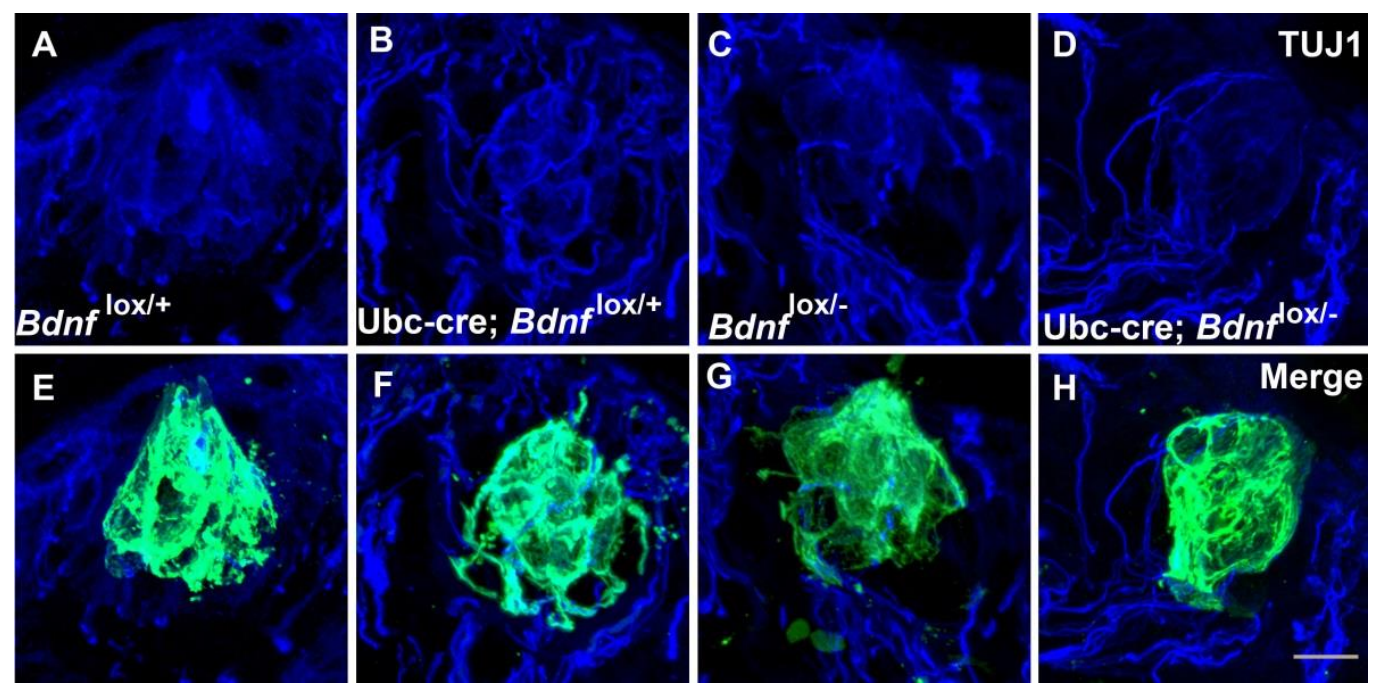


Figure 18. Remaining taste buds have lost most of their innervation two weeks after nerve chorda tympani section. Some TUJ1 (neuron specific beta III Tubulin) positivefibers but no P2X3-positive fibers were present in remaining taste buds following chorda tympani nerve section. A-P: Confocal images of taste buds and their innervation in $B d n f^{\text {lox } /+}$ mice $(\mathrm{A}, \mathrm{E}), \mathrm{Ubc}-\mathrm{cre}^{\mathrm{ER}} B d n f^{\mathrm{lox} /+}$ mice $(\mathrm{B}, \mathrm{F}), B d n f^{\mathrm{lox} /-}$ mice $(\mathrm{C}$, G) and $\mathrm{Ubc}-\mathrm{cre}^{\mathrm{ER}} \mathrm{Bdnf^{ \text {lox/- } }}$ mice $(\mathrm{D}, \mathrm{H})$ at two weeks after nerve section. Anti-TUJ1 (neuron specific beta III Tubulin, nerve fibers, blue), anti-cytokeratin 8 (taste buds, green) were merged to observe taste nerves and taste buds in the same image (E-G). There was no obvious difference between these four groups in the amount of innervation to the taste bud. The scale bar $=10 \mu \mathrm{m}$ and applies to all figures. 
Figure 19
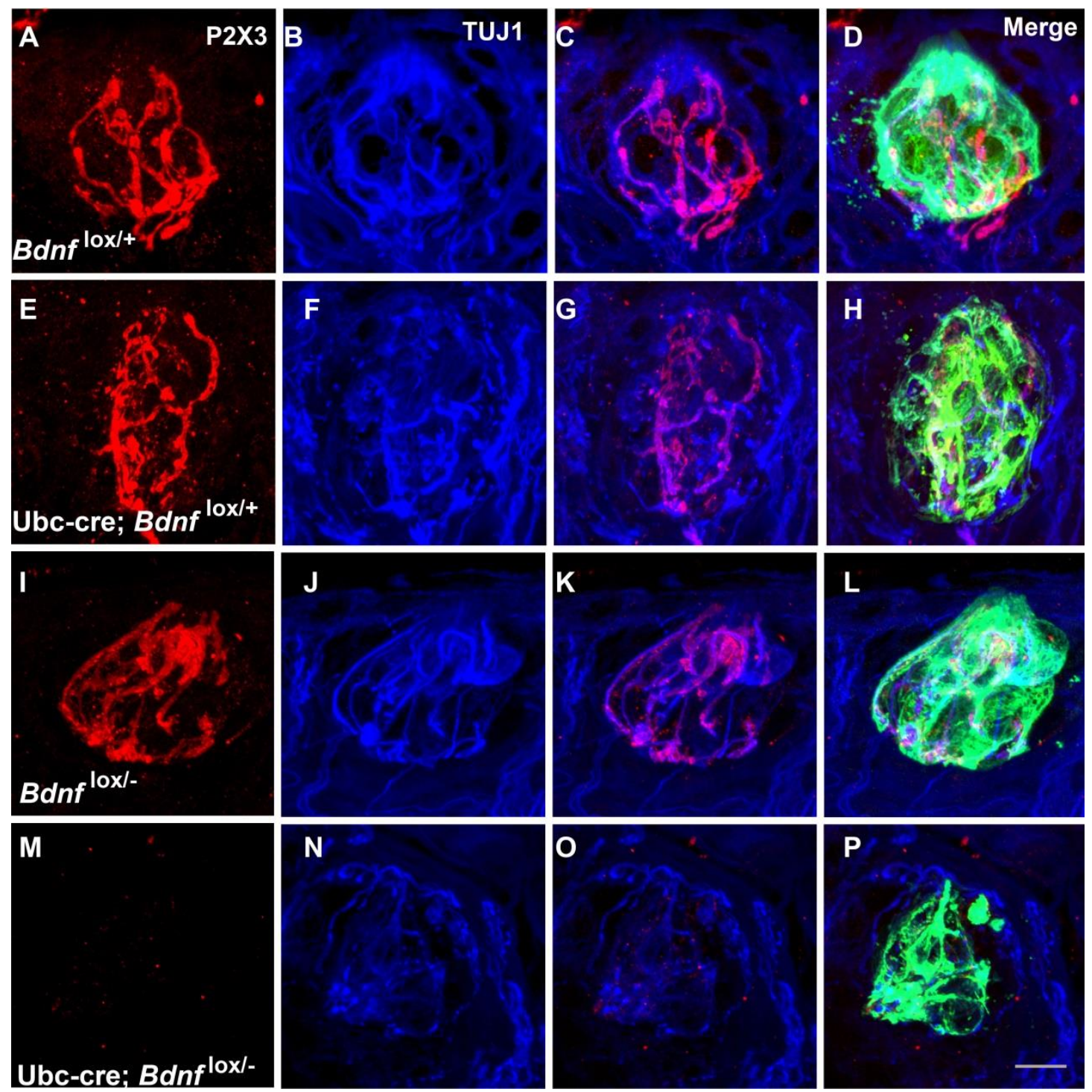
Figure 19. Reinnervation (P2X3 and TUJ1 labeled nerve fibers) of the taste bud was prevented or slowed by $B d n f$ gene deletion at eight weeks after nerve section. A-P: Confocal images of innervation with in a taste bud in $B d n f^{\text {lox/+ }}$ mice (A-D), Ubccre $^{\mathrm{ER}} B d n f^{\text {lox/+ }}$ mice $(\mathrm{E}-\mathrm{H}), B d n f^{\text {lox/- }}$ mice (I-L) and Ubc-cre ${ }^{\mathrm{ER}} B d n f^{\text {lox/- }}$ mice $(\mathrm{M}-\mathrm{P})$ at eight weeks after nerve section. Anti-P2X3 (nerve fibers, red) and anti-TUJ1 (nerve fibers, blue) were merged to observe the overlap (purple) between the two makers for nerve fibers $(\mathrm{C}, \mathrm{G}, \mathrm{K}, \mathrm{O})$. Anti-cytokeratin 8 (taste bud, green), anti-P2X3 (nerve fibers, red) and anti-TUJ1 (nerve fibers, blue) were merged in $B d n f^{\text {lox/+ }}$ mice (D), Ubc-cre ${ }^{\mathrm{ER}} B d n f^{\text {lox } /+}$ mice $(\mathrm{H}), B d n f^{\text {lox } /-}$ mice $(\mathrm{K})$ and Ubc-cre ${ }^{\mathrm{ER}} B d n f^{\text {lox/- }}$ mice $(\mathrm{P})$. Innervation to the taste bud in Ubc-cre ${ }^{\mathrm{ER}} B d n f^{\text {lox/- }}$ mice was reduced and $\mathrm{P} 2 \mathrm{X} 3$ positive innervation was absent, compared to other three genotypes. The scale bar $=10$ $\mu \mathrm{m}$ and applies to all figures. 
Figure 20

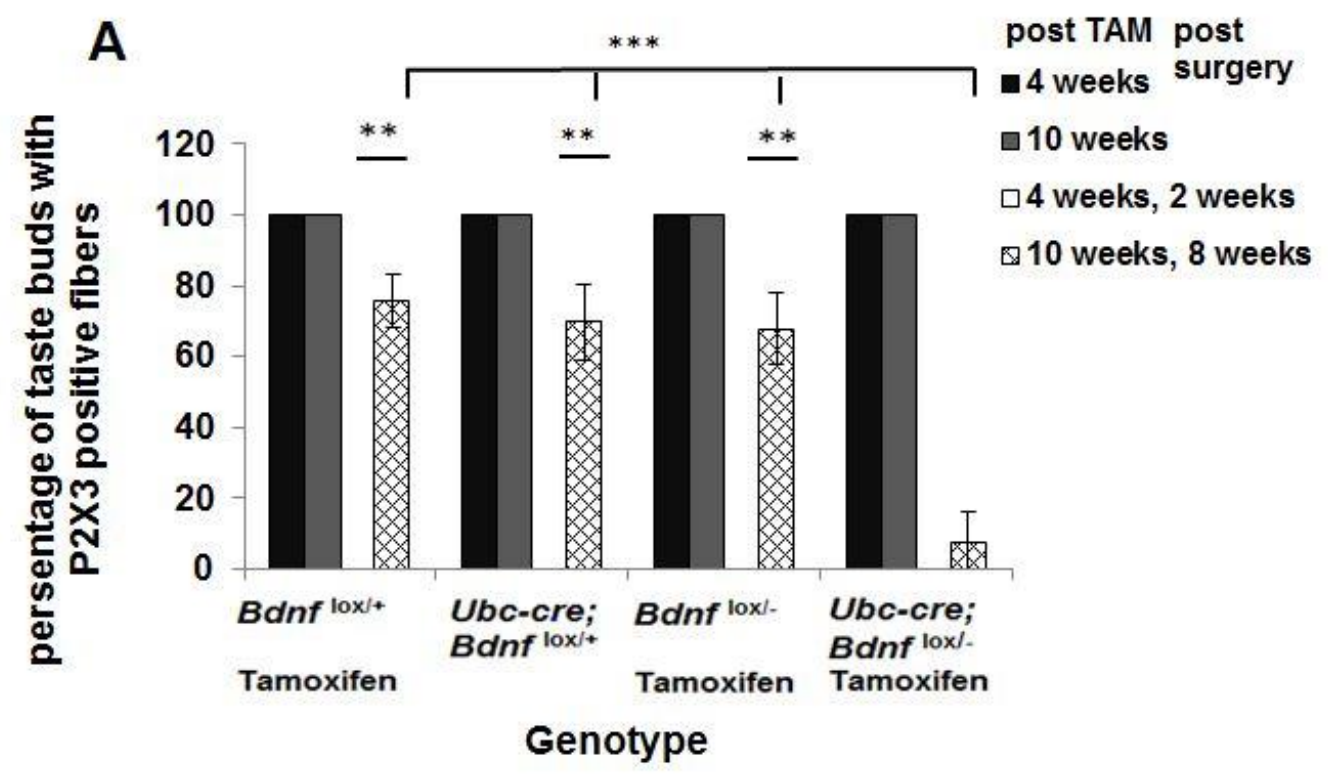

B

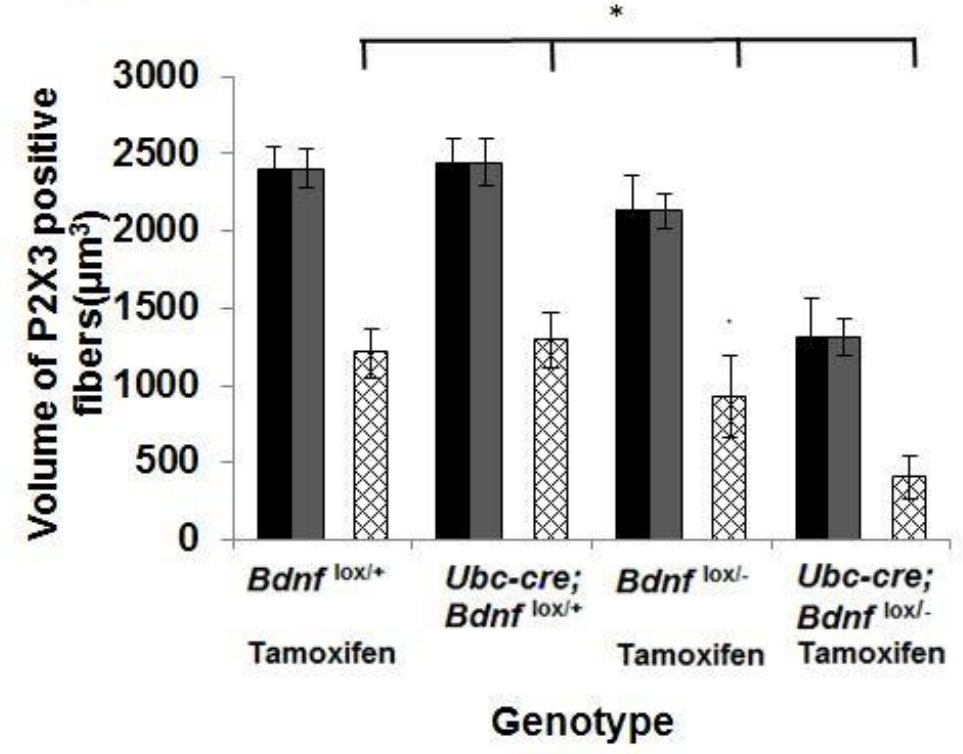


Figure 20. Deletion of the Bdnf gene had no effect on loss of P2X3-positive fibers from taste buds following chorda tympani nerve section, but prevented or slowed reinnervation of the taste bud. In the non-surgical groups (four weeks after tamoxifen, $\mathrm{n}=3$ for each genotype; ten weeks after tamoxifen, $\mathrm{n}=4$ for each genotype), all taste buds contain P2X3 positive fibers. At two weeks after nerve section, all taste buds lost $\mathrm{P} 2 \mathrm{X} 3$ positive fibers ( $\mathrm{n}=3$ for each genotype). Eight weeks after chorda tympani nerve section, the percentage of taste buds that regained P2X3 labeled nerve fibers increased in mice expressing $B d n f\left(B d n f^{\text {lox/+ }}\right.$ mice $(\mathrm{n}=3)$, Ubc-cre ${ }^{\mathrm{ER}} B d n f^{\text {lox/+ }}$ mice $(\mathrm{n}=3), B d n f$ ${ }_{\text {lox/- }}$ mice $(\mathrm{n}=4)$, but few taste buds regained P2X3-positive innervation when the Bdnf gene was deleted $\left(\mathrm{Ubc}-\mathrm{cre}^{\mathrm{ER}} B d n f^{\text {lox/- }}\right.$ mice $\left.(\mathrm{n}=4)\right)$. There was no difference in the three control genotypes (A). At two weeks after nerve section, all taste buds lost all P2X3 positive fibers ( $\mathrm{n}=3$ for each genotype). At eight weeks after nerve section, the volume of P2X3 positive fibers was much lower in those few taste buds that regained innervation from mice with reduced $B d n f\left(\mathrm{Ubc}-\mathrm{cre}^{\mathrm{ER}} B d n f^{\text {lox/- }}\right.$ mice $\left.(\mathrm{n}=4)\right)$ compared to taste buds from the other three genotypes $\left(B d n f^{\text {lox } /+}\right.$ mice $(\mathrm{n}=3)$, Ubc-cre ${ }^{\mathrm{ER}} B d n f^{\mathrm{lox} /+}$ mice $(\mathrm{n}=3), B d n f^{\text {lox/- }}$ mice $\left.(\mathrm{n}=4)\right)$. There was no difference in the three control genotypes (B). ${ }^{*} \mathrm{p}<0.05, * * \mathrm{p}<0.01 . * * * \mathrm{p}<0.005$. 
Figure 21
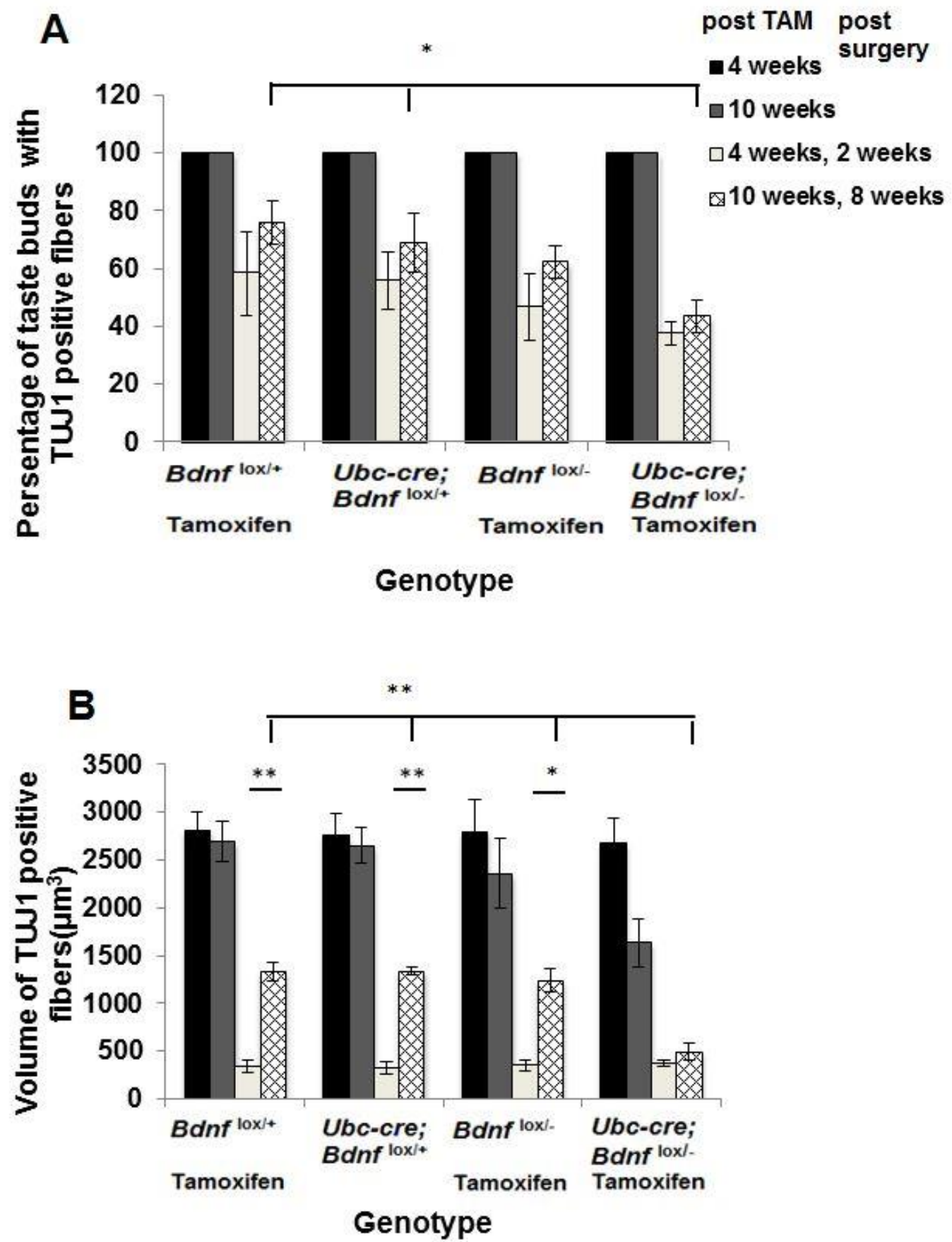
Figure 21. Bdnf removal did not influence the loss of TUJ1 (neuron specific beta III Tubulin) positive fibers in the taste bud two weeks after chorda tympani nerve section, but did prevent re-innervation of taste buds by TUJ1 fibers. In the non-surgery groups (four weeks after tamoxifen, $n=3$ for each genotype; ten weeks after tamoxifen, $n=4$ for each genotype), all taste buds contained TUJ1 positive fibers. At two weeks after nerve section, only $50 \%$ taste buds contained TUJ1 positive fibers in all four genotypes ( $\mathrm{n}=3$ for each genotype). Eight weeks after chorda tympani nerve section, the percentage of taste buds that regained TUJ1 labeled nerve fibers was higher in mice without $B d n f$ gene deletion $\left(B d n f^{\text {lox } /+}\right.$ mice $(\mathrm{n}=3)$ and $\mathrm{Ubc}-\mathrm{cre}^{\mathrm{ER}} B d n f^{\text {lox } /+}$ mice (n=3), compared to mice lacking $B d n f\left(\mathrm{Ubc}-\mathrm{cre}^{\mathrm{ER}} B d n f^{\text {lox/- }}\right.$ mice $\left.(\mathrm{n}=4)\right)$. There was no difference in the three control genotypes (A). At two weeks after nerve section, all taste buds lost nearly $85 \%$ of their TUJ1-positive fibers ( $n=3$ for each genotype). At eight weeks after nerve section, the other three genotypes $\left(B d n f^{\text {lox/+ }}\right.$ mice $(n=3)$, Ubccre $^{\mathrm{ER}} B d n f^{\text {lox/+ }}$ mice $(\mathrm{n}=3), B d n f^{\text {lox/- }}$ mice $(\mathrm{n}=4)$ regained the TUJ1-positive fibers in taste bud, while mice lacking BDNF (Ubc-cre $\left.{ }^{\mathrm{ER}} B d n f^{\text {lox/- }}(\mathrm{n}=4)\right)$ failed to regain TUJ1positive innervation. There was no difference in the three control genotypes (B). ${ }^{*} \mathrm{p}<0.05, * * \mathrm{p}<0.01$. 
Figure 22

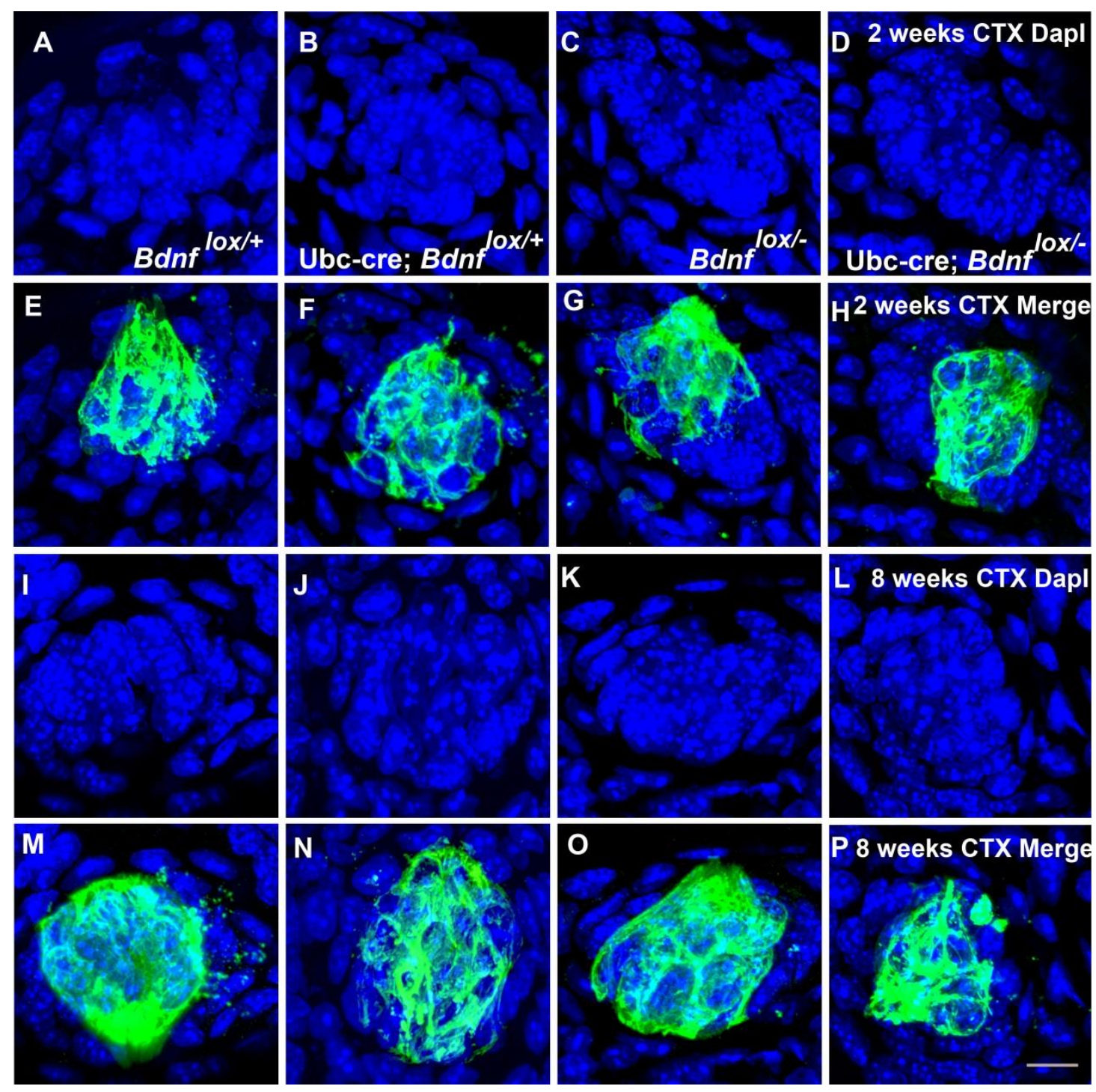


Figure 22. Taste bud size decreased two weeks after chorda tympani nerve section, recovery of taste bud size occurred eight weeks after nerve section and appeared to be prevented or delayed by $B d n f$ gene deletion. (A-H) Confocal images of taste buds (anti-cytokeratin 8, green) and taste cell (DAPI, blue) in $B d n f^{\text {lox/+ }}$ mice (A, E, I, M), Ubc-cre ${ }^{\mathrm{ER}} B d n f^{\text {lox/+ }}$ mice $(\mathrm{B}, \mathrm{F}, \mathrm{J}, \mathrm{N})$ and $B d n f^{\text {lox/- }}$ mice $(\mathrm{C}, \mathrm{G}, \mathrm{K}, \mathrm{O})$ and Ubc$\mathrm{cre}^{\mathrm{ER}} B d n f^{\text {lox/- }}$ mice $(\mathrm{D}, \mathrm{H}, \mathrm{L}, \mathrm{P})$ at two weeks and eight weeks after nerve section. Anti-cytokeratin 8 and DAPI were merged to visualize taste buds. There was no obvious difference between these four genotypes in taste bud size and/or cell number at two weeks after nerve section, while at eight weeks after nerve section, Ubccre $^{\mathrm{ER}} B d n f^{\text {lox/- }}$ mice $(\mathrm{P})$ had appeared smaller taste buds with fewer taste cells compared to $B d n f^{\text {lox/+ }}$ mice (M), Ubc-cre ${ }^{\mathrm{ER}} B d n f^{\text {lox/+ }}$ mice $(\mathrm{N}), B d n f^{\text {lox/- }}$ mice $(\mathrm{O})$. Scale bar $=10 \mu \mathrm{m}$ and applies to all figures. 
Figure 23
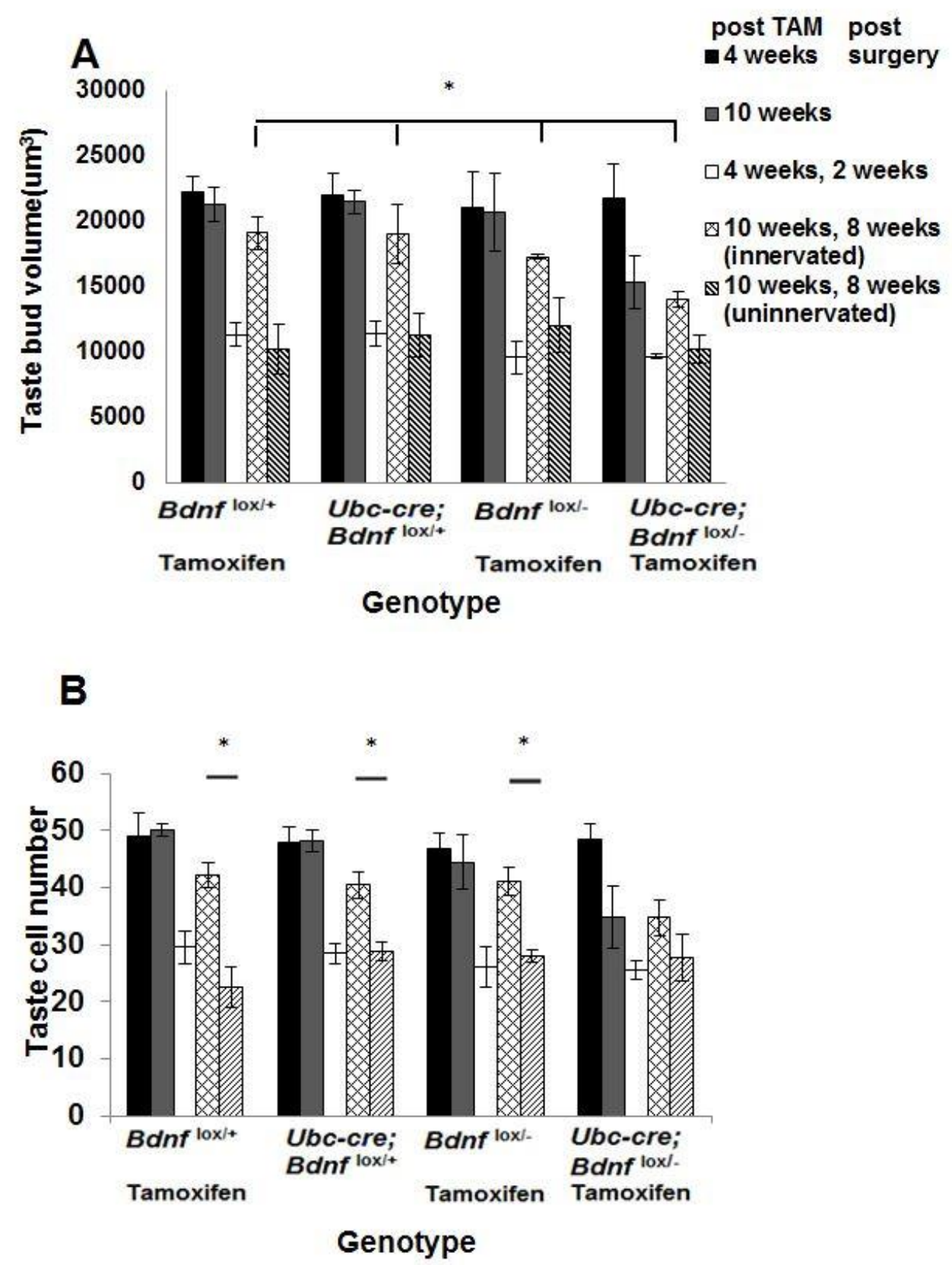
Figure 23. Taste bud size (A) and cell number (B) were reduced by half following taste nerve degeneration, but only recovered in mice that retained $B d n f$ expression. Two weeks after nerve section remaining taste buds had half the volume, in $B d n f^{\text {lox/+ }}$ mice $(\mathrm{n}=3), \operatorname{Ubc}-\mathrm{cre}^{\mathrm{ER}} B d n f^{\text {lox/+ }}$ mice $(\mathrm{n}=3), B d n f^{\text {lox/- }}$ mice $(\mathrm{n}=3)$ and Ubc-cre ${ }^{\mathrm{ER}} B d n f$ lox/- mice $(n=3)$ compared to non-surgical controls ( $n=3 /$ genotype) and there were no differences among four genotypes. At eight weeks after nerve section, taste bud sizes recovered in the reinnervated taste buds from $B d n f^{\text {lox } /+}$ mice $(\mathrm{n}=3), \mathrm{Ubc}-\mathrm{cre}^{\mathrm{ER}} B d n f$ ${ }_{\text {lox/+ }}$ mice $(\mathrm{n}=3), B d n f^{\text {lox/- }}$ mice $(\mathrm{n}=4)$, but not in $\operatorname{Ubc-cre}{ }^{\mathrm{ER}} B d n f^{\text {lox/- }}$ mice $(\mathrm{n}=4)$. While uninnervated taste buds did not recover in all four genotypes (A). Two weeks after nerve section remaining taste buds lost nearly $40 \%$ of their taste cells, and there were no differences among 4 genotypes. As with taste bud volume, taste buds that regained innervation also regained taste cells, while those that were not reinnervated did not (B). ${ }^{*} p<0.05,{ }^{* *} p<0.01$ 
Figure 24

A

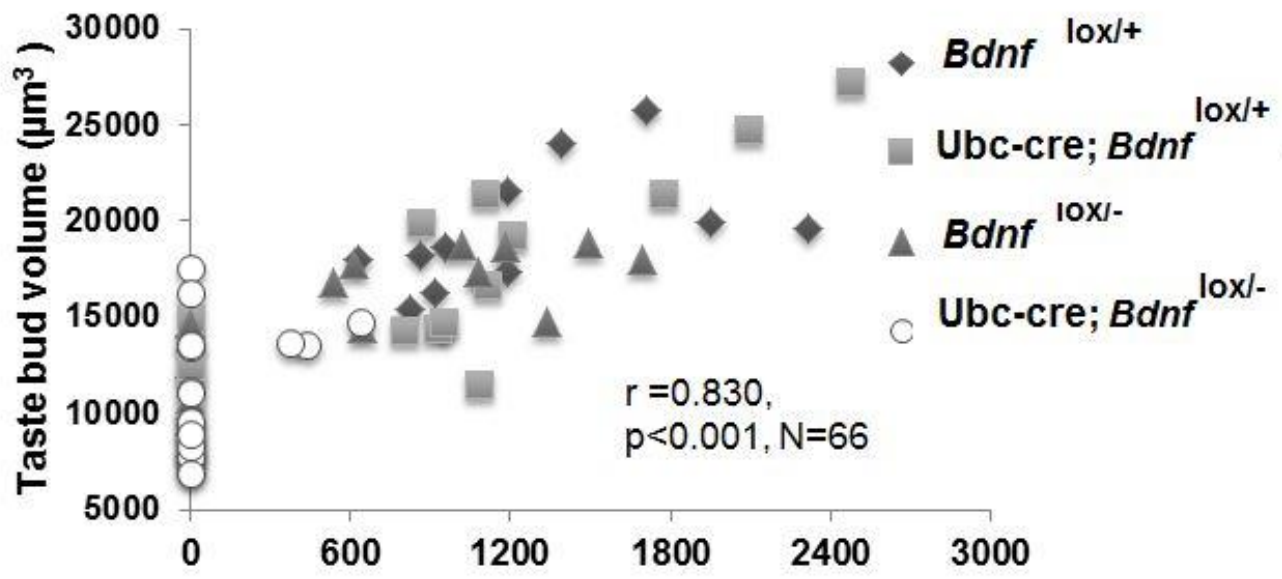

Volume of P2X3 labeled positive fiber $\left(\mu \mathrm{m}^{3}\right)$

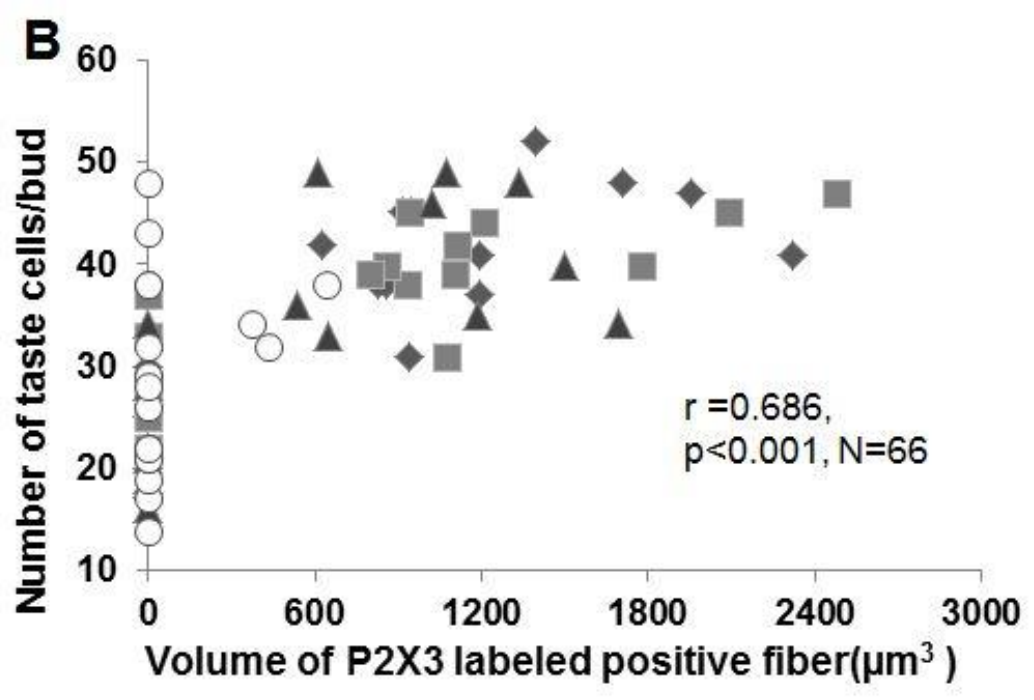


Figure 24. The correlation between $\mathrm{P} 2 \mathrm{X} 3$ positive innervation and taste bud size was reestablished after nerve section. At eight weeks after nerve section, taste bud volume and taste cell number are plotted against the volume of $\mathrm{P} 2 \mathrm{X} 3$ positive fibers for individual taste buds from $B d n f^{\text {lox/+ }}$ mice $(\mathrm{n}=3), \mathrm{Ubc}-\mathrm{cre}^{\mathrm{ER}} B d n f^{\text {lox/+ }}$ mice $(\mathrm{n}=3), B d n f$ ${ }^{\text {lox/- }}$ mice $(n=4)$ and Ubc-cre ${ }^{\mathrm{ER}} B d n f^{\text {lox/- }}$ mice $(\mathrm{n}=4)(\mathrm{A}, \mathrm{B})$. In general, smaller taste buds with fewer taste cells also have reduced innervation in regenerated taste buds after nerve section. 
Figure 25

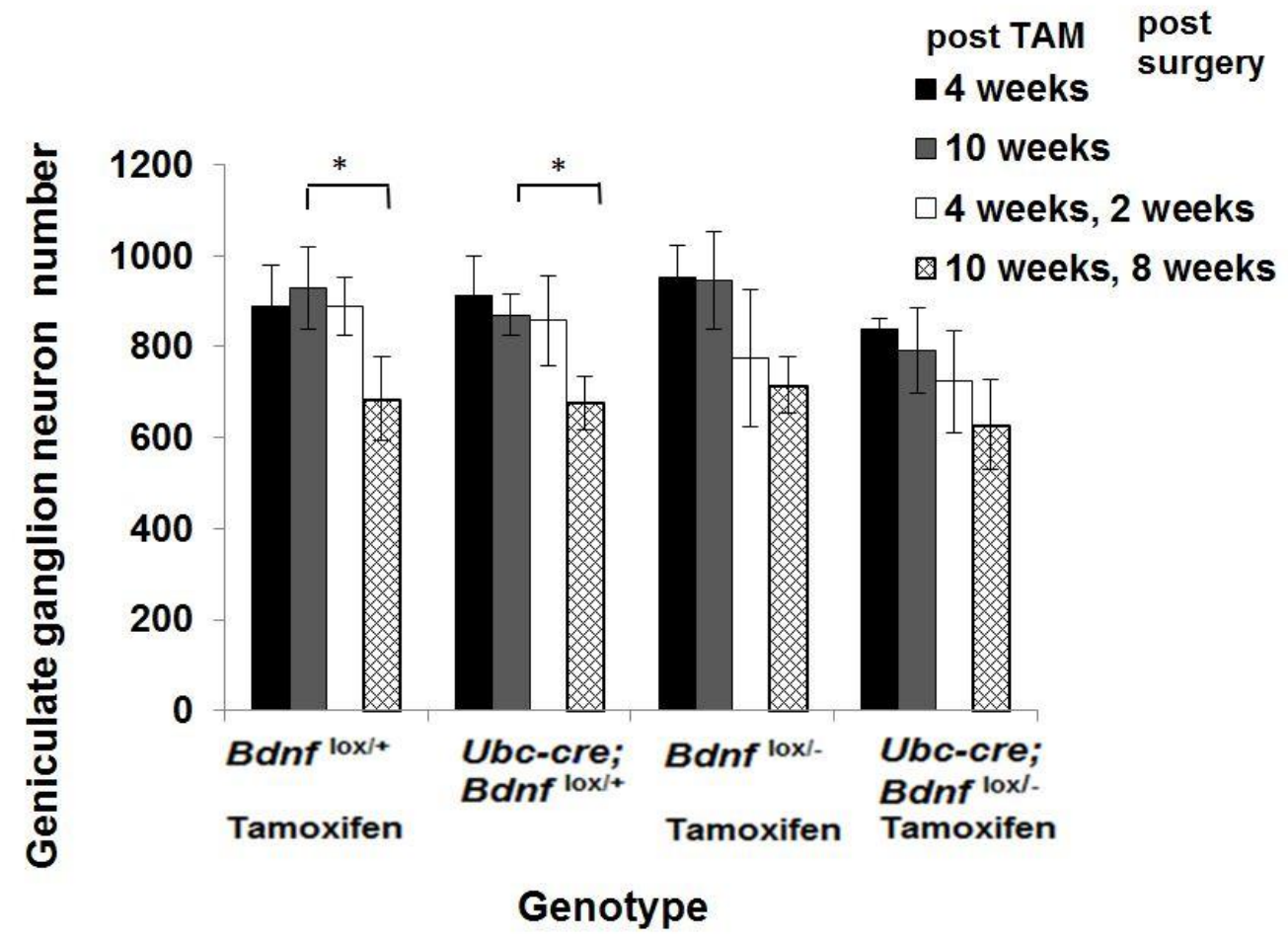


Figure 25. Bdnf gene deletion did not increase geniculate neuron death after nerve section. The number of geniculate ganglion neurons did not change in $B d n f^{\text {lox } /+}$ mice $(\mathrm{n}=3)$, Ubc-cre ${ }^{\mathrm{ER}} B d n f^{\text {lox/+ }}$ mice $(\mathrm{n}=5), B d n f^{\text {lox/- }}$ mice $(\mathrm{n}=3)$ and Ubc-cre ${ }^{\mathrm{ER}} B d n f^{\text {lox/- }}$ mice $(n=4)$ at two weeks after nerve section compared to non-surgical controls. There was also no difference among four genotypes. At eight weeks after nerve section, the geniculate ganglion decreased by $22 \%$ of normal levels for $B d n f^{\text {lox } /+}$ mice $(n=5)$, Ubccre $^{\mathrm{ER}} B d n f^{\text {lox/+ }}$ mice $(\mathrm{n}=3)$ compared to non-surgical genotypes. There was no difference in geniculate neuron number among the four genotypes at eight weeks after nerve section. Therefore, there was a slight reduction in neuron number as the result of chorda tympani nerve section, but $B d n f$ gene removal did not add to this neuron loss. ${ }^{*} \mathrm{p}<0.05^{* *} \mathrm{p}<0.01$ 


\section{CHAPTER IV}

\section{BDNF MAY BE IMPORTANT FOR PLASTICITY CHANGES IN GUSTATORY SYSTEM}

\subsection{Introduction}

When a peripheral sensory nerve is injured, remaining intact nerves will frequently show changes in both anatomy and function (Nixon et al., 1984; Hill and Phillips, 1994; Guagliardo and Hill, 2007), we term this "plasticity". For example, neighboring intact axons from the dorsal root ganglion grow into a denervated area, after nerve section (Nixon et al., 1984). In the gustatory system, there is no evidence that denervation of one side of the tongue leads to innervation from the contralateral nerve. However, there are both physiological and anatomical changes on the contralateral side of the tongue. Specifically, increases in responses to $\mathrm{NaCl}$ occur in the contralateral taste nerve following unilateral chorda tympani section (Hill and Phillips, 1994). In addition, taste buds on the contralateral side increase in size due to an increase in the number of taste cells per bud (Guagliardo and Hill, 2007). Possible regulators of gustatory plasticity include neurotrophins.

Evidence from somatic sensory systems suggests that neurotrophins may be involved in plasticity in uninjured nerves following nerve section (i.e. collateral sprouting). Specifically, nerve growth factor (NGF) deprivation (with anti-NGF serum) prevents collateral sprouting following dorsal root nerve section (Diamond et al., 1987). This effect was reversible in that once administration of the anti-NGF 
serum was stopped, collateral sprouting resumed (Diamond et al., 1992a). Therefore, collateral sprouting of intact sensory nerves following partial denervation of skin is dependent on NGF. In addition to a role for NGF in collateral sprouting there could be a role for BDNF. Specifically, following dorsal cutaneous nerve section the neurons of the adjacent DRG (which will undergo collateral sprouting) have increased levels of Bdnf mRNA (Dr Petruska's seminar). The up-regulated neurotrophin in adjacent intact neurons indicates that neurotrophins may promote plasticity (collateral sprouting) following peripheral sensory nerve section.

To address whether the plasticity on the contralateral side following unilateral chorda tympani nerve section is dependent on neurotrophins, I focused on BDNF because BDNF is the major neurotrophin expressed in and regulating the taste system during both development and adulthood (Nosrat and Olson, 1995; Yee et al., 2003; Huang and Krimm, 2010; Nosrat et al., 2012). I found that Bdnf mRNA level increased in contralateral geniculate ganglion after unilateral chorda tympani nerve section. Following unilateral nerve cut, mice without Bdnf gene deletion had an increase in taste buds size and innervation on the contralateral side, while taste bud volume, taste cell number and nerve fibers in mice with $B d n f$ gene deletion fail to increase on the contralateral side. Thus, BDNF may be important for plastic changes in the gustatory system following nerve injury.

4.2 Materials and Methods

\subsubsection{Animals}


For Real time RT-PCR, C57Bl/6J mice were purchased from Jackson laboratories (Bar Harbor, ME). The surgical groups received unilateral chorda tympani nerve transaction at 2 months. Geniculate ganglia and the anterior tongues were dissected 2 days $(n=6), 2$ weeks $(n=6), 1$ month $(n=6)$ and 2 months $(n=6)$ following unilateral chorda tympani nerve section (CTX). Control animals were age matched to the surgical animals.

In order to remove $B d n f$ in conjunction with chorda tympani nerve section, Ubc-cre ${ }^{\mathrm{ER}} B d n f^{\mathrm{dox} / \mathrm{lox}}$ mice were generated by crossing $B d n f^{\text {dox/lox }}$ mice (JAX, \#004339) with Ubc-cre ${ }^{\mathrm{ER}}$ mice $(\mathrm{JAX}, \# 007001)$. Bdnf ${ }^{\mathrm{dox} / \mathrm{lox}}$ mice possess loxP sites on either side of exon 5 of $B d n f$ gene (JAX, \#004339 description) and Ubc-cre ${ }^{\mathrm{ER}}$ mice expresses the $\mathrm{Cre}^{\mathrm{ER}}$ from the human ubiquitin $\mathrm{C}$ promoter. Since ubiquitin is found in almost all tissues of eukaryotic organisms, $\mathrm{Cre}^{\mathrm{ER}}$ is also expressed in all tissues under ubiquitin promoter. $\mathrm{Cre}^{\mathrm{ER}}$ is a fusion protein composed of Cre recombinase and a mutant form of the estrogen receptor ligand-binding domain that is selectively activated only in the presence of tamoxifen (TAM) (Feil et al., 1997). Upon introduction of tamoxifen, the Cre recombinase is able to penetrate the nucleus and remove $B d n f$ in Ubc-cre ${ }^{\mathrm{ER}} B d n f$ lox/lox mice.

In order to increase the probability that $B d n f$ would be successfully removed, Ubc-cre ${ }^{\mathrm{ER}} B d n f^{\mathrm{ox} /-}$ mice were generated by crossing Ubc-cre ${ }^{\mathrm{ER}} B d n f^{\text {lox/lox }}$ with heterozygous Bdnf knockout mice $B d n f^{+/}(\mathrm{JAX}, \# 002266)$. The end result is an experimental animal which lacks a functional $B d n f$ gene on one allele and in which $B d n f$ can be removed inducibly from the other allele. Three controls were analyzed for three different purposes of comparison. $B d n f^{\text {ox/ } /+}$ mice (with tamoxifen) was used to exclude potential effects of tamoxifen administration. Ubc-cre ${ }^{\text {ER }} B d n f{ }^{\text {lox } /+}$ mice 
(without tamoxifen) when compared to Ubc-cre ${ }^{\mathrm{ER}} B d n f^{\text {lox/- }}$ mice. $B d n f^{\text {lox/- }}$ mice (with tamoxifen) controlled for any effects in heterozygous Bdnf knockouts.

\subsubsection{Tamoxifen administration}

Tamoxifen was administered (Sigma, T5648; mixed in peanut oil; $188 \mathrm{ng} / \mathrm{g}$ body weight, once per day for 5 days) by oral gavage (Ruzankina et al., 2007) which maximized recombination and decreased the loss of animals through toxicity (Ruzankina et al., 2007).

\subsubsection{Chorda tympani nerve transection}

The mice were anesthetized with an intramuscular injection of dexmedetomadine hydrochloride $(0.4 \mathrm{mg} / \mathrm{kg}$ body weight $)$ followed by ketamine hydrochloride (40mg/kg body weight)(Guagliardo and Hill, 2007). The mice were placed in a non-traumatic head holder to provide access to the nerve in the neck via a ventral approach. The chorda tympani nerve was located as it bifurcates from the lingual branch of the trigeminal nerve and was cut without damaging the trigeminal nerve. The wound was sutured, and the mice were allowed to recover on a watercirculating heating pad before being returned to their home cage. Atipamezole hydrochloride $(2 \mathrm{mg} / \mathrm{kg}$ body weight) was injected intramuscularly to the mice immediately after surgery to help wake them up.

\subsubsection{Lingual epithelium isolation for Real Time RT-PCR}

Mice were euthanized with avertin $(4 \mathrm{mg} / \mathrm{kg}$ body weight), the tongue and geniculate ganglion were collected for Real Time RT-PCR. The tongue was cut gently anterior to circumvallate papillae, removed and rinsed in a $0.1 \mathrm{M}$ phosphate-buffered saline $(\mathrm{PBS})$ solution $(\mathrm{PH}=7.4)$ and then was cut in half evenly under microscope. To 
isolate the lingual epithelium, half tongues were incubated in sterile dispase I-solution (BD Biosciences) for 50 minutes. After incubation, the epithelial sheets were peeled from the underlying lamina propria. The lingual epithelium from each animal was transferred into a $1.5 \mathrm{ml}$ tube containing RNAlater (Ambion, Austin, TX). All samples were stored at $80^{\circ} \mathrm{C}$ until RNA extraction.

4.2.5 Taste bud and ganglion neuron isolation using LCM (laser capture micro dissection)

Geniculate ganglia were quickly dissected under a microscope, and transferred into OCT and frozen immediately on dry ice. All samples are stored at $80^{\circ} \mathrm{C}$ until RNA extraction. Geniculate ganglia and tongues were cut into $10 \mathrm{um}$ thick sections on a cryostat and directly mounted onto glass slides. The sections were then fixed in a solution of $75 \%$ ethyl alcohol $(\mathrm{ETOH})$ for $30 \mathrm{sec}$ and then rinsed in nuclease-free water. The slides were then taken through an alcohol dehydration series of $75 \%, 95 \%$, and $100 \%$ ETOH for $30 \mathrm{sec}$ each, followed by immersion in xylene for $5 \mathrm{~min}$. After the slides were removed from xylene and the remaining xylene had evaporated, they were placed onto a laser capture microscope (Arcturus). Geniculate ganglia and taste buds were identified and captured onto CapSure Macro LCM Caps (Molecular Devices, Sunnyvale, CA). For each animal, all sections containing geniculate ganglia and all taste buds in lingual epithelium were collected and captured for RNA isolation. The captured samples were then collected into tubes containing total RNA isolation reagent (Qiagen, Chatsworth, CA) for later RNA isolation.

\subsubsection{RNA Extraction and Real Time RT- PCR}

To determine how $B d n f$ mRNA responds to nerve section, $B d n f$ mRNA level in tongue epithelium and geniculate ganglion were measured using Real Time RT- 
PCR. Total RNA from each geniculate ganglion, and the epithelia was extracted using RNeasy micro kit or RNeasy mini kit (Qiagen). DNase I treatment was applied to eliminate traces of DNA during the procedure. After the extraction, RNA was analyzed with RNA 6000 Pico/Nano Chip kits in Bioanalyzer 2100 (Agilent Technologies, Santa Clara, CA) and RNA Integrity Number (RIN) and 28S/18S ratio were used to estimate the RNA quality. Only RNA samples with RNA integrity number (RIN) more than 8.0 were used in this study. Reverse transcription was performed using 200 U Superscript III Reverse Transcriptase (Invitrogen, Carlsbad, CA) and 50ng random hexamers (Invitrogen) in $25 \mathrm{ml}$ reaction volume containing first strand buffer (Invitrogen), $0.5 \mathrm{mM}$ dNTPs, and $40 \mathrm{U}$ of RNase inhibitor. All samples produced sufficient amounts of RNA for Real Time PCR. To control for differences in the amount of RNA isolated from different groups, the same amount of RNA from each sample was used for the geniculate ganglion (3ng) and for the lingual epithelium (50ng). After incubation for $50 \mathrm{~min}$ at $50^{\circ} \mathrm{C}$, the reaction was stopped by heating $\left(5 \mathrm{~min}\right.$ at $\left.85^{\circ} \mathrm{C}\right)$.

Real Time RT-PCR was performed with the ABI PRISM/7900HT sequence detection system (Applied Biosystems, Foster City, CA), using Taq-Man Universal PCR kit (Applied Biosystems), and oligonucleotide primer/probe sets, which were designed from the sequences in the GenBank database using Beacon Designer software (Premier Biosoft International, Atlanta GA). When it was possible, the primers were chosen to span an intron to avoid the detection of any contamination of genomic DNA. TaqMan probes were labeled at the 50-end with a fluorescent reporter dye (FAM) and at the 30-end with a quencher dye (TAMRA). The Real Time RTPCR reaction (Table 1) was conducted using $10 \mathrm{ml}$ total volume with Master Mix, 720/200 Nm primer/probe sets (TaqMan PCR kit) and the same amount of target 
cDNA across different time periods. For normalization of cDNA loading, all samples were run in parallel with the housekeeping gene, $18 \mathrm{~S}$ ribosomal RNA, and mouse glyceraldehyde 3 phosphate dehydrogenase (GAPDH). Each assay was carried out in triplicate. Amplification of cDNA was performed for 40 cycles of $95^{\circ} \mathrm{C}$ for $15 \mathrm{sec}$ and $60^{\circ} \mathrm{C}$ for $1 \mathrm{~min}$.

For Real Time RT-PCR, the comparative 2-DDCT method was used to determine target gene expression levels (Livak and Schmittgen, 2001). The normalized expression of the target gene was calculated as normalized expression (Etarget) DCT target (control - sample)/ (Eref) DCT ref (control - sample), where Etarget is reaction efficiency of the gene of interest; Eref, reaction efficiency of the reference gene; and DCT, the cycle difference between the control and the sample.

\subsubsection{Tissue preparation for Immunohistochemistry}

Mice were scarified by avertin overdose $(4 \mathrm{mg} / \mathrm{kg}$ body/weight $)$ and perfused through the heart using 4\% paraformaldehyde (PFA). The anterior two-thirds of the tongue was separated from the circumvallate papillae, rinsed with $0.1 \mathrm{M}$ phosphatebuffered saline (PBS) solution $(\mathrm{PH}=7.4)$ and then cut in half evenly under microscope. The geniculate ganglia were dissected under a microscope (Leica MZFLIII). Both the anterior tongue and geniculate ganglia were fixed in 4\% paraformaldehyde for 2 hours, rinsed with PBS, and then transferred to $30 \%$ sucrose at $4{ }^{\circ} \mathrm{C}$ overnight. These tissues were frozen the next day in OCT and stored at $-80{ }^{\circ} \mathrm{C}$ until sectioned on a cryostat. Serial sagittal sections of tongue (20um) and geniculate ganglion (50um) were mounted on glass slides for quantification.

\subsubsection{Immunohistochemistry}


To visualize taste buds and innervation, slides containing tongue sections were first dried on a slide warmer $\left(37^{\circ} \mathrm{C}\right)$ overnight. The next day they were rehydrated, placed into Citric Acid buffer (10mM Citric Acid, 0.05\% Tween 20, PH=6.0), heated to $98-100{ }^{\circ} \mathrm{C}$ for approximately 15 minutes in boiling bath, and allowed to cool for 20 minutes at room temperature for antigen retrieval. Slides were washed in PBS $(\mathrm{PH}=7.4)$ and incubated overnight at room temperature in anti-cytokerain- 8 antibody in PBS (Table 2). Following the incubation with the anti-cytokeratin-8 antibody the slides were rinsed in PBS and incubated for 1.5 hours with Alexa 488 anti-rat secondary antibody (1:500; Invitrogen). After washing in PBS, the slides were incubated for 2 hours in blocking solution (5\% NGS 2\% Triton X-100 made in $1 \mathrm{X}$ PBS) followed by rabbit anti-P2X3 (1:500; Table 2), mouse anti-TUJ1 (1:500; Table 2 in blocking solution in room temperature overnight. Following the overnight incubation, the slides were rinsed in PBS ( 4 X 5 minutes), and the tissue was incubated for 1.5 hours at room temperature in Alexa 555 anti-rabbit secondary antibody (1:500; Invitrogen), and Alexa 647 anti-mouse secondary antibody (1:500; Invitrogen) in blocking solution. The slides were then rinsed in PBS (3 X 5 minutes) and stained with DAPI (4, 6-diamidino-2-phenylindole, dihydrochloride, 2ul/50ml ddH2O, Life technologies, Foster City, CA) for 15 minutes. After a rinse in PBS (3 X 5 mins), the slides were mounted with Fluoromount-G (SouthernBiotech, Birmingham, AL).

\subsubsection{Taste bud counts}

Taste buds are defined by cytokeratin 8 florescent staining and span the entire height of the lingual epithelium from the surface to the basement membrane with keratin 8 staining. Taste buds were counted in 20 -um serial sections of the immunofluorescent sagittal section of tongue using enabled Leica DMLB microscope. 
Taste buds were tracked through individual sections, such that each taste bud was only counted once.

\subsubsection{Stereology}

Stereological methods were used to count the total number of geniculate ganglion neurons. Fixed ganglia were serial sectioned $(50 \mu \mathrm{m})$, mounted on slides, and stained with cresyl violet for $15 \mathrm{mins}$. To maintain section thickness, sections were not dehydrated and were mounted in Dako Glycergel Mounting Medium for stereological quantification (Dako North America, Carpinteria, CA). Using Stereo Investigator software (MBF Bioscience), an experimenter blind to the genotype of the animals traced a contour around the geniculate ganglion (20X). Every section containing the ganglion was traced, and a total of at least 4 sections were quantified. Within each traced contour of the geniculate ganglion, the computer randomly determined the placement of the counting frames. The depth of the counting frame was equal to minimal thickness of the section, minus a total guard zone of $10 \mu \mathrm{m}(5 \mu \mathrm{m}$ from the top and bottom of the section). Geniculate ganglion neurons were counted (100X mag) in each counting frame $\left(15 \mu \mathrm{m}^{2}\right)$. Neurons were counted only when they first came into focus (cell top) so that each cell was counted only once. Based on these measurements, the total cell number in the ganglion was estimated for the entire volume of the ganglion using the optical fractionator probe (MBF Bioscience).

\subsubsection{Analysis of Individual Taste Buds}

To minimize variability, the analysis of individual taste buds was limited to the dorsal tongue tip (Figure 1). Immunofluorescent image stacks each consisting of multiple optical image planes (step size $1 \mu \mathrm{m}$ ) were obtained with an Olympus Fluoview FV1000Laser scanning confocal microscope (LSI3-FV1000-Inverted). During both image capture and analysis the experimenter was blind to the genotype of 
animals. For each triple-labeled immunohistochemical image, the four channels were collected separately, with single wavelength excitation and then merged to produce the composite image. Serial optical sections were captured every $1 \mu \mathrm{m}$ in labeled whole taste buds under $60 \mathrm{X}$ lens at $3.5 \mathrm{zoom}$. A single taste bud from an intact tongue was typically found in 2-3 physical sections (i.e. 36-60um); all 2-3 sections containing the taste bud were captured so that the entire taste bud could be quantified.

4.2.12 Taste bud analysis: Quantification of taste bud size, innervation and taste cells

Each physiological section contains $15-20$ optical images. Each $1 \mu \mathrm{m}$ optical image was traced and the area measured using Neurolucida imaging software (MicroBrightField). Total area was summed and multiplied by the total number of optical images in all physical sections to yield taste bud volume.

The volume of anti-P2X3 and anti-Tuj1 immunostaining with in the taste bud was measured using MBF ImageJ software (ImageJ 1.47) (Jensen, 2013). ImageJ software set an unbiased threshold automatically, and the number of labeled pixels inside the taste buds was measured for each optical section. Pixels were converted to volume and summed to obtain the total volume occupied by nerve fibers with in one taste bud.

Taste cell number was quantified by counting DAPI stained nuclei within the keratin 8 defined taste buds. DAPI labeled nuclei were followed through the optical sections, such that each nucleus was only counted once. Because each taste bud was in more than one physical section, the number of cells was added for each physical section. A few cells may have been counted twice due to split nuclei across physical sections. 


\subsubsection{Statistics}

All the measurements within the same group of mice were determined to have equal variance (using Levene's test for homogeneity of variance, $P>0.05$ ). When comparing Bdnf mRNA level in RT-PCR Real Time, one-way ANOVA was applied to analyze the difference between genotypes. For taste bud volumes, nerve innervation, taste cell number, taste bud number and ganglion cell numbers, two-way ANOVA's were used for analysis. After overall significance was determined, a Tukey post-hoc test was used to identify which groups within the analysis were significant. The mean value representing each group derived from 4-5 mice and mean value of each mouse was derived from 5-6 taste buds/mouse. For all the above measurements, 5 mice were analyzed in Ubc-cre ${ }^{\mathrm{ER}} B d n f^{\text {lox/- }}$ group, while 4 mice in $B d n f^{\text {lox/+ }}$ mice, Ubc-cre ${ }^{\mathrm{ER}} B d n f^{\text {lox/+ }}$ mice, and $B d n f^{\text {lox/+ }}$ mice. The significance level was set at $\mathrm{p}<0.05$ for all statistical comparisons.

\subsection{Results}

4.3.1 Bdnf expression level increased in the contralateral geniculate ganglia following nerve section.

Following unilateral chorda tympani nerve section, taste bud size increases on the contralateral side (Guagliardo and Hill, 2007). I hypothesized that this plasticity may depend on neurotrophins. Since BDNF is the most important neurotrophic factor in the taste system during both development and adulthood (Nosrat and Olson, 1995; Yee et al., 2003; Huang and Krimm, 2010; Nosrat et al., 2012), BDNF may also mediate taste system plasticity on the contralateral side. To test this hypothesis, I first examined $B d n f$ expression in the contralateral geniculate ganglion using Real Time 
RT-PCR at 2, 14, 30 and 60 days after unilateral chorda tympani nerve section. $B d n f$ expression was increased in geniculate ganglion on the contralateral side at two weeks after unilateral chorda tympani nerve cut $(\mathrm{p}<0.05)$ (Figure 26A). Neurofilament expression was the same across all groups, indicating that relatively equal number of neurons were isolated from each geniculate ganglion $(\mathrm{p}>0.05)$.

I also examined $B d n f$ level in lingual epithelium on the contralateral side; $B d n f$ expression was unchanged in lingual epithelium at 2, 14, 30 and 60 days after nerve section (Figure 26B). Expression of cytokertatin-8 (which is expressed in taste buds but not surrounding epithelia) was also unchanged in lingual epithelium at 2, 14, 30 and 60 days after nerve section (Figure 26C). To examine $B d n f$ expression in the separate tissues of the lingual epithelium, I isolated taste buds, lamina propria and non-taste epithelium filiform papillae on the contralateral side using laser capture micro-dissection (LCM) at 14 days following nerve section. Bdnf expression was analyzed using Real Time RT-PCR. None of these tissues show a change in Bdnf expression following contralateral nerve section (Figure 27). I conclude that $B d n f$ expression increased in contralateral geniculate ganglion but not taste buds or lingual epithelium following nerve section. I hypothesize this increase in $B d n f$ expression could regulate taste system plasticity on the uninjured side.

4.3.2 Taste bud size increases on the contralateral side following unilateral nerve section and this increase may be supported by $B d n f$.

Taste bud size has been shown to increase on the contralateral side following chorda tympani nerve section (Guagliardo and Hill, 2007). Since $B d n f$ expression also increased in the contralateral geniculate ganglion after nerve section, it is possible that these two phenomenon are related. If so, once the $B d n f$ gene is deleted, the increase in 
taste bud size on contralateral side should be prevented. To determine if this is the case, $B d n f$ was inducibly removed all over the body in adult mice by using the CreLoxP system. Efficiency of gene recombination was demonstrated by Real Time RTPCR in aim 1. The chorda tympani nerve was sectioned unilaterally in mice following $B d n f$ deletion. Taste bud size was defined by staining with anti-tromal (cytokeratin 8 ), which labels most columnar taste cells and a nuclear label (DAPI) was used for counting cell number inside taste bud. At two weeks after nerve section, there were no obvious differences in taste bud size and cell number among the four genotypes on the contralateral side (Figure 28). However, at eight weeks after nerve section, taste bud volume and cell number appeared increased in mice without $B d n f$ gene deletion ( $B d n f$ ${ }^{\text {lox } /+}$ mice, Ubc-cre ${ }^{\mathrm{ER}} B d n f^{\mathrm{lox} /+}$ mice) compared to those lacking $B d n f\left(\mathrm{Ubc}-\mathrm{cre}{ }^{\mathrm{ER}} B d n f\right.$ lox/- mice) on contralateral side (Figure 28).

In order to quantify these observations, taste bud volume was analyzed. Two weeks after surgery taste buds on the contralateral side were not different from nonsurgical controls (Figure 29A). However, by eight weeks after nerve section, taste bud volume increased on the contralateral side compared to non-surgical controls when $B d n f$ expression remained normal $\left(B d n f^{\text {lox } /+}\right.$ mice $(\mathrm{p}<0.01), \mathrm{Ubc}-\mathrm{cre}^{\mathrm{ER}} B d n f^{\mathrm{lox} /+}$ mice $(\mathrm{p}<0.01))$, while mice with the heterozygous $B d n f$ mutation $\left(B d n f^{\text {lox/- }}\right)$ and mice with Bdnf deletion (Ubc-cre ${ }^{\mathrm{ER}} B d n f^{\text {lox/- }}$ mice) did not show statistically significant increases in taste bud volume (Figure 29A). Therefore, the slight reduction in $B d n f$ expression, which occurs in $B d n f^{\text {lox/- }}$, is sufficient to prevent the increase in taste bud volume on the contralateral side from reaching statistical significance. This is also the case for taste buds from mice in which the second $B d n f$ allele is removed in adulthood (Ubc-cre ${ }^{\mathrm{ER}} B d n f^{\text {lox/- }}$ mice), but the more substantial effect in these mice is the loss of taste bud size that occurs with $B d n f$ removal and was described in Chapter $1(\mathrm{p}<0.01)$. 
To determine if increased taste bud volume was due to an increase in taste cell number, taste cells were counted at two weeks and eight weeks after nerve section on contralateral side. Two weeks after surgery taste cell number on the contralateral side was not different from non-surgical controls (Figure 29B). However, by eight weeks after nerve section, taste cell number increased on the contralateral side compared to non-surgical controls without $B d n f$ gene deletion $\left(B d n f^{\text {lox } /+}\right.$ mice $(\mathrm{p}<0.01)$, Ubc-cre ${ }^{\mathrm{ER}}$ $B d n f^{\text {lox/+ }}$ mice $\left.(\mathrm{p}<0.01)\right)$, while mice with a heterozygous $B d n f$ mutation $\left(B d n f^{\text {lox/- }}\right)$ and mice with $B d n f$ deletion (Ubc-cre ${ }^{\mathrm{ER}} B d n f^{\text {lox/- }}$ mice) did not show increases in taste cell number (Figure 29B). Given that differences in taste cell number were similar to volume differences; it appears that any increases in taste bud volume are due to increases in taste cell number.

4.3.3 Increased taste bud size was correlated with increased TUJ1-positive innervation.

One possible explanation for the increased taste bud size and cell number on contralateral side after nerve section is that increased innervation to the taste bud supports the addition of taste cells. To address this possibility, I examined innervation with in the taste bud on the contralateral side following nerve section using two markers, anti-P2X3 (red) and anti-TUJ1 (neuron specific beta III Tubulin) (blue). $\mathrm{P} 2 \mathrm{X} 3$ is an ATP channel that is required for neural responses to taste stimuli (Finger et al., 2005; Murata et al., 2010) and primarily labels taste fibers (Finger et al., 2005; Ishida et al., 2009). Neuron specific beta III Tubulin is present in all nerve fibers. I observed no obvious difference in innervation between the 4 genotypes at two weeks after nerve section on contralateral side (Figure 30). However, by eight weeks after nerve section, TUJ1 positive fibers increased on the contralateral side following nerve 
section in mice without $B d n f$ gene deletion $\left(B d n f^{\text {lox/+ }}\right.$ mice and Ubc-cre ${ }^{\mathrm{ER}} B d n f$ ${ }^{\text {lox/+}}$ mice) compared to intact mice. Ubc-cre ${ }^{\mathrm{ER}} B d n f^{\text {lox/- }}$ mice appeared to have fewer TUJ1 positive nerve fibers than those in taste buds of in mice without Bdnf gene deletion $\left(B d n f^{\text {lox/+ }}\right.$ mice and Ubc-cre ${ }^{\mathrm{ER}} B d n f^{\text {lox/+ }}$ mice) and a heterozygous $B d n f$ mutation $\left(B d n f^{\text {lox/- }}\right.$ mice) (Figure 31).

In order to quantify these observations, the volume of TUJ1 positive nerve fibers inside the taste bud was analyzed. Two weeks after nerve section, there was no difference in the volume of TUJ1 positive nerve fibers in the taste bud between intact mice and those with the contralateral nerve section for any genotype (Figure 32A). However, at eight weeks after nerve section, the volume of TUJ1 positive fibers in the taste bud increased on the contralateral side of the tongue in surgical animals compared to intact mice without $B d n f$ gene deletion $\left(B d n f^{\text {lox/+ }}\right.$ mice $(\mathrm{p}<0.05)$, Ubc$\left.\mathrm{cre}^{\mathrm{ER}} B d n f^{\mathrm{lox} /+}(\mathrm{p}<0.05)\right)$ (Figure 32A). This finding indicates that an increase in TUJ1 positive nerve fibers may support the bigger taste buds seen on the contralateral side of the tongue after nerve section. Similar to changes in taste bud size, there was not a significant increase in TUJ1-positive innervation in $B d n f^{\text {lox/- }}$ mice regardless of whether the floxed $B d n f$ gene was removed in adulthood (Ubc-cre ${ }^{\mathrm{ER}} B d n f^{\text {lox/- }}$ mice) (Figure 32A). In conclusion, the taste buds increase in size on the contralateral side following chorda tympani nerve section and this increase is accompanied by increased TUJ1-positive innervation, and reducing the expression of $B d n f$ obscures the increase in both taste buds size and innervation.

I also measured the volume of $\mathrm{P} 2 \mathrm{X} 3$ positive nerve fibers inside contralateral taste buds following nerve section. There was no difference in the volume of P2X3 positive fibers on the contralateral side compared to intact mice at either two or eight weeks following nerve section for in any of the four genotypes (Figure 32B). These 
data indicated that $\mathrm{P} 2 \mathrm{X} 3$ positive fibers did not increase on the contralateral side following nerve sectioning. The only effect on P2X3 labeling was the loss of innervation due to $B d n f$ removal in adulthood $(\mathrm{p}<0.01)$, which still occurs as described in Chapter 1 even when the contralateral nerve is sectioned.

4.3.4 Increased innervation on contralateral side was not caused by increased geniculate neuron number.

Since $B d n f$ expression in the geniculate ganglion increased in the contralateral geniculate ganglion after nerve section and TUJ1-positive innervation also increased on that side, it is possible geniculate neuron number also increased. To determine if this was the case, geniculate neuron number was counted at two weeks and eight weeks after nerve section on the contralateral side and the results show geniculate neuron number did not differ across genotypes (Figure 33A). When compared to intact mice neuron number on the contralateral side did not change in any genotype at either two or eight weeks after never section (Figure 33A). Therefore, increased innervation was not caused by neuron number on the contralateral side, and $B d n f$ gene removal had no effect of neuron number on the contralateral side.

Similar to neuron number, taste bud number did not change on the contralateral side in all four genotypes (Figure 33B). In addition, there was no difference in taste bud number on the contralateral side compared to intact controls at either two or eight weeks after nerve section for any genotype (Figure 33B). Therefore, even though taste bud size increased on the contralateral side following nerve section, taste bud number was unaffected. 


\subsection{Discussion}

In the gustatory system, plastic changes (i.e. a larger taste bud on the contralateral side) have been observed following unilateral chorda tympani nerve section (Guagliardo and Hill, 2007). However, the mechanism underlying this phenomenon is unclear. I hypothesized that increased taste bud size could be due to more innervation and the neurotrophic factor, BDNF, may be involved. To test these ideas I examined taste bud size and nerve innervation following unilateral chorda tympani nerve section in inducible $B d n f$ knockout mice to reveal BDNF's role in plasticity on contralateral side. My results indicate that innervation (but not necessarily gustatory innervation) supported by $B d n f$ may be important for supporting increased taste bud innervation resulting in a larger taste bud.

$B d n f$ expression increases in the contralateral geniculate ganglion two weeks after unilateral chorda tympani nerve section. This increase could be related to other plastic phenomenon (i.e. larger taste bud size) on the contralateral side. BDNF can support axon outgrowth and target innervation in development (Ringstedt et al., 1999), and it could also support nerve innervation during adulthood (Chapter 2). Therefore, it seemed reasonable to hypothesize that increases in $B d n f$ in the contralateral geniculate ganglion could result in increases innervation branching to support a larger taste bud. In addition, BDNF could also modulate synaptic density in the taste bud (Causing et al., 1997; Yee et al., 2003). However, the timing of the increase in Bdnf expression is not consistent with this idea. Specifically, increased taste bud size and innervation was detected at a later time (two months post-surgery) compared to when $B d n f$ increased in geniculate ganglion (two weeks post-surgery). The delay in timing may due to increases in mRNA occurring much earlier than the downstream anatomical effect. It would take time for increased $B d n f$ expression to lead to increased 
innervation which might only then influence taste bud size. Alternatively, these two phenomenon may not be related.

Taste buds increase in size on the contralateral side following nerve section. This increase in taste bud size could be the result of increased innervation to the taste bud. Taste cells are supported by nerve fibers during development and in adulthood (Guth, 1957; Cheal and Oakley, 1977; Guagliardo and Hill, 2007; Patel et al., 2010). Therefore, increases in nerve fibers could lead to more taste cells within the bud. Previous studies had not determined whether the increase in taste bud size was accompanied by increased innervation. Our results confirmed this was indeed the case. In addition, according to the results, TUJ1 (neuron specific beta III Tubulin) positive fibers increased in contralateral taste buds, while $\mathrm{P} 2 \mathrm{X} 3$ positive fibers did not. It is possible that taste specific nerve fibers ( $\mathrm{P} 2 \mathrm{X} 3$ positive fibers) are lower in quantity than TUJ1 (neuron specific beta III Tubulin) positive fibers, making the change in P2X3 positive fibers less noticeable. Alternatively, non-taste fibers could support the larger taste bud (Ishida et al., 2009). In conclusion, increased taste bud size could be the result of increased innervation and this innervation is not necessarily taste specific.

Whether $B d n f$ removal blocks plasticity on the contralateral side is still unclear. According to our data, mice with $B d n f$ deletion (Ubc-cre ${ }^{\mathrm{ER}} B d n f^{\text {lox/- }}$ mice) fail to show increased taste bud size and innervation on the contralateral side. This finding is consistent with $B d n f$ removal blocking plasticity on the contralateral side. However, the slight reduction in $B d n f$ expression that occurs in $B d n f^{l o x /-}$ mice, is sufficient to prevent an increase in taste bud size on the contralateral side from reaching statistical significance. It could be that taste buds fail to become significantly larger on the contralateral side of $B d n f^{\text {lox/- }}$ mice because of variability in taste bud size in the $B d n f$ lox/- mice. My RT-PCR results (Chapter 1), demonstrated that Bdnf expression level is 
also highly variable in $B d n f^{\text {lox/- }}$ mice (ranging from $60 \%-80 \%$ remaining $B d n f$ ), which may contribute to the variability in taste buds size in non-surgical controls. Unlike $B d n f^{l o x /-}$ mice, complete $B d n f$ removal in adulthood (Ubc-cre ${ }^{\mathrm{ER}} B d n f^{\text {lox/- }}$ mice) causes a substantial loss in taste bud size independent of nerve section. Following nerve section there was not a significant increase in taste bud size. Therefore, $B d n f$ removal during adulthood may contribute to diminished plasticity on the contralateral side. TUJ1-positive nerve fibers also failed to increase indicating that $B d n f$ may contribute to larger taste buds on the contralateral side following nerve section by supporting increased innervation to the larger taste bud. 
Figure 26

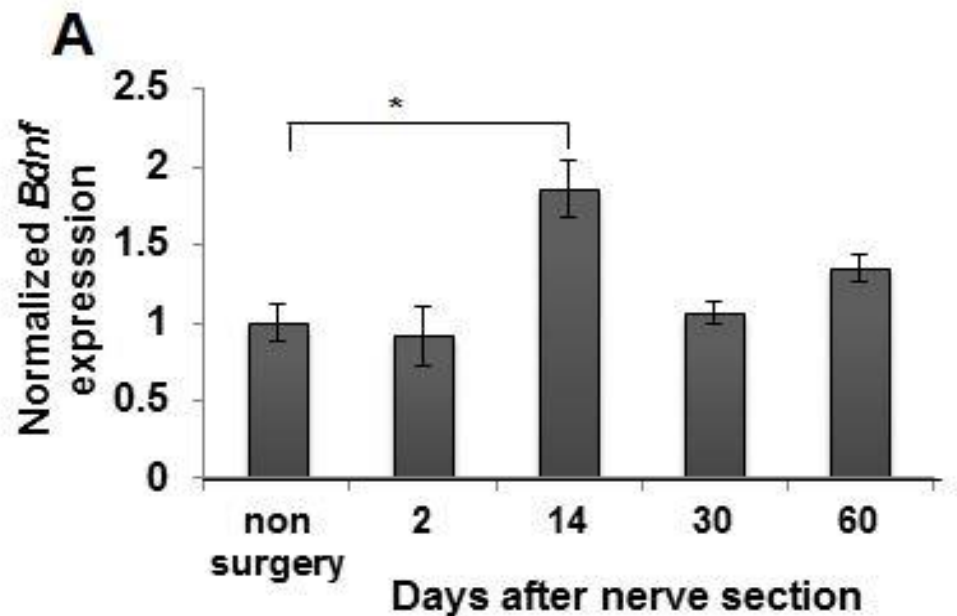

\section{B}

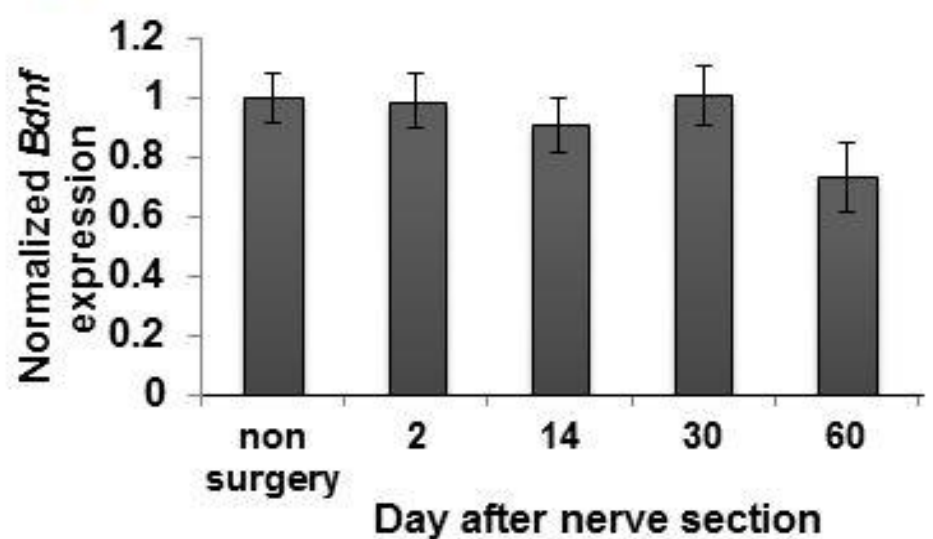

\section{C}

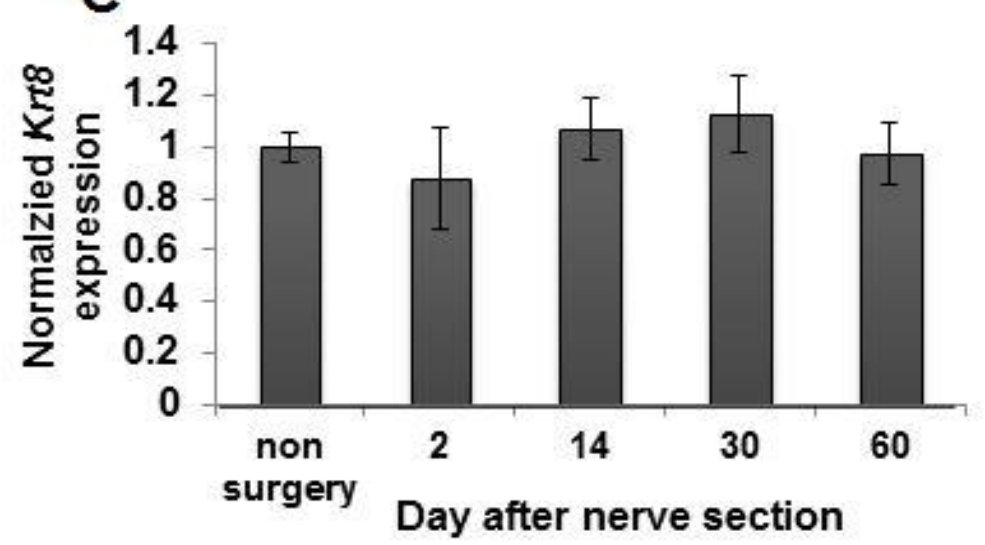


Figure 26. $B d n f$ expression increased in the geniculate ganglion on the contralateral side after unilateral chorda tympani nerve section at 14 days after surgery, while $B d n f$ and $K r t 8$ remained unchanged in lingual epithelium on the contralateral side. $B d n f$ expression (normalized to non-surgical controls) in geniculate ganglia increased at 14 days $(\mathrm{n}=6)$ on the contralateral side after nerve section (A) $B d n f$ expression did not change in the lingual epithelium on the contralateral side at 2 days $(n=6), 14$ days $(\mathrm{n}=6), 30$ days $(\mathrm{n}=6), 60$ days $(\mathrm{n}=6)$ after nerve section $(\mathrm{B})$. Krt8 expression did not change in the lingual epithelium on the contralateral side at 2 days $(n=6), 14$ days $(\mathrm{n}=6), 30$ days $(\mathrm{n}=6), 60$ days $(\mathrm{n}=6)$ after nerve section $(\mathrm{C})$. Increased $B d n f$ expression level in contralateral geniculate ganglion may support plasticity. ${ }^{*} \mathrm{p}<0.05^{* *} \mathrm{p}<0.01$ 
Figure 27

A

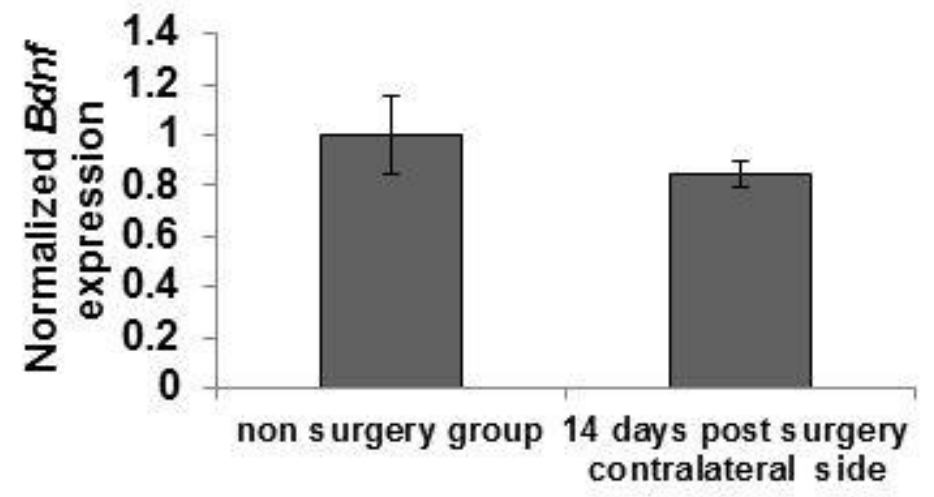

B

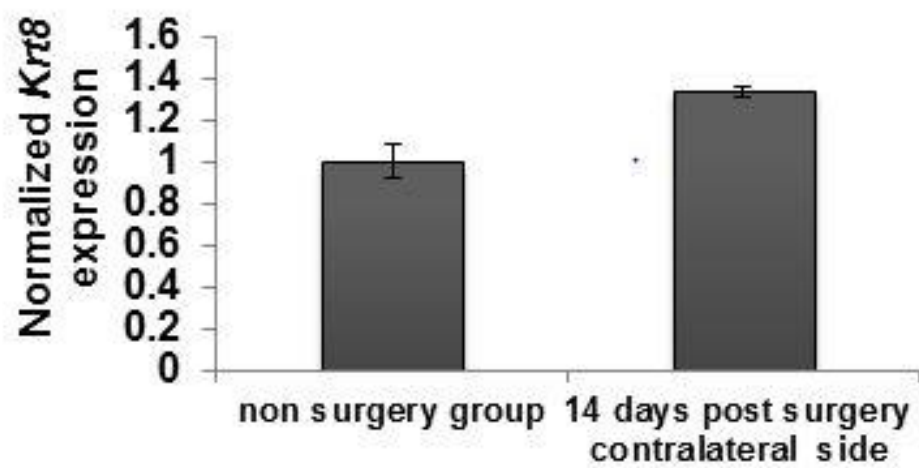


Figure 27. Taste bud specific Bdnf expression was unchanged at 14 days after nerve section on the contralateral side ( $\mathrm{n}=3$ ) (A). $\operatorname{Krt} 8$ (marker for taste bud) expression was unchanged at 14 days after nerve section on the contralateral side $(n=3)(B)$. 
Figure 28

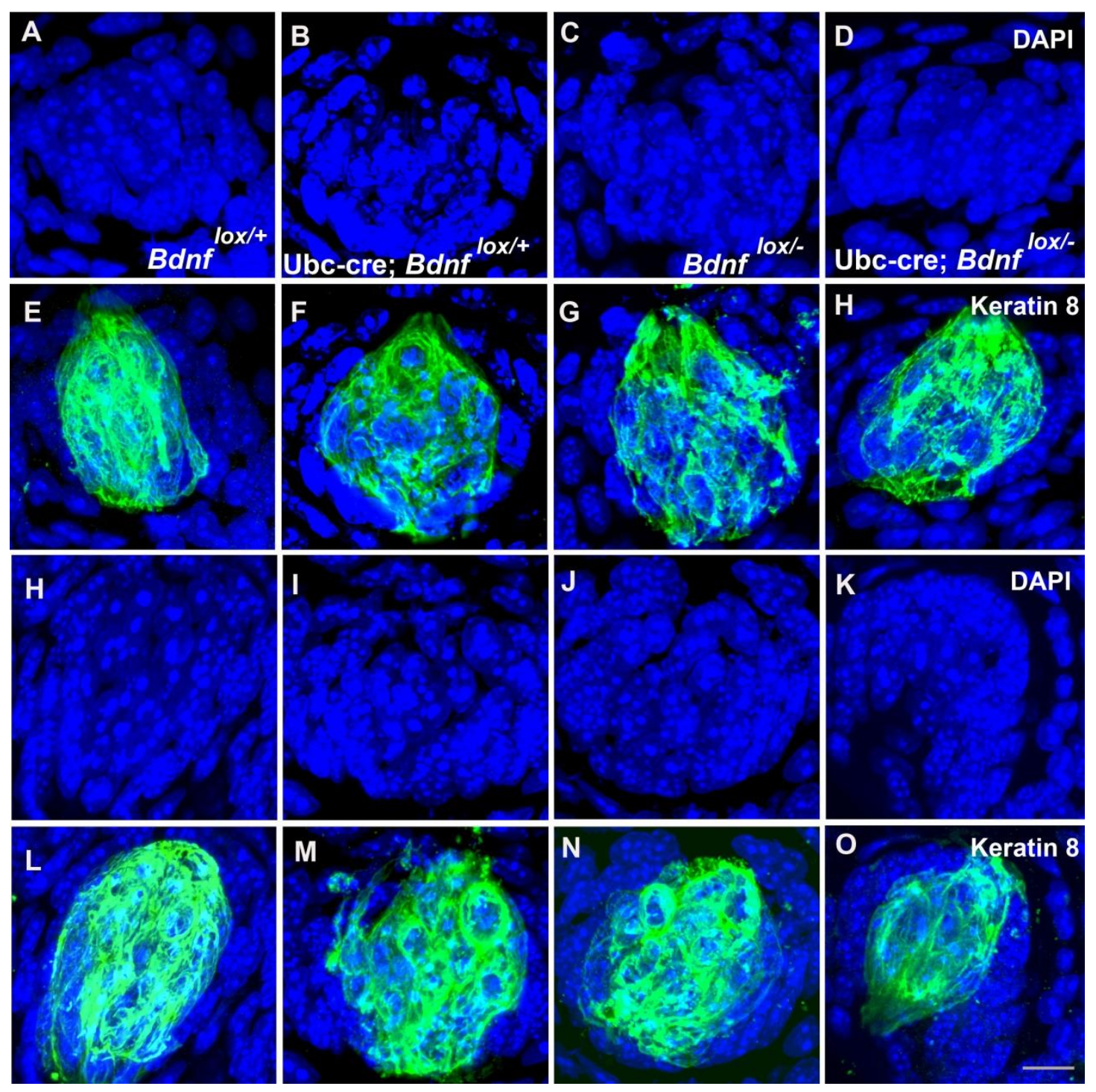


Figure 28. Taste bud size was unchanged at two weeks, but increased at eight weeks after nerve section on the contralateral side in mice without Bdnf gene deletion. (A-H) Confocal images of taste buds (anti-cytokeratin 8, green) and taste cells (DAPI, blue) in $B d n f^{\text {lox/+ }}$ mice $(\mathrm{A}, \mathrm{E}, \mathrm{I}, \mathrm{M}), \mathrm{Ubc}-\mathrm{cre}^{\mathrm{ER}} B d n f^{\mathrm{lox} /{ }^{+}}$mice $(\mathrm{B}, \mathrm{F}, \mathrm{J}, \mathrm{N})$ and $B d n f^{\mathrm{lox} /{ }_{-}}$mice $(\mathrm{C}, \mathrm{G}, \mathrm{K}, \mathrm{O})$ and $\mathrm{Ubc}-\mathrm{cre}^{\mathrm{ER}} B d n f^{\text {lox/- }}$ mice $(\mathrm{D}, \mathrm{H}, \mathrm{L}, \mathrm{P})$ from the contralateral side of the tongue two weeks and eight weeks after nerve section. Anti-cytokeratin 8 and DAPI were merged to visualize taste buds. There was no obvious difference between these four genotypes in taste bud size and/or cell number at two weeks after nerve section on the contralateral side, while at eight weeks after nerve section, Ubc$\mathrm{cre}^{\mathrm{ER}} B d n f^{\text {lox/- }}$ mice $(\mathrm{P})$ appear to have smaller taste buds with fewer taste cells compared to $B d n f^{\mathrm{lox} /+}$ mice $(\mathrm{M})$, Ubc-cre ${ }^{\mathrm{ER}} B d n f^{\text {lox/++}}$ mice $(\mathrm{N}), B d n f^{\text {lox/- }}$ mice $(\mathrm{O})$. Scale bar $=10 \mu \mathrm{m}$ and applies to all figures. 
Figure 29
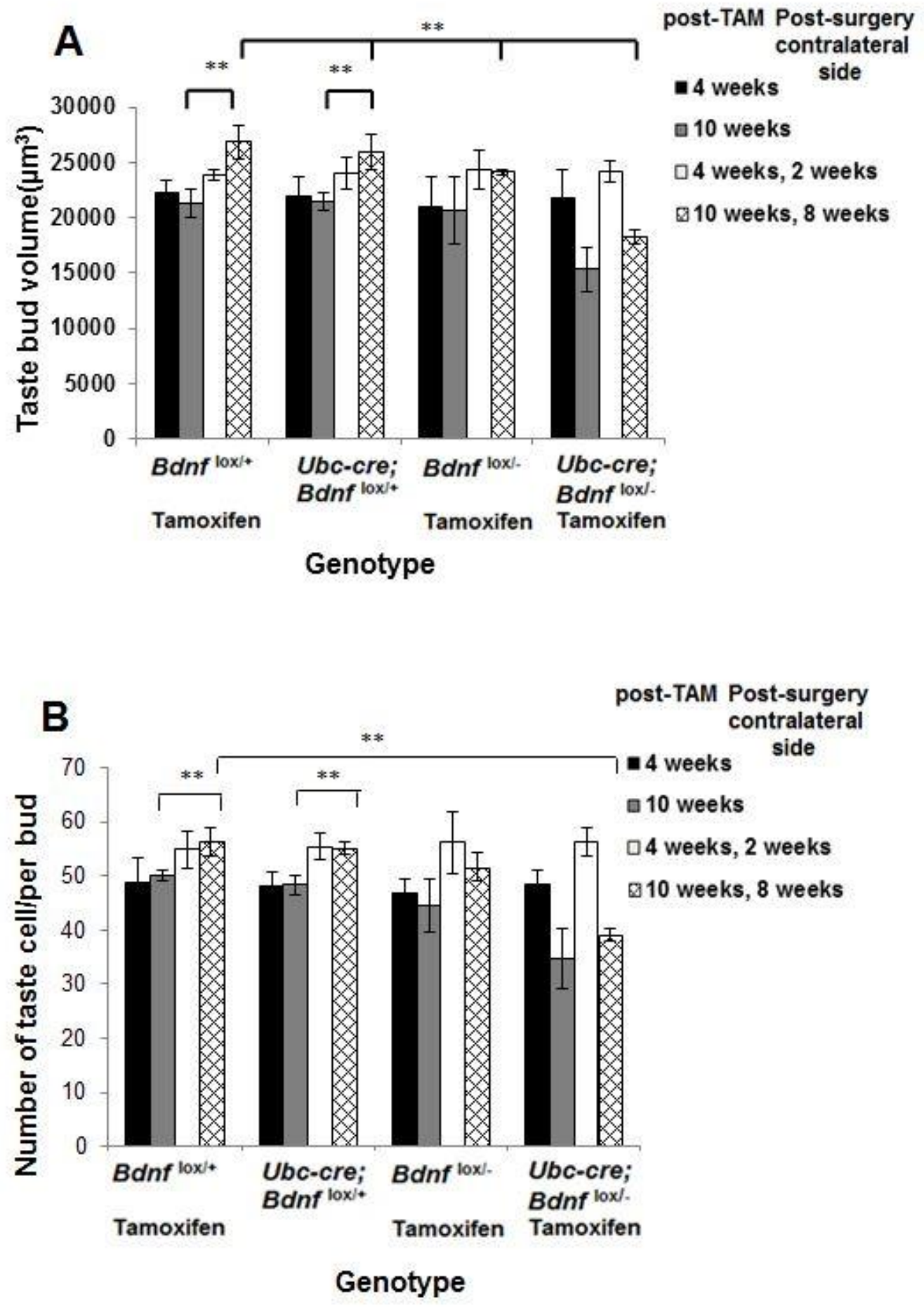
Figure 29. Taste bud volume and cell number increased on the contralateral side at eight weeks after nerve section in mice without Bdnf gene deletion, but not in mice with reduced $B d n f$ expression. At two weeks after nerve section there was no increase in taste bud volume and cell number on the contralateral side of the tongue among the four genotypes when compared to intact controls ( $\mathrm{n}=3$ for each genotypes) (A, B). At eight weeks after nerve section taste bud volume and cell number is significantly increased on the contralateral side compared with intact controls $(\mathrm{p}<0.01)$. However, pairwise comparisons reveal that this effect is only significant in mice without Bdnf gene deletion $\left(B d n f^{\mathrm{lox} /+}\right.$ mice $(\mathrm{n}=3), \mathrm{Ubc}-\mathrm{cre}^{\mathrm{ER}} B d n f^{\mathrm{lox} /+}$ mice $\left.(\mathrm{n}=3)\right)$, but not $B d n f^{\mathrm{lox} /-}$ mice $(\mathrm{n}=3)$ and $\mathrm{Ubc}-\mathrm{cre}^{\mathrm{ER}} B d n f^{\text {lox/- }}$ mice $(\mathrm{n}=3)$. This indicates that $B d n f$ may promote increased in taste bud volume on contralateral side (A, B). ${ }^{*} \mathrm{p}<0.05, * * \mathrm{p}<0.01$ 
Figure 30

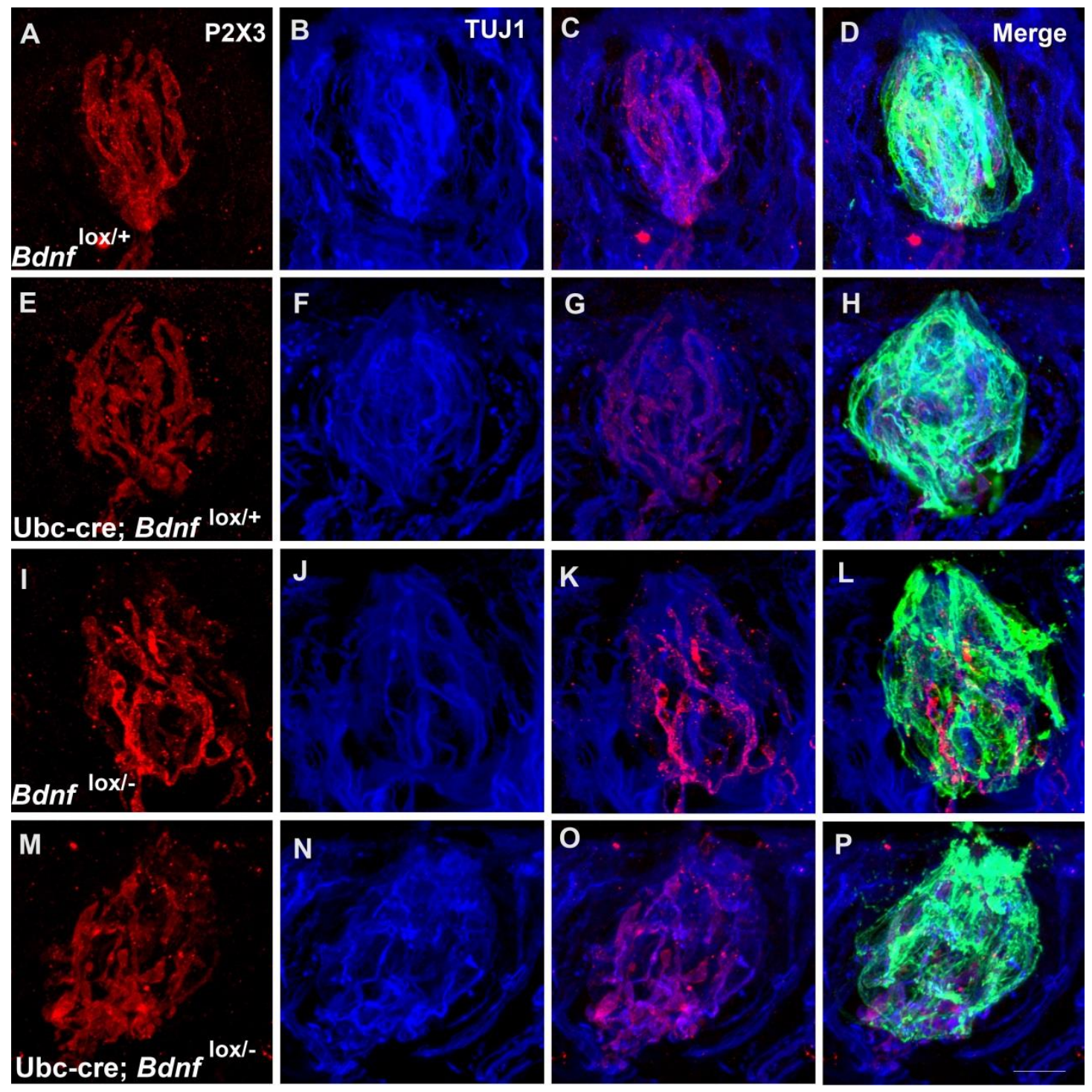


Figure 30. Innervation ( $\mathrm{P} 2 \mathrm{X} 3$ positive-fibers and TUJ1 labeled nerve fibers) appears unchanged at 2 weeks after nerve section on the contralateral side for all genotypes. A-P: Confocal images of taste buds and their innervation in $B d n f^{\text {lox/+ }}$ mice (A, E), Ubc-cre ${ }^{\mathrm{ER}} B d n f^{\mathrm{lox} /+}$ mice $(\mathrm{B}, \mathrm{F}), B d n f^{\mathrm{lox} /-}$ mice $(\mathrm{C}, \mathrm{G})$ and $\mathrm{Ubc}-\mathrm{cre}^{\mathrm{ER}} B d n f^{\mathrm{lox} /-}$ mice $(\mathrm{D}$, H) at two weeks after nerve section on the contralateral side. Anti-TUJ1 (neuron specific beta III Tubulin, nerve fibers, blue), anti-cytokeratin 8 (taste buds, green) were merged to observe taste nerves and taste buds in the same image (E-G). There was no obvious difference between these four groups in the amount of innervation to the taste bud. The scale bar $=10 \mu \mathrm{m}$ and applies to all figures. 
Figure 31

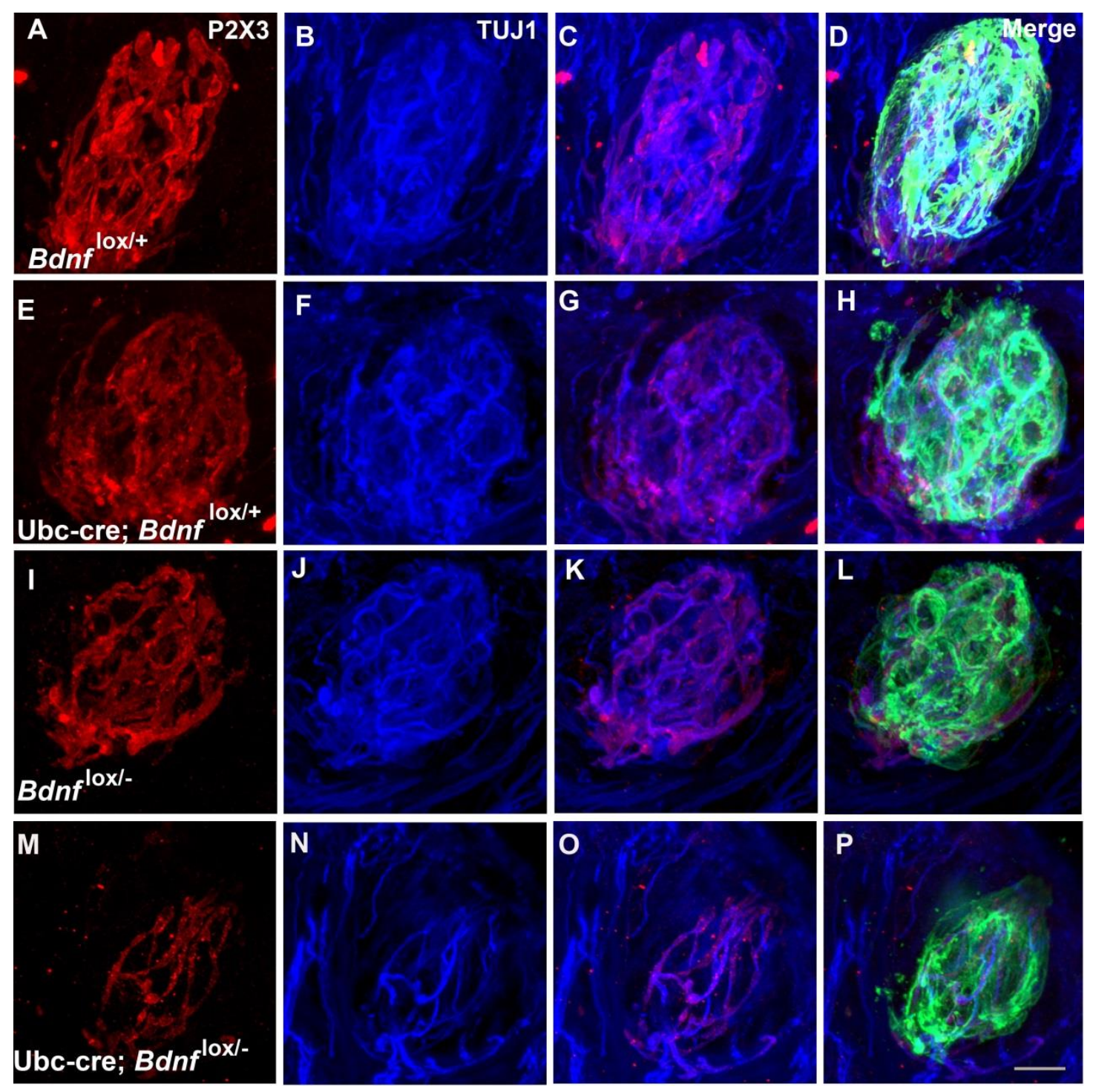


Figure 31. Innervation (P2X3 and TUJ1 labeled nerve fibers) of taste buds appears reduced on the contralateral side of the tongue in mice with an adult $B d n f$ deletion at 8 weeks after nerve section. A-P: Confocal images of innervation with in a taste bud in $B d n f^{\text {lox/+ }}$ mice (A-D), Ubc-cre ${ }^{\mathrm{ER}} B d n f^{\mathrm{lox} /+}$ mice (E-H), $B d n f^{\text {lox/- }}$ mice (I-L) and Ubc$\mathrm{cre}^{\mathrm{ER}} B d n f^{\mathrm{lox} /-}$ mice (M-P) at eight weeks after nerve section on the contralateral side. Anti-P2X3 (nerve fibers, red) and anti-TUJ1 (nerve fibers, blue) were merged to observe the overlap (purple) between the two makers for nerve fibers $(C, G, K, O)$. Anti-cytokeratin 8 (taste bud, green), anti-P2X3 (nerve fibers, red) and anti-TUJ1 (nerve fibers, blue) were merged in $B d n f^{\text {lox/+ }}$ mice (D), Ubc-cre ${ }^{\mathrm{ER}} B d n f^{\mathrm{lox} /+}$ mice (H), $B d n f^{\text {lox/- }}$ mice $(\mathrm{K})$ and Ubc-cre ${ }^{\mathrm{ER}} B d n f^{\text {lox/- }}$ mice $(\mathrm{P})$. Innervation to the taste bud in Ubc-cre ${ }^{\mathrm{ER}} B d n f^{\text {lox/- }}$ mice appeared reduced, compared to other three genotypes, in both intact mice and also on the contralateral side following nerve section. The scale bar $=10 \mu \mathrm{m}$ and applies to all. 
Figure 32
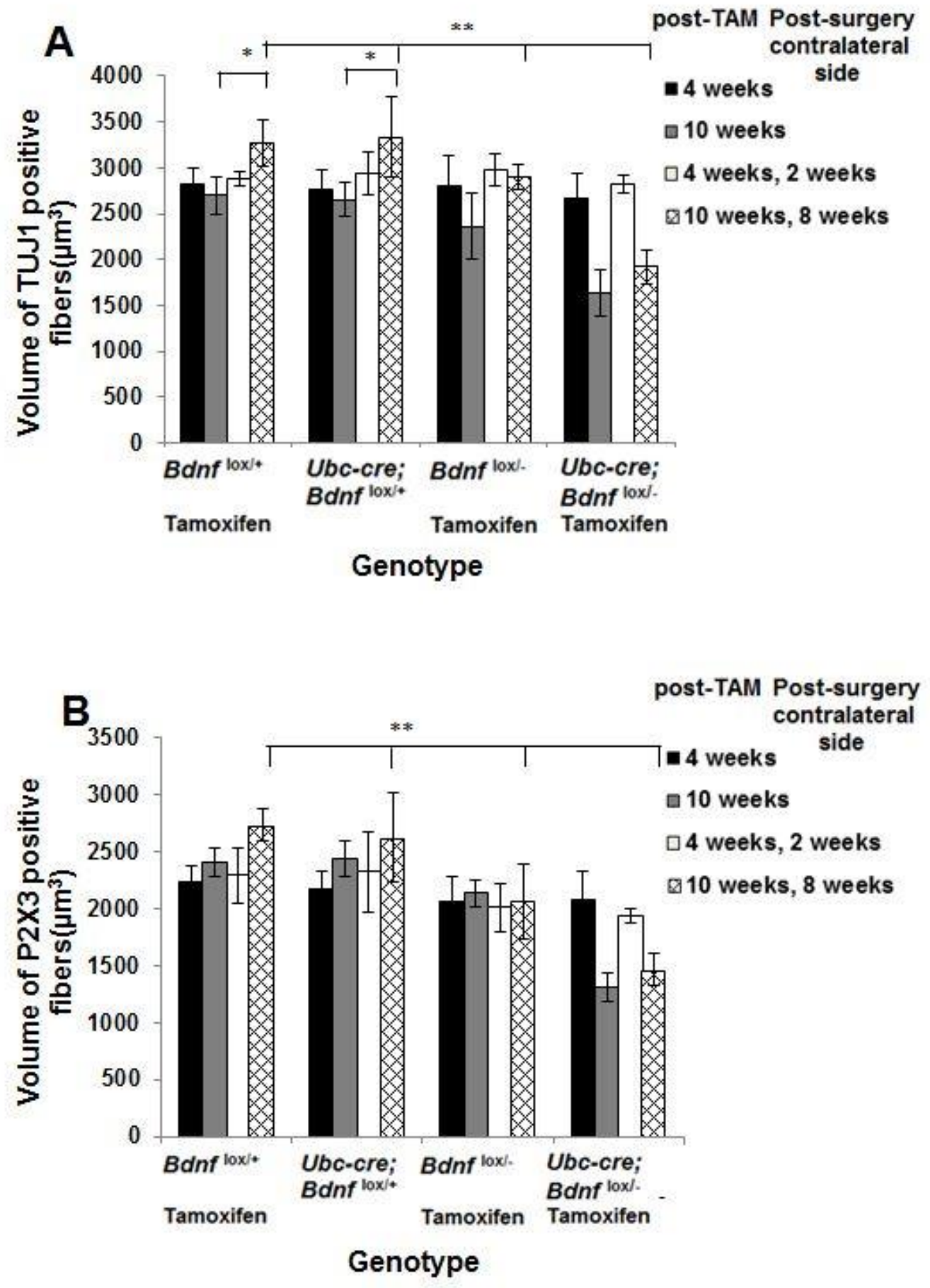
Figure 32. The volume of TUJ1-positive fibers in the taste bud increased on the contralateral side at eight weeks after nerve section in mice without $B d n f$ gene deletion, while $\mathrm{P} 2 \mathrm{X} 3$ positive fibers in the taste bud on contralateral side did not increase at two weeks and eight weeks after nerve section for any genotype. At two weeks after nerve section there was no increase in volume of TUJ1-positive fibers on the contralateral side of the tongue among all four genotypes when compared to intact controls ( $\mathrm{n}=3$ for each genotypes). At eight weeks after nerve section, the volume of TUJ1-positive fibers is significantly increased on the contralateral side compared with intact controls $(\mathrm{p}<0.01)$. However, pairwise comparisons reveal that this effect is only significant in mice without $B d n f$ gene deletion $\left(B d n f^{\text {lox } /+}\right.$ mice $(\mathrm{n}=3), \mathrm{Ubc}-\mathrm{cre}^{\mathrm{ER}} B d n f$ ${ }^{\text {lox/+ }}$ mice $\left.(\mathrm{n}=3)\right)$, but not $B d n f^{\text {lox/- }}$ mice $(\mathrm{n}=3)$ and Ubc-cre ${ }^{\mathrm{ER}} B d n f^{\text {lox/- }}$ mice $(\mathrm{n}=3)$. This finding indicates that taste buds with normal $B d n f$ expression on the contralateral side of the tongue following nerve section contain more TUJ1 positive fibers which support bigger taste buds (A). At two weeks and eight weeks after nerve section there was no increase in volume of P2X3-positive fibers on the contralateral side of the tongue following nerve section for any genotype when compared to intact controls ( $\mathrm{n}=3$ for each genotypes) (B). ${ }^{*} \mathrm{p}<0.05, * * \mathrm{p}<0.01$ 
Figure 33
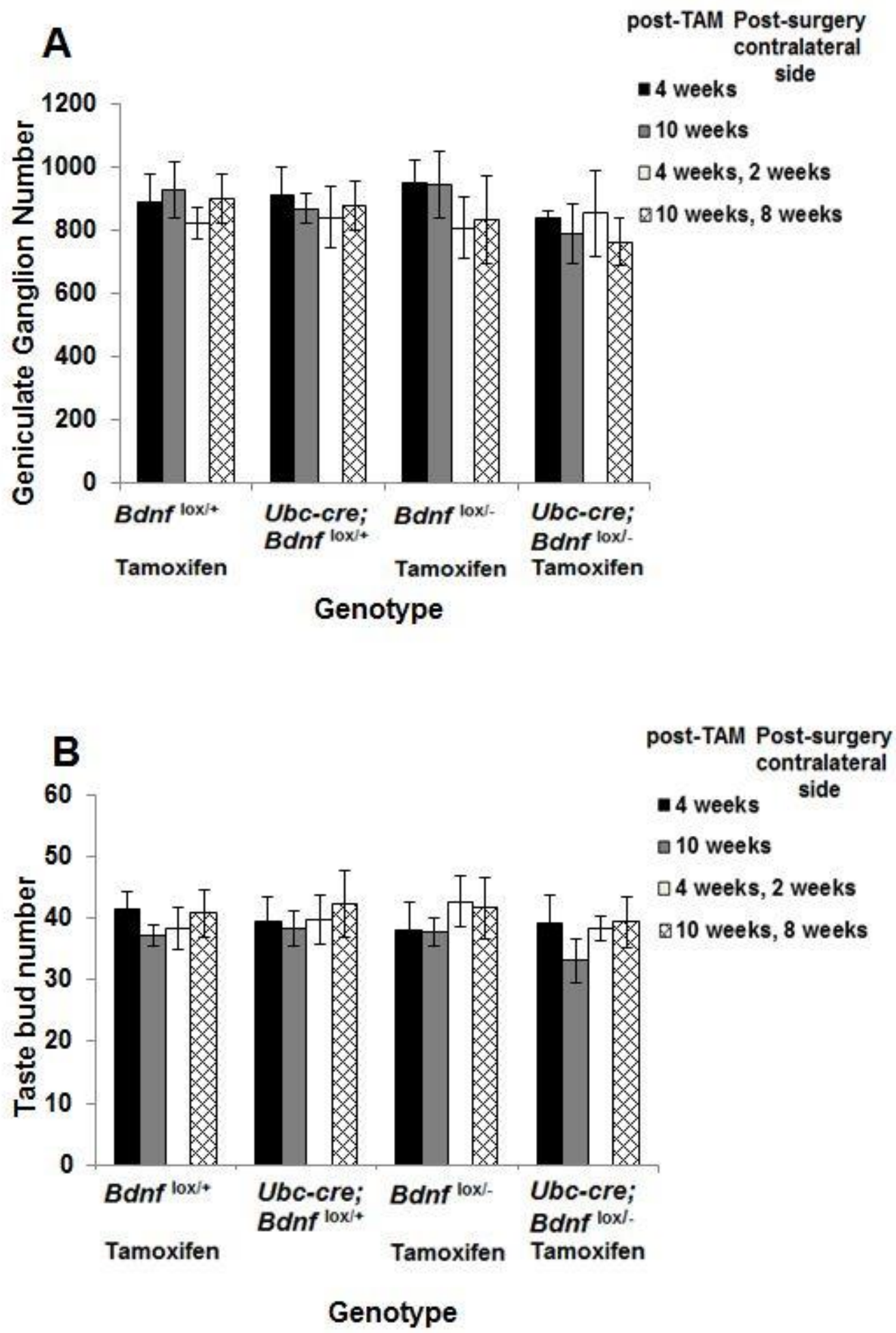
Figure 33. Geniculate ganglion number and taste bud number was not influenced by contralateral nerve section. Geniculate neuron number did not differ at either two or eight weeks ( $\mathrm{n}=4$ for each genotypes) after nerve section on the contralateral side, compared to intact mice for all genotypes (A). At two weeks ( $n=3$ for each genotypes) or eight weeks ( $\mathrm{n}=3$ for each genotypes), after nerve section taste bud number did not differ on the contralateral side compared to intact mice for any genotype (B). 


\section{CHAPTER V}

\section{SUMMARY AND DISCUSSION}

During development, BDNF is both sufficient and necessary for gustatory fibers to locate and innervate taste buds (Lopez and Krimm, 2006b; Ma et al., 2009; Patel et al., 2010). By adulthood BDNF becomes restricted to a subpopulation of taste cells in the bud, but its role was previously undetermined (Yee et al., 2003). Adulthood taste cells constantly turn over and must be reinnervated (Beidler and Smallman, 1965), the factors which regulate this process and determine which taste cells are innervated by what fibers has been - until now - a complete mystery. My findings indicate that BDNF functions in adulthood to attract new innervation to BDNF containing taste bud cells (Figure 34). Specifically, BDNF expressed by newly-formed BDNF-expressing taste cells encourages innervation by gustatory fibers. Loss/removal of BDNF results in a loss of innervation to BDNF-expressing taste cells. However, non-BDNF expressing taste cells remain innervated indicating that there is an unknown factor which encourages their innervating during adulthood. Gustatory nerve fibers may also produce a trophic factor (which could also be BDNF) to support the survival of taste cells. Because those fibers innervate a specific taste cell population, BDNF expressing taste cells appear to be lost to a greater extent than taste cells that do not express BDNF (i.e. PLC $\beta 2$ expressing taste cells). In conclusion, my findings suggest that BDNF plays an important role encouraging innervation of newly formed BDNF-expressing taste buds, possibly by a specific type of gustatory neurons, which in turn support taste cells. 
Because BDNF plays such an important role in the continuing reinnervation of renewing taste cells, I thought it may also be important for regeneration. When the chorda tympani nerve is sectioned, Schwann cells may aggregate surrounding the cut end of the nerve. These Schwann cells can help clear the death debris and promote nerve myelination. These Schwann cells also likely express BDNF (English et al., 2005) which may help support axon outgrow allowing the axons to re-enter the distal nerve sheath. This is constistent with my findings and BDNF support motor axon regneeration (English et al., 2005). When the growing axons arrive at tongue epithelium, BDNF from the epithelium is needed to for axons to invade the epithelium and reconnect with taste cells (Ma et al., 2009). Therefore, BDNF from taste cells can help taste cells reconnect with newly arrived axons. In conclusion, my findings are consistent with the idea that BDNF from lingual epithelium and Schwann cells can promote nerve outgrowth and targeting into taste bud after nerve injury to promote regeneration.

Reduced neurotrophin expression occurs with aging and neurodegenerative diseases and could impact the taste system. In general with these conditions, decreases in neurotrophin were accompanied with a loss of sensory axons (Jakobsen et al., 1981; Le Floch et al., 1989; Bergman et al., 2000). These experiments are correlative; while both neurotrophins and innervation are reduced, it is still unclear whether it is the loss of neurotrophins that results in the loss of sensory innervation. My data confirms that BDNF is required to maintain the full complement of gustatory innervation to taste buds in adulthood. Therefore it seems likely that sensory innervation lost with aging or with neurodegenerative diseases is due to a loss of neurotrophins.

Aging profoundly delays functional recovery from gustatory nerve injury ( $\mathrm{He}$ et al., 2012), which could also be due to a loss of neurotrophins. I demonstrated that 
removal of BDNF prevents regeneration of gustatory neurons; taste fibers need BDNF to reinnervate taste buds after the nerve injury. In the absence of BDNF, axons may grow some distance but fail to reach the taste bud. Therefore, loss of BDNF in could be the cause of delayed or halted of functional recovery from gustatory nerve injury in aging mice (He et al., 2012). To address this idea, it would be interesting to determine if adding exogenous BDNF into aging mice would rescue gustatory nerve regeneration. 
Figure 34
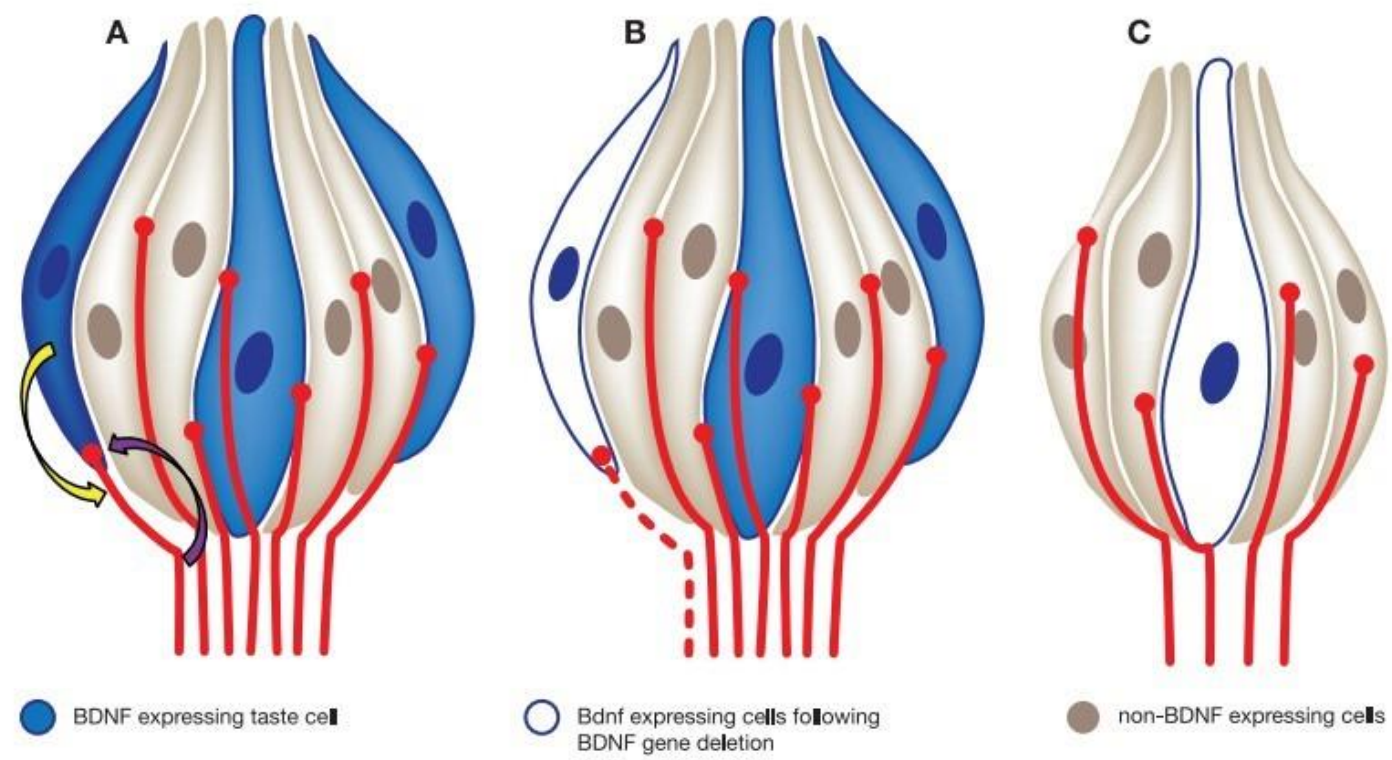
Figure 34. A model illustrating how we think BDNF functions in the adult taste system. BDNF expressed in new taste cells, (dark blue cell in A), encourages innervation from nerve fibers, these fibers in turn support the taste cell. Once taste cells are innervated they retain their innervation even when BDNF is removed (blue taste cells in B). However, new taste cells that would normally express BDNF can no longer recruit new fibers to innervate the taste bud following BDNF gene removal (white cell outline in blue in B). This results in a loss of both innervation and taste cells that would normally express BDNF (C). 


\section{REFERENCE}

Aguado F, Carmona MA, Pozas E, Aguilo A, Martinez-Guijarro FJ, Alcantara S, Borrell V, Yuste R, Ibanez CF, Soriano E (2003) BDNF regulates spontaneous correlated activity at early developmental stages by increasing synaptogenesis and expression of the K+/Cl- co-transporter KCC2. Development 130:1267-1280.

Beidler LM, Smallman RL (1965) Renewal of cells within taste buds. The Journal of cell biology 27:263-272.

Bergman E, Fundin BT, Ulfhake B (1999) Effects of aging and axotomy on the expression of neurotrophin receptors in primary sensory neurons. The Journal of comparative neurology 410:368-386.

Bergman E, Ulfhake B, Fundin BT (2000) Regulation of NGF-family ligands and receptors in adulthood and senescence: correlation to degenerative and regenerative changes in cutaneous innervation. The European journal of neuroscience 12:2694-2706.

Bradbury EJ, Khemani S, Von R, King, Priestley JV, McMahon SB (1999) NT-3 promotes growth of lesioned adult rat sensory axons ascending in the dorsal columns of the spinal cord. The European journal of neuroscience 11:3873-3883.

Cain P, Frank ME, Barry MA (1996) Recovery of chorda tympani nerve function following injury. Experimental neurology 141:337-346.

Campenot RB (1977) Local control of neurite development by nerve growth factor. Proceedings of the National Academy of Sciences of the United States of America 74:4516-4519.

Carleton A, Accolla R, Simon SA (2010) Coding in the mammalian gustatory system. Trends in neurosciences 33:326-334.

Carr VM, Sollars SI, Farbman AI (2005) Neuronal cell death and population dynamics in the developing rat geniculate ganglion. Neuroscience 134:1301-1308.

Causing CG, Gloster A, Aloyz R, Bamji SX, Chang E, Fawcett J, Kuchel G, Miller FD (1997) Synaptic innervation density is regulated by neuron-derived BDNF. Neuron 18:257267.

Cheal M, Oakley B (1977) Regeneration of fungiform taste buds: temporal and spatial characteristics. The Journal of comparative neurology 172:609-626.

Cheal M, Dickey WP, Jones LB, Oakley B (1977) Taste fiber responses during reinnervation of fungiform papillae. The Journal of comparative neurology 172:627-646.

Cho TT, Farbman AI (1999) Neurotrophin receptors in the geniculate ganglion. Brain research Molecular brain research 68:1-13.

Christianson JA, Ryals JM, Johnson MS, Dobrowsky RT, Wright DE (2007) Neurotrophic modulation of myelinated cutaneous innervation and mechanical sensory loss in diabetic mice. Neuroscience 145:303-313.

Cohen-Cory S, Kidane AH, Shirkey NJ, Marshak S (2010) Brain-derived neurotrophic factor and the development of structural neuronal connectivity. Developmental neurobiology 70:271-288.

Conover JC, Erickson JT, Katz DM, Bianchi LM, Poueymirou WT, McClain J, Pan L, Helgren M, Ip NY, Boland P, et al. (1995) Neuronal deficits, not involving motor neurons, in mice lacking BDNF and/or NT4. Nature 375:235-238.

Crowley C, Spencer SD, Nishimura MC, Chen KS, Pitts-Meek S, Armanini MP, Ling LH, McMahon SB, Shelton DL, Levinson AD, et al. (1994) Mice lacking nerve growth 
factor display perinatal loss of sensory and sympathetic neurons yet develop basal forebrain cholinergic neurons. Cell 76:1001-1011.

Davies AM, Horton A, Burton LE, Schmelzer C, Vandlen R, Rosenthal A (1993) Neurotrophin-4/5 is a mammalian-specific survival factor for distinct populations of sensory neurons. The Journal of neuroscience : the official journal of the Society for Neuroscience 13:4961-4967.

Diamond J, Holmes M, Coughlin M (1992a) Endogenous NGF and nerve impulses regulate the collateral sprouting of sensory axons in the skin of the adult rat. The Journal of neuroscience : the official journal of the Society for Neuroscience 12:1454-1466.

Diamond J, Foerster A, Holmes M, Coughlin M (1992b) Sensory nerves in adult rats regenerate and restore sensory function to the skin independently of endogenous NGF. The Journal of neuroscience : the official journal of the Society for Neuroscience 12:1467-1476.

Diamond J, Coughlin M, Macintyre L, Holmes M, Visheau B (1987) Evidence that endogenous beta nerve growth factor is responsible for the collateral sprouting, but not the regeneration, of nociceptive axons in adult rats. Proceedings of the National Academy of Sciences of the United States of America 84:6596-6600.

Donnerer J (2003) Regeneration of primary sensory neurons. Pharmacology 67:169-181.

English AW, Meador W, Carrasco DI (2005) Neurotrophin-4/5 is required for the early growth of regenerating axons in peripheral nerves. The European journal of neuroscience 21:2624-2634.

Ernfors P (2001) Local and target-derived actions of neurotrophins during peripheral nervous system development. Cellular and molecular life sciences : CMLS 58:1036-1044.

Farbman AI (1965) Fine Structure of the Taste Bud. Journal of ultrastructure research 12:328350.

Farbman AI (1969) Fine structure of degenerating tast buds after denervation. Journal of embryology and experimental morphology 22:55-68.

Farbman AI, Mbiene JP (1991) Early development and innervation of taste bud-bearing papillae on the rat tongue. The Journal of comparative neurology 304:172-186.

Farbman AI, Brann JH, Rozenblat A, Rochlin MW, Weiler E, Bhattacharyya M (2004) Developmental expression of neurotrophin receptor genes in rat geniculate ganglion neurons. Journal of neurocytology 33:331-343.

Farinas I, Wilkinson GA, Backus C, Reichardt LF, Patapoutian A (1998) Characterization of neurotrophin and Trk receptor functions in developing sensory ganglia: direct NT-3 activation of TrkB neurons in vivo. Neuron 21:325-334.

Feil R, Wagner J, Metzger D, Chambon P (1997) Regulation of Cre recombinase activity by mutated estrogen receptor ligand-binding domains. Biochemical and biophysical research communications 237:752-757.

Finger TE (2005) Cell types and lineages in taste buds. Chemical senses 30 Suppl 1:i54-55.

Finger TE, Danilova V, Barrows J, Bartel DL, Vigers AJ, Stone L, Hellekant G, Kinnamon SC (2005) ATP signaling is crucial for communication from taste buds to gustatory nerves. Science 310:1495-1499.

Fundin BT, Silos-Santiago I, Ernfors P, Fagan AM, Aldskogius H, DeChiara TM, Phillips HS, Barbacid M, Yancopoulos GD, Rice FL (1997) Differential dependency of cutaneous mechanoreceptors on neurotrophins, trk receptors, and P75 LNGFR. Developmental biology 190:94-116.

Ganchrow D, Ganchrow JR, Verdin-Alcazar M, Whitehead MC (2003) Brain-derived neurotrophic factor-, neurotrophin-3-, and tyrosine kinase receptor-like immunoreactivity in lingual taste bud fields of mature hamster. The Journal of comparative neurology 455:11-24.

Ganchrow JR, Ganchrow D (1989) Long-term effects of gustatory neurectomy on fungiform papillae in the young rat. The Anatomical record 225:224-231.

Ganchrow JR, Ganchrow D, Oppenheimer M (1986) Chorda tympani innervation of anterior mandibular taste buds in the chicken (Gallus gallus domesticus). The Anatomical record 216:434-439. 
Gardiner J, Barton D, Vanslambrouck JM, Braet F, Hall D, Marc J, Overall R (2008) Defects in tongue papillae and taste sensation indicate a problem with neurotrophic support in various neurological diseases. The Neuroscientist : a review journal bringing neurobiology, neurology and psychiatry 14:240-250.

Greene DA, Stevens MJ, Feldman EL (1999) Diabetic neuropathy: scope of the syndrome. The American journal of medicine 107:2S-8S.

Grothe C, Unsicker K (1987) Neuron-enriched cultures of adult rat dorsal root ganglia: establishment, characterization, survival, and neuropeptide expression in response to trophic factors. Journal of neuroscience research 18:539-550.

Guagliardo NA, Hill DL (2007) Fungiform taste bud degeneration in C57BL/6J mice following chorda-lingual nerve transection. The Journal of comparative neurology 504:206-216.

Guth L (1957) The effects of glossopharyngeal nerve transection on the circumvallate papilla of the rat. The Anatomical record 128:715-731.

Guth L (1958) Taste buds on the cat's circumvallate papilla after reinnervation by glossopharyngeal, vagus, and hypoglossal nerves. The Anatomical record 130:25-37.

Ha SO, Kim JK, Hong HS, Kim DS, Cho HJ (2001) Expression of brain-derived neurotrophic factor in rat dorsal root ganglia, spinal cord and gracile nuclei in experimental models of neuropathic pain. Neuroscience 107:301-309.

Hagg T (2006) Collateral sprouting as a target for improved function after spinal cord injury. Journal of neurotrauma 23:281-294.

He L, Yadgarov A, Sharif S, McCluskey LP (2012) Aging profoundly delays functional recovery from gustatory nerve injury. Neuroscience 209:208-218.

Hill DL (2004) Neural plasticity in the gustatory system. Nutrition reviews 62:S208-217; discussion S224-241.

Hill DL, Phillips LM (1994) Functional plasticity of regenerated and intact taste receptors in adult rats unmasked by dietary sodium restriction. The Journal of neuroscience : the official journal of the Society for Neuroscience 14:2904-2910.

Hirsch S, Labes M, Bahr M (2000) Changes in BDNF and neurotrophin receptor expression in degenerating and regenerating rat retinal ganglion cells. Restorative neurology and neuroscience 17:125-134.

Hoon MA, Adler E, Lindemeier J, Battey JF, Ryba NJ, Zuker CS (1999) Putative mammalian taste receptors: a class of taste-specific GPCRs with distinct topographic selectivity. Cell 96:541-551.

Hoshino N, Vatterott P, Egwiekhor A, Rochlin MW (2010) Brain-derived neurotrophic factor attracts geniculate ganglion neurites during embryonic targeting. Developmental neuroscience 32:184-196.

Hou S, Nicholson L, van Niekerk E, Motsch M, Blesch A (2012) Dependence of regenerated sensory axons on continuous neurotrophin-3 delivery. The Journal of neuroscience : the official journal of the Society for Neuroscience 32:13206-13220.

Huang EJ, Reichardt LF (2001) Neurotrophins: roles in neuronal development and function. Annual review of neuroscience 24:677-736.

Huang T, Stahler F (2009) Effects of dietary $\mathrm{Na}+$ deprivation on epithelial $\mathrm{Na}+$ channel $(\mathrm{ENaC}), \mathrm{BDNF}$, and TrkB mRNA expression in the rat tongue. BMC neuroscience 10:19.

Huang T, Krimm RF (2010) Developmental expression of Bdnf, Ntf4/5, and TrkB in the mouse peripheral taste system. Developmental dynamics : an official publication of the American Association of Anatomists 239:2637-2646.

Huang YJ, Maruyama Y, Dvoryanchikov G, Pereira E, Chaudhari N, Roper SD (2007) The role of pannexin 1 hemichannels in ATP release and cell-cell communication in mouse taste buds. Proceedings of the National Academy of Sciences of the United States of America 104:6436-6441.

Ishida Y, Ugawa S, Ueda T, Yamada T, Shibata Y, Hondoh A, Inoue K, Yu Y, Shimada S (2009) P2X(2)- and P2X(3)-positive fibers in fungiform papillae originate from the 
chorda tympani but not the trigeminal nerve in rats and mice. The Journal of comparative neurology 514:131-144.

Jakobsen J, Brimijoin S, Skau K, Sidenius P, Wells D (1981) Retrograde axonal transport of transmitter enzymes, fucose-labeled protein, and nerve growth factor in streptozotocin-diabetic rats. Diabetes 30:797-803.

Jensen EC (2013) Quantitative analysis of histological staining and fluorescence using ImageJ. Anatomical record 296:378-381.

Kim JY, Mochizuki T, Akita K, Jung HS (2003) Morphological evidence of the importance of epithelial tissue during mouse tongue development. Experimental cell research 290:217-226.

Kinnamon JC, Taylor BJ, Delay RJ, Roper SD (1985) Ultrastructure of mouse vallate taste buds. I. Taste cells and their associated synapses. The Journal of comparative neurology 235:48-60.

Krimm RF (2007) Factors that regulate embryonic gustatory development. BMC neuroscience 8 Suppl 3:S4.

Krimm RF, Hill DL (1998a) Quantitative relationships between taste bud development and gustatory ganglion cells. Annals of the New York Academy of Sciences 855:70-75.

Krimm RF, Hill DL (1998b) Innervation of single fungiform taste buds during development in rat. The Journal of comparative neurology 398:13-24.

Krimm RF, Hill DL (1999) Early dietary sodium restriction disrupts the peripheral anatomical development of the gustatory system. Journal of neurobiology 39:218-226.

Krimm RF, Hill DL (2000) Neuron/target matching between chorda tympani neurons and taste buds during postnatal rat development. Journal of neurobiology 43:98-106.

Krimm RF, Miller KK, Kitzman PH, Davis BM, Albers KM (2001) Epithelial overexpression of BDNF or NT4 disrupts targeting of taste neurons that innervate the anterior tongue. Developmental biology 232:508-521.

Langworthy OR (1924) A study of the innervation of the tongue musculature with particular reference to the proprioceptive mechanism. Journal of Comparative Neurology 36:273-297.

Le Floch JP, Le Lievre G, Sadoun J, Perlemuter L, Peynegre R, Hazard J (1989) Taste impairment and related factors in type I diabetes mellitus. Diabetes care 12:173-178.

Lindsay RM (1988) Nerve growth factors (NGF, BDNF) enhance axonal regeneration but are not required for survival of adult sensory neurons. The Journal of neuroscience : the official journal of the Society for Neuroscience 8:2394-2405.

Liu X, Ernfors P, Wu H, Jaenisch R (1995) Sensory but not motor neuron deficits in mice lacking NT4 and BDNF. Nature 375:238-241.

Lopez GF, Krimm RF (2006a) Refinement of innervation accuracy following initial targeting of peripheral gustatory fibers. Journal of neurobiology 66:1033-1043.

Lopez GF, Krimm RF (2006b) Epithelial overexpression of BDNF and NT4 produces distinct gustatory axon morphologies that disrupt initial targeting. Developmental biology 292:457-468.

Lopez GF, Krimm RF (2006c) Epithelial overexpression of BDNF and NT4 produces distinct gustatory axon morphologies that disrupt initial targeting. Developmental biology 292:457-468.

Ma L, Lopez GF, Krimm RF (2009) Epithelial-derived brain-derived neurotrophic factor is required for gustatory neuron targeting during a critical developmental period. The Journal of neuroscience : the official journal of the Society for Neuroscience 29:3354-3364.

Matsumoto I, Emori Y, Ninomiya Y, Abe K (2001) A comparative study of three cranial sensory ganglia projecting into the oral cavity: in situ hybridization analyses of neurotrophin receptors and thermosensitive cation channels. Brain research Molecular brain research 93:105-112.

May RM (1925) The relation of nerves to degenerating and regenerating taste buds. Journal of Experimental Zoology 42:371-410. 
Mbiene JP, Mistretta CM (1997) Initial innervation of embryonic rat tongue and developing taste papillae: nerves follow distinctive and spatially restricted pathways. Acta anatomica 160:139-158.

McCluskey LP (2004) Up-regulation of activated macrophages in response to degeneration in the taste system: effects of dietary sodium restriction. The Journal of comparative neurology 479:43-55.

Mistretta C, Hill D (1994) Development of the taste system: basic neurobiology. NEUROLOGICAL DISEASE AND THERAPY 32:635-635.

Mistretta CM, Goosens KA, Farinas I, Reichardt LF (1999) Alterations in size, number, and morphology of gustatory papillae and taste buds in BDNF null mutant mice demonstrate neural dependence of developing taste organs. The Journal of comparative neurology 409:13-24.

Miyoshi MA, Abe K, Emori Y (2001) IP(3) receptor type 3 and PLCbeta2 are co-expressed with taste receptors T1R and T2R in rat taste bud cells. Chemical senses 26:259-265.

Montavon P, Hellekant G, Farbman A (1996) Immunohistochemical, electrophysiological, and electron microscopical study of rat fungiform taste buds after regeneration of chorda tympani through the non-gustatory lingual nerve. The Journal of comparative neurology 367:491-502.

Murata Y, Yasuo T, Yoshida R, Obata K, Yanagawa Y, Margolskee RF, Ninomiya Y (2010) Action potential-enhanced ATP release from taste cells through hemichannels. Journal of neurophysiology 104:896-901.

Murray RG, Murray A, Fujimoto S (1969) Fine structure of gustatory cells in rabbit taste buds. Journal of ultrastructure research 27:444-461.

Nagahama S, Kurihara K (1985) Norepinephrine as a possible transmitter involved in synaptic transmission in frog taste organs and $\mathrm{Ca}$ dependence of its release. The Journal of general physiology 85:431-442.

Nagai T, Delay RJ, Welton J, Roper SD (1998) Uptake and release of neurotransmitter candidates, $[3 \mathrm{H}]$ serotonin, $[3 \mathrm{H}]$ glutamate, and [3H]gamma-aminobutyric acid, in taste buds of the mudpuppy, Necturus maculosus. The Journal of comparative neurology 392:199-208.

Nixon BJ, Doucette R, Jackson PC, Diamond J (1984) Impulse activity evokes precocious sprouting of nociceptive nerves into denervated skin. Somatosensory research 2:97126.

Nosrat CA, Olson L (1995) Brain-derived neurotrophic factor mRNA is expressed in the developing taste bud-bearing tongue papillae of rat. The Journal of comparative neurology 360:698-704.

Nosrat CA, Ebendal T, Olson L (1996) Differential expression of brain-derived neurotrophic factor and neurotrophin 3 mRNA in lingual papillae and taste buds indicates roles in gustatory and somatosensory innervation. The Journal of comparative neurology 376:587-602.

Nosrat CA, Blomlof J, ElShamy WM, Ernfors P, Olson L (1997) Lingual deficits in BDNF and NT3 mutant mice leading to gustatory and somatosensory disturbances, respectively. Development 124:1333-1342.

Nosrat IV, Margolskee RF, Nosrat CA (2012) Targeted taste cell-specific overexpression of brain-derived neurotrophic factor in adult taste buds elevates phosphorylated TrkB protein levels in taste cells, increases taste bud size, and promotes gustatory innervation. The Journal of biological chemistry 287:16791-16800.

Oakley B (1970) Reformation of taste buds by crossed sensory nerves in the rat's tongue. Acta physiologica Scandinavica 79:88-94.

Oakley B, Keppel E, Hughes SE (1984) Trophic capacity of experimentally lengthened gustatory axons. Brain research 318:195-201.

Oakley B, Wu LH, Lawton A, deSibour C (1990) Neural control of ectopic filiform spines in adult tongue. Neuroscience 36:831-838. 
Oakley B, Lawton A, Riddle DR, Wu LH (1993) Morphometric and immunocytochemical assessment of fungiform taste buds after interruption of the chorda-lingual nerve. Microscopy research and technique 26:187-195.

Ola MS, Nawaz MI, El-Asrar AA, Abouammoh M, Alhomida AS (2013) Reduced levels of brain derived neurotrophic factor (BDNF) in the serum of diabetic retinopathy patients and in the retina of diabetic rats. Cellular and molecular neurobiology 33:359-367.

Olmsted J (1922) Taste fibers and the chorda tympani nerve. Journal of Comparative Neurology 34:337-341.

Patel AV, Krimm RF (2010) BDNF is required for the survival of differentiated geniculate ganglion neurons. Developmental biology 340:419-429.

Patel AV, Krimm RF (2012) Neurotrophin-4 regulates the survival of gustatory neurons earlier in development using a different mechanism than brain-derived neurotrophic factor. Developmental biology 365:50-60.

Patel AV, Huang T, Krimm RF (2010) Lingual and palatal gustatory afferents each depend on both BDNF and NT-4, but the dependence is greater for lingual than palatal afferents. The Journal of comparative neurology 518:3290-3301.

Perea-Martinez I, Nagai T, Chaudhari N (2013) Functional cell types in taste buds have distinct longevities. PloS one 8:e53399.

Phillips LM, Hill DL (1996) Novel regulation of peripheral gustatory function by the immune system. The American journal of physiology 271:R857-862.

Popper P, Lopez I, Beizai P, Li G, Kim J, Micevych PE, Honrubia V (1999) Expression of BDNF and TrkB mRNAs in the crista neurosensory epithelium and vestibular ganglia following ototoxic damage. Brain research 846:40-51.

Putcha GV, Deshmukh M, Johnson EM, Jr. (2000) Inhibition of apoptotic signaling cascades causes loss of trophic factor dependence during neuronal maturation. The Journal of cell biology 149:1011-1018.

Ramer MS, Priestley JV, McMahon SB (2000) Functional regeneration of sensory axons into the adult spinal cord. Nature 403:312-316.

Ringstedt T, Ibanez CF, Nosrat CA (1999) Role of brain-derived neurotrophic factor in target invasion in the gustatory system. The Journal of neuroscience : the official journal of the Society for Neuroscience 19:3507-3518.

Robinson PP (1989) The reinnervation of the tongue and salivary glands after lingual nerve injuries in cats. Brain research 483:259-271.

Ruiz CJ, Stone LM, McPheeters M, Ogura T, Bottger B, Lasher RS, Finger TE, Kinnamon SC (2001) Maintenance of rat taste buds in primary culture. Chemical senses 26:861873.

Ruzankina Y, Pinzon-Guzman C, Asare A, Ong T, Pontano L, Cotsarelis G, Zediak VP, Velez M, Bhandoola A, Brown EJ (2007) Deletion of the developmentally essential gene ATR in adult mice leads to age-related phenotypes and stem cell loss. Cell stem cell 1:113-126.

Sartini S, Bartolini F, Ambrogini P, Betti M, Ciuffoli S, Lattanzi D, Di Palma M, Cuppini R (2013) Motor activity affects adult skeletal muscle re-innervation acting via tyrosine kinase receptors. The European journal of neuroscience 37:1394-1403.

Segerstad CHA, Hellekant G, Farbman AI (1989) Changes in Number and Morphology of Fungiform Taste-Buds in Rat after Transection of the Chorda Tympani or Chordalingual Nerve. Chemical senses 14:335-348.

Shuler MG, Krimm RF, Hill DL (2004) Neuron/target plasticity in the peripheral gustatory system. The Journal of comparative neurology 472:183-192.

Sloan HE, Hughes SE, Oakley B (1983) Chronic impairment of axonal transport eliminates taste responses and taste buds. The Journal of neuroscience : the official journal of the Society for Neuroscience 3:117-123.

Smeyne RJ, Klein R, Schnapp A, Long LK, Bryant S, Lewin A, Lira SA, Barbacid M (1994) Severe sensory and sympathetic neuropathies in mice carrying a disrupted Trk/NGF receptor gene. Nature 368:246-249. 
Sollars SI (2005) Chorda tympani nerve transection at different developmental ages produces differential effects on taste bud volume and papillae morphology in the rat. Journal of neurobiology 64:310-320.

Sollars SI, Bernstein IL (2000) Neonatal chorda tympani transection permanently disrupts fungiform taste bud and papilla structure in the rat. Physiology \& behavior 69:439444.

Starostik MR, Rebello MR, Cotter KA, Kulik A, Medler KF (2010) Expression of GABAergic receptors in mouse taste receptor cells. PloS one 5:e13639.

State FA, Dessouky HI (1977) Effect of the length of the distal stump of transected nerve upon the rate of degeneration of taste buds. Acta anatomica 98:353-360.

Taruno A, Vingtdeux V, Ohmoto M, Ma Z, Dvoryanchikov G, Li A, Adrien L, Zhao H, Leung S, Abernethy M, Koppel J, Davies P, Civan MM, Chaudhari N, Matsumoto I, Hellekant G, Tordoff MG, Marambaud P, Foskett JK (2013) CALHM1 ion channel mediates purinergic neurotransmission of sweet, bitter and umami tastes. Nature 495:223-226.

Tom VJ, Sandrow-Feinberg HR, Miller K, Domitrovich C, Bouyer J, Zhukareva V, Klaw MC, Lemay MA, Houle JD (2013) Exogenous BDNF enhances the integration of chronically injured axons that regenerate through a peripheral nerve grafted into a chondroitinase-treated spinal cord injury site. Experimental neurology 239:91-100.

Torrey TW (1936) The relation of nerves to degenerating taste buds. Journal of Comparative Neurology 64:325-336.

Uchida N, Kanazawa M, Suzuki Y, Takeda M (2003) Expression of BDNF and TrkB in mouse taste buds after denervation and in circumvallate papillae during development. Archives of histology and cytology 66:17-25.

Unger TJ, Calderon GA, Bradley LC, Sena-Esteves M, Rios M (2007) Selective deletion of Bdnf in the ventromedial and dorsomedial hypothalamus of adult mice results in hyperphagic behavior and obesity. The Journal of neuroscience : the official journal of the Society for Neuroscience 27:14265-14274.

Vilbig R, Cosmano J, Giger R, Rochlin MW (2004) Distinct roles for Sema3A, Sema3F, and an unidentified trophic factor in controlling the advance of geniculate axons to gustatory lingual epithelium. Journal of neurocytology 33:591-606.

White FA, Keller-Peck CR, Knudson CM, Korsmeyer SJ, Snider WD (1998) Widespread elimination of naturally occurring neuronal death in Bax-deficient mice. The Journal of neuroscience : the official journal of the Society for Neuroscience 18:1428-1439.

Whitehead MC, McGlathery ST, Manion BG (1995) Transganglionic degeneration in the gustatory system consequent to chorda tympani damage. Experimental neurology 132:239-250.

Wilhelm JC, Xu M, Cucoranu D, Chmielewski S, Holmes T, Lau KS, Bassell GJ, English AW (2012) Cooperative roles of BDNF expression in neurons and Schwann cells are modulated by exercise to facilitate nerve regeneration. The Journal of neuroscience : the official journal of the Society for Neuroscience 32:5002-5009.

Wolthers M, Moldovan M, Binderup T, Schmalbruch H, Krarup C (2005) Comparative electrophysiological, functional, and histological studies of nerve lesions in rats. Microsurgery 25:508-519.

Yang R, Crowley HH, Rock ME, Kinnamon JC (2000) Taste cells with synapses in rat circumvallate papillae display SNAP-25-like immunoreactivity. The Journal of comparative neurology 424:205-215.

Yasumatsu K, Shigemura N, Yoshida R, Ninomiya Y (2005) Recovery of salt taste responses and PGP 9.5 immunoreactive taste bud cells during regeneration of the mouse chorda tympani nerve. Chemical senses 30 Suppl 1:i62-63.

Yasumatsu K, Kusuhara Y, Shigemura N, Ninomiya Y (2007) Recovery of two independent sweet taste systems during regeneration of the mouse chorda tympani nerve after nerve crush. The European journal of neuroscience 26:1521-1529. 
Yee C, Bartel DL, Finger TE (2005) Effects of glossopharyngeal nerve section on the expression of neurotrophins and their receptors in lingual taste buds of adult mice. The Journal of comparative neurology 490:371-390.

Yee CL, Jones KR, Finger TE (2003) Brain-derived neurotrophic factor is present in adult mouse taste cells with synapses. The Journal of comparative neurology 459:15-24.

Yu TW, Bargmann CI (2001) Dynamic regulation of axon guidance. Nature neuroscience 4 Suppl:1169-1176.

Zhang C, Brandemihl A, Lau D, Lawton A, Oakley B (1997) BDNF is required for the normal development of taste neurons in vivo. Neuroreport 8:1013-1017.

Zhang JY, Luo XG, Xian CJ, Liu ZH, Zhou XF (2000) Endogenous BDNF is required for myelination and regeneration of injured sciatic nerve in rodents. The European journal of neuroscience 12:4171-4180.

Zhou XF, Chie ET, Deng YS, Zhong JH, Xue Q, Rush RA, Xian CJ (1999) Injured primary sensory neurons switch phenotype for brain-derived neurotrophic factor in the rat. Neuroscience 92:841-853. 


\title{
CURRICULUM VITAE
}

\author{
Meng Lingbin \\ Department of Anatomy and Neurobiology \\ School of Medicine, University of Louisville \\ Louisville, KY40202
}

\section{Education:}

July 2008 B.M. Anhui Medical University

Weighted Average Mark $=88.7 / 100$, Rank $=2 \%$

2009-2012 M.S. Department of Anatomy and Neurobiology, School of Medicine, University of Louisville.

2012-present Ph.D Candidate, Department of Anotatomy and Neurobiology, School of Medicine, University of Louisville. GPA=3.92/4.0

English Proficiency:

GRE Verbal: 490 (58\%), Quantitative: 790 (92\%), AW 3.5(20\%); V+Q: 1280

TOEFL Section1: 20 , Section2: 22 , Section3 : 20, section 4: 24; Total:86

Research Experience:

2009.8-present Graduate student in Dr Robin Krimm's lab, Department of ASNB, University of Louisville 
2008.9-2009.8 Worked as a master student in Plastic Surgery Department of China Xiehe Medical University, focusing on the field of Neural Repair.

2006.6-2007.7 Worked as a research assistant in the Lab of Neurodegenerative Diseases, Anhui Medical University.

Honors and Awards:

$2013.4,2^{\text {nd }}$ place in UofL Neuroscience Day Poster Competition

2003-2007, Highest Scholarship (every year)

2006, the 1st prize of the National English Competition for Undergraduates

2005, the 1st place in the Host Contest of Anhui Province

2004, the 2nd prize in the 10th Debating Contest of Anhui Medical University

2003, the first prize of Hefei Song Contest

Membership and Affiliations:

Society For Neuroscience

Music Association of Anhui Medical University

Hefei Volunteer Union

Lab of Neurodegerative Diseases

Anhui Radio 